\title{
Calcium signaling in closely related protozoan groups (Alveolata): Non-parasitic ciliates (Paramecium, Tetrahymena) vs. parasitic Apicomplexa (Plasmodium, Toxoplasma)
}

\author{
H. Plattner ${ }^{\mathrm{a}, *}$, I.M. Sehring ${ }^{\mathrm{a}, 1}$, I.K. Mohamed ${ }^{\mathrm{b}}$, K. Miranda $^{\mathrm{c}}$, W. De Souza ${ }^{\mathrm{c}}$, R. Billington ${ }^{\mathrm{d}}$, \\ A. Genazzani ${ }^{\text {, }}$ E.-M. Ladenburger ${ }^{a}$ \\ a Department of Biology, University of Konstanz, P.O. Box 5560, 78457 Konstanz, Germany \\ ${ }^{\mathrm{b}}$ Faculty of Science, Ain-Shams University, Cairo, Egypt \\ 'Instituto de Biofísica and Instituto Nacional de Ciéncia e Tecnologia, Universidade Federal de Rio de Janeiro, Rio de Janeiro, Brasil \\ d School of Biomedical and Biological Sciences, University of Plymouth, UK \\ e Istituto di Farmacologia, Università del Piemonte Orientale, Novara, Italy
}

Keywords:

Alveolata

Apicomplexa

$\mathrm{Ca}^{2+}$

Calcium

Ciliates

Paramecium

Plasmodium

Tetrahymena

Toxoplasma

\begin{abstract}
A B S T R A C T
The importance of $\mathrm{Ca}^{2+}$-signaling for many subcellular processes is well established in higher eukaryotes, whereas information about protozoa is restricted. Recent genome analyses have stimulated such work also with Alveolates, such as ciliates (Paramecium, Tetrahymena) and their pathogenic close relatives, the Apicomplexa (Plasmodium, Toxoplasma). Here we compare $\mathrm{Ca}^{2+}$ signaling in the two closely related groups. Acidic $\mathrm{Ca}^{2+}$ stores have been characterized in detail in Apicomplexa, but hardly in ciliates. Two-pore channels engaged in $\mathrm{Ca}^{2+}$-release from acidic stores in higher eukaryotes have not been stingently characterized in either group. Both groups are endowed with plasma membrane- and endoplasmic reticulum-type $\mathrm{Ca}^{2+}$-ATPases (PMCA, SERCA), respectively. Only recently was it possible to identify in Paramecium a number of homologs of ryanodine and inositol 1,3,4-trisphosphate receptors $\left(R y R, I P_{3} R\right)$ and to localize them to widely different organelles participating in vesicle trafficking. For Apicomplexa, physiological experiments suggest the presence of related channels although their identity remains elusive. In Paramecium, $\mathrm{IP}_{3}$ Rs are constitutively active in the contractile vacuole complex; RyR-related channels in alveolar sacs are activated during exocytosis stimulation, whereas in the parasites the homologous structure (inner membrane complex) may no longer function as a $\mathrm{Ca}^{2+}$ store. Scrutinized comparison of the two closely related protozoan phyla may stimulate further work and elucidate adaptation to parasitic life. See also "Conclusions" section.
\end{abstract}

\section{Introduction}

Early in evolution, eukaryotes have established small changes in intracellular free $\mathrm{Ca}^{2+}$ concentration, $\left[\mathrm{Ca}^{2+}\right]_{i}$, as a second messenger system, in many cases connected to a variety of external stimuli. Such mechanisms and corollaries of $\mathrm{Ca}^{2+}$ signaling have been extensively summarized for multicellular organisms [1-4]. Basic aspects are as follows. $\mathrm{Ca}^{2+}$ can come from outside the cell by influx and/or from internal stores, and both components may cooperate. $\mathrm{Ca}^{2+}$ signals can trigger widely different effects, from cell contraction, secretion and gene activation to cell death etc. Thus, to be specific, precise spatial and temporal regulation of $\left[\mathrm{Ca}^{2+}\right]_{i}$

\footnotetext{
* Corresponding author. Tel.: +49753188 2228; fax: +49 7531882245.

E-mail address: helmut.plattner@uni-konstanz.de (H. Plattner).

1 Present address: Sars International Centre for Marine Molecular Biology, Universitetet i Bergen, Norge.
}

in microdomains is required [5-7]. This is achieved by precisely positioning $\mathrm{Ca}^{2+}$ influx channels and/or $\mathrm{Ca}^{2+}$ release channels at strategic sites and rapid downregulation of the signal. Local regulation is even more important as, on the one hand, the effect achieved shows an extremely superlinear dependency on local $\left[\mathrm{Ca}^{2+}\right]_{i}[5]$, while on the other hand rapid inactivation of the signal by diffusion, binding to cytosolic $\mathrm{Ca}^{2+}$-binding proteins (CaBPs, immobile $\mathrm{Ca}^{2+}$ buffers), sequestration into stores, and extrusion from the cell rapidly counteract the stimulatory effect of a $\left[\mathrm{Ca}^{2+}\right]_{\mathrm{i}}$ increase after activation [8]. Strict regulation also serves to impede toxic effects of too high concentrations of $\mathrm{Ca}^{2+}[9]$.

Only some of these aspects have been analyzed in some detail in protozoa, as summarized for the groups to be compared here, ciliates [10] and Apicomplexa [11,12]. Comparison of current knowledge on $\mathrm{Ca}^{2+}$ signaling in ciliates (predominantly Paramecium) with older reviews [13-15] shows that some implications could be more clearly specified, while others could not be verified. Beyond that, since about 1995, introduction of imaging 
methods and of molecular biology has allowed unforeseeable progress.

Among $\mathrm{Ca}^{2+}$-influx channels, from protozoa on, some are activated by depolarization (voltage-dependent [gated] $\mathrm{Ca}^{2+}$ channels), while others are activated mechanically or by specific ligands or other compounds [16]. Among $\mathrm{Ca}^{2+}$ stores, some are located in the cell cortex and structurally coupled to influx channels. For instance, in higher eukaryotes, stores may be activated by conformational coupling (sarcoplasmic reticulum [SR] of skeletal muscle) or by $\mathrm{Ca}^{2+}$ influx $\left[\mathrm{Ca}^{2+}\right.$ induced $\mathrm{Ca}^{2+}$ release, $\mathrm{CICR}$, in SR of heart muscle] [17]. Alternatively $\mathrm{Ca}^{2+}$ influx can be activated by emptying of cortical stores (store-operated $\mathrm{Ca}^{2+}$ influx, SOC) in response to a stimulus (Section 3.2). For the latter, two proteins are known to interact in mammalian cells [18]: Stim acts as a transmembrane reporter of lumenal $\left[\mathrm{Ca}^{2+}\right]$ in cortical ER which signals store emptying to the cell membrane where Orai mediates $\mathrm{Ca}^{2+}$ influx (Section 3.2).

In contrast, many stores are distributed deeper inside the cell. They encompass a large part of the ER, mitochondria, and some widely different vesicle subpopulations involved in trafficking from endosomes to lysosomes and secretory vesicles. This variety, including some more or less acidic compartments, can be complemented - from protozoa to man - by dedicated acidic $\mathrm{Ca}^{2+}$ stores, such as the acidocalcisomes [19-22]. In higher eukaryotes, activation of non-acidocalcisomal $\mathrm{Ca}^{2+}$ stores is achieved by second messengers, such as inositol-1,4,5-trisphosphate $\left(\mathrm{InsP}_{3}\right.$, derived from phosphatidylinositol-4,5-bisphosphate, $\mathrm{PIns}_{2}$ ) which binds to the $\mathrm{Ins}_{3}$ receptor, $\mathrm{IP}_{3} \mathrm{R}$ [23], or by cyclic adenosinediphosphoribose (cADPR which activates the ryanodine receptor, RyR [24]). Nicotinic acid-adenine-dinucleotide phosphate $\left(\mathrm{NAADP}^{+}\right)$binds to two-pore channels, TPC, in the membranes of some acidic compartments - members of the endo-lysosomal trafficking system - which it thus activates [25-27]. Both, CADPR and NAADP ${ }^{+}$are derived from NAD and NADP, respectively [28].

A variety of drugs has been used to characterize the different types of $\mathrm{Ca}^{2+}$ release channels in mammalian cells, while their physiological activators have been detected only gradually, some remaining under discussion up to recently. However, specificity and efficacy of channel-modulating drugs, such as ryanodine and caffeine (1,3,7-trimethylxanthine) for RyRs, may vary with concentration in the case of ryanodine [29], between cell types and particularly at different levels of evolution. The effects can vary widely from protozoa to metazoa, or - more specifically - mammalian cells [30]. Intracellular $\mathrm{Ca}^{2+}$ release channels, therefore, have been more difficult to approach than channels in the cell membrane which are also easily amenable to electrophysiological analysis.

Only quite recently several developments have facilitated further analysis. This has involved rapid progress in elaborating genomic databases (DB) for many species, and increasing availability of domain DBs. This is of particular importance considering the requirement of defined domain structure particularly also for proteins dedicated to the handling of $\mathrm{Ca}^{2+}$. Data obtained by molecular biology can then be correlated with antibody $(\mathrm{AB})$ and green fluorescent protein- (GFP-) tagging in vivo as well as with functional analyses (gene silencing) and recording of $\left[\mathrm{Ca}^{2+}\right]_{i}$ signals generated under defined conditions.

$\mathrm{Ca}^{2+}$ transients are rapidly counterbalanced by binding of $\mathrm{Ca}^{2+}$ to cytosolic CaBPs [5]. These encompass some with EFhand $\mathrm{Ca}^{2+}$-binding loops, such as calmodulin (CaM) and centrin, while others possess $\mathrm{C} 2$ domains ( $\beta$-sheats with a $\mathrm{Ca}^{2+}$-binding loop). Among them are the $\mathrm{Ca}^{2+}$-sensor proteins (Section 5 ) for membrane-membrane interaction (synaptotagmin and related proteins), copines, phospholipase C (PLC) and the regulatory subunit (SU) of the $\mathrm{Ca}^{2+} / \mathrm{CaM}$-activated protein phosphatase type $2 \mathrm{~B}$ $(\mathrm{PP} 2 \mathrm{~B}=$ calcineurin, CaN). Such high affinity/low capacity CaBPs proteins cooperate, or compete, with $\mathrm{Ca}^{2+}$ effectors in the cytosol or

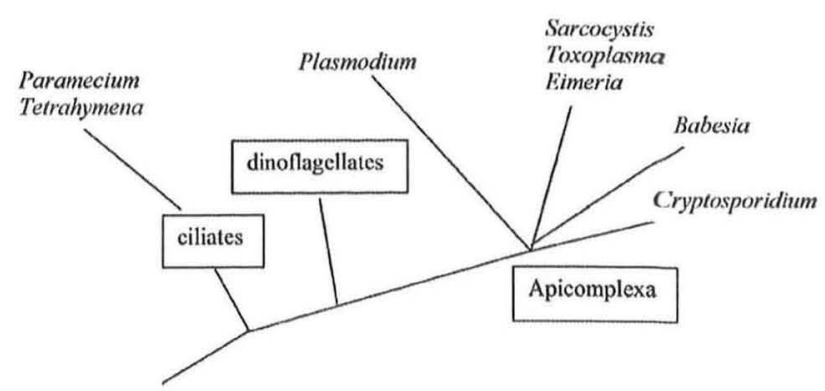

Fig. 1. Outline of the approximate evolutionary relationship between members of the phylum Alveolata. Evolutionary distances are not drawn to scale. After Aravind et al. [38].

on membranes. In contrast, many stores contain low affinity/high capacity CaBPs, such as calreticulin (ER) and calsequestrin (SR). The abundance of acidic aminoacids in these proteins enables rapid binding of large quantities of $\mathrm{Ca}^{2+}$ in the store lumen from where it can easily be released.

Finally, in higher eukaryotes the plasma membrane can extrude $\mathrm{Ca}^{2+}$ by a plasmalemmal $\mathrm{Ca}^{2+}$-ATPase/pump (PMCA) or by cation exchangers, e.g. a $\mathrm{Na}^{+} / \mathrm{Ca}^{2+}$ antiporter. Mitochondria possess a $\mathrm{Ca}^{2+}$ uniporter for rapid uptake and a $\mathrm{Na}^{+} / \mathrm{Ca}^{2+}$ antiporter for rapid release. Internal stores, such as ER and SR, possess a sarcoplasmic/endoplasmic reticulum $\mathrm{Ca}^{2+}$-ATPase (SERCA) which - in contrast to PMCA - lacks the CaM-binding domain. Both belong to the P-type of ATPases because they form a phospho-intermediate during each pumping cycle $[31,32]$. In contrast, acidic stores can exploit the chemiosmotic $\mathrm{H}^{+}$-gradient $\left(\Delta \mathrm{H}^{+}\right)$, generated by a $\mathrm{H}^{+}$. ATPase, using a $\mathrm{H}^{+} / \mathrm{Ca}^{2+}$ exchanger. The vesicular $\mathrm{Ca}^{2+}$-pumps (V-type $\mathrm{Ca}^{2+}$-ATPases) form no phospho-intermediate. Among protozoa, some of these molecules and, in addition, some other pumps are in use, such as $\mathrm{H}^{+}$-pyrophosphatases ( $\mathrm{H}^{+}$-PPases), as well as alternative cation antiporter systems.

All this makes the basic process of $\mathrm{Ca}^{2+}$ signaling very complex, but this complexity also enables a variety of local responses in a cell with a considerable degree of fine-tuning. For basic references, see Berridge et al. [2], Clapham [3], Dodd et al. [4], and Palmgren and Nissen [32] and the following text. In protozoa, knowledge even of some of the basic principles has been rather fragmentary until quite recently - and in part it still is.

\section{Calcium signaling in Alveolates}

\subsection{Why compare ciliates and apicomplexan parasites?}

As mentioned, all Alveolates contain flat cortical sacs, designated "alveolar sacs" in Ciliophora/ciliates (R.D. Allen at http://www5.pbrc.hawaii.edu/allen/) as well as in dinoflagellates, and the "inner membrane complex" (IMC) in Apicomplexa [33], respectively. It is reduced in Theileria [34] when compared to Toxoplasma [35], Plasmodium etc. Therefore, the phyla of ciliates and Apicomplexa, together with dinoflagellates, are united in the superphylum Alveolata. Recent detection in deep-sea samples of abundant gene sequences tentatively ascribable to ciliates, dinoflagellates or Apicomplexa of unknown identity $[36,37]$ will further stimulate the interest in Alveolata.

Whereas most work on $\mathrm{Ca}^{2+}$ signaling has concentrated on mammalian cells, with considerable gaps also in higher plant cells, the question arises as to when in evolution specific signaling mechanisms have evolved, including $\mathrm{Ca}^{2+}$ signaling and the subsiding mechanisms? Alternatively, some signaling mechanisms may have been modified or eliminated during the transition to parasitism, when cells have reduced and streamlined their genome 

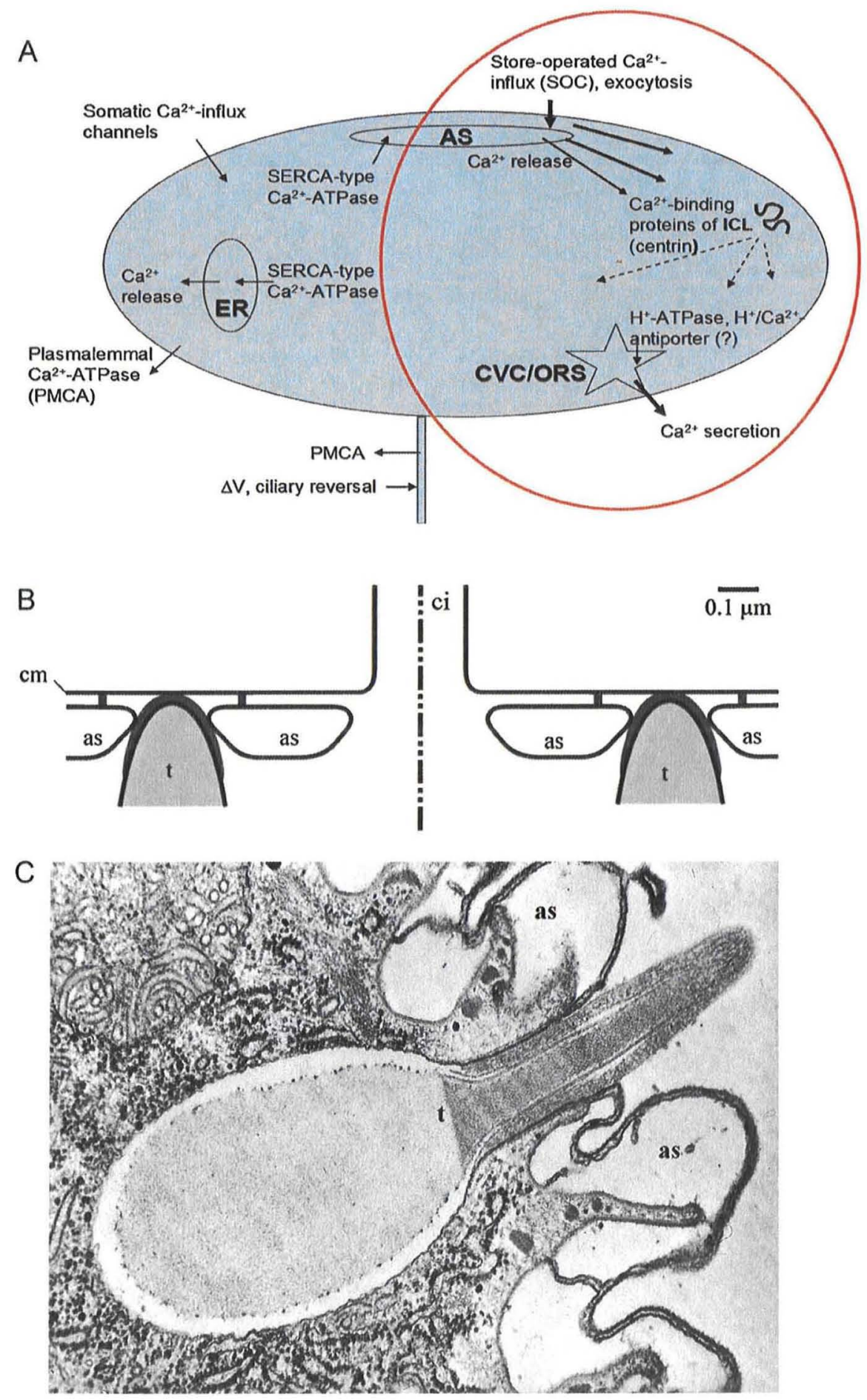

Fig. 2. Important aspects of $\left[\mathrm{Ca}^{2+}\right]_{\mathrm{i}}$ regulation and some $\mathrm{Ca}^{2+}$-regulated processes in Paramecium, as derived from the combination of methods outlined in the text. This includes EM analyses based quenched-flow/fast freezing (cryofixation), freeze-fracture and element analysis (EDX, ESI), as well as immuno-gold localization of proteins identified by cloning the respective genes. (A) Note the occurrence of passive or stimulated influx of $\mathrm{Ca}^{2+}$ via somatic influx channels and, upon depolarization, influx via voltage-dependent channels in cilia. During exocytosis store-operated $\mathrm{Ca}^{2+}$-influx (SOC) occurs in concert with $\mathrm{Ca}^{2+}$ release from alveolar sacs (AS), as ascertained by a combination of EDX with electrophysiology and fluorochrome analysis. From the stimulation site the $\mathrm{Ca}^{2+}$ signal is dissipated and first rapidly bound to centrin of the infraciliary lattice (ICL) in the cell cortex; further dissociation and diffusion to acidic compartments, such as the $\mathrm{CVC} / \mathrm{ORS}$ (osmoregulatory system) leads to $\mathrm{Ca}^{2+}$ sequestration and reduction of $\left[\mathrm{Ca}^{2+}\right]_{\mathrm{i}}$. Components most relevant for exocytosis (the emphasis of our work) and subsequent regulation steps are encircled. In the stores, ER and alveolar sacs, Ca ${ }^{2+}$ is enriched by a SERCA-type pump. Other potential stores, such as further acidic compartments, are not yet sufficiently analyzed in these cells and, therefore, not considered in the figure. (B) Scheme of a trichocyst (t) docking site, surrounded by alveolar sacs (as), at the cell membrane (cm), alternating with cilia (ci). (C) Electron micrograph of a trichocyst (t) just undergoing exocytosis. Alveolar sacs (as) are swollen after this standard preparation, but would appear flat after cryopreparation. Magnification $\sim 100,000 \times$. 

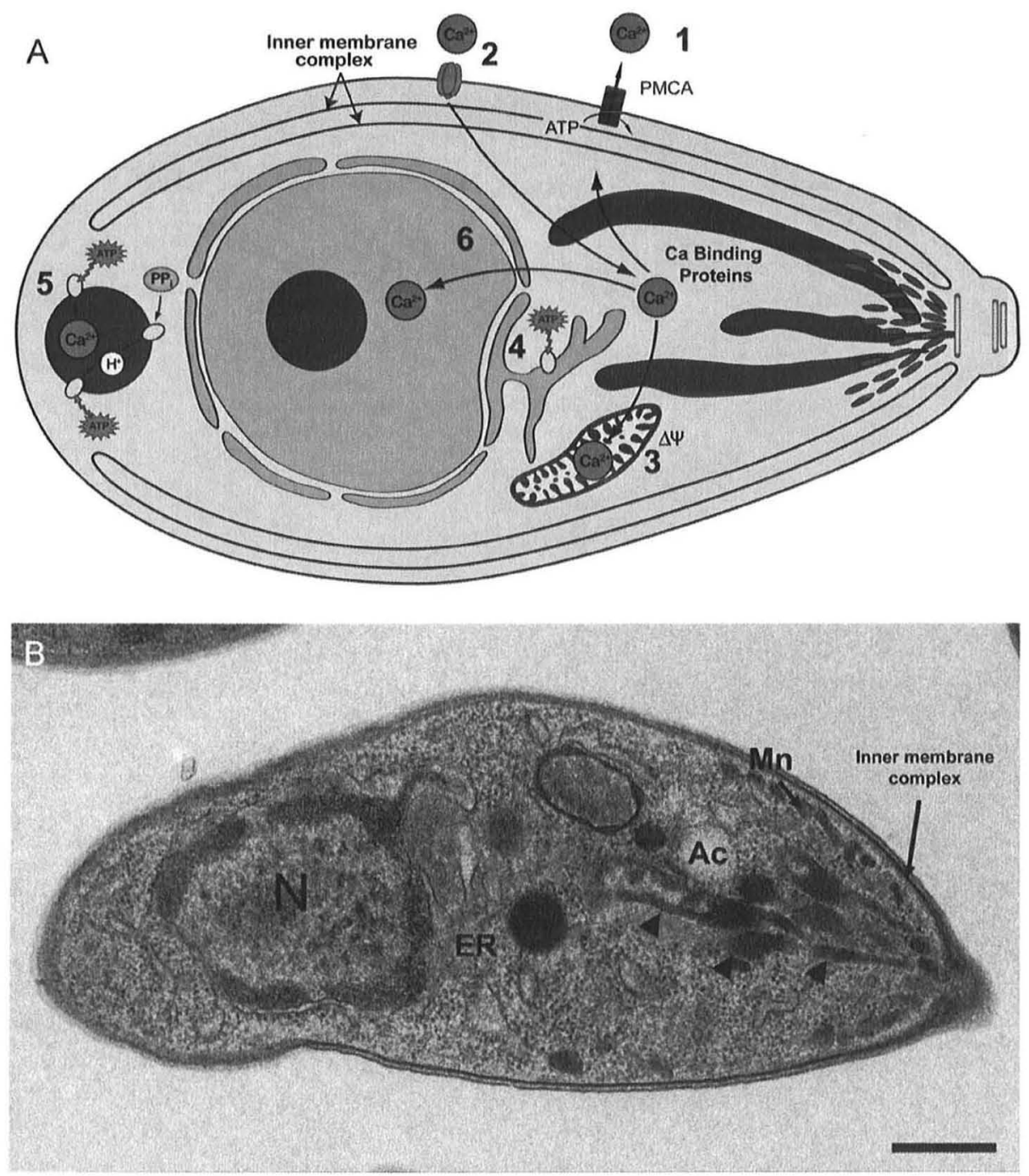

Fig. 3. Schematic and EM representation of structures relevant for $\mathrm{Ca}^{2+}$ signaling in Apicomplexan parasites. (A) $\mathrm{Ca}^{2+}$ transport mechanisms in a tachyzoite form of $T$. gondii. $\mathrm{Ca}^{2+}$ extrusion to the extracellular milieu occurs through a plasma membrane-type $\mathrm{Ca}^{2+}-\mathrm{ATPase}(\mathrm{PMCA})(1)$. After influx, probably through a Ca ${ }^{2+}$ channel (2), the intracellular $\mathrm{Ca}^{2+}$ can interact with $\mathrm{Ca}^{2+}$-binding proteins or be transported into different intracellular compartments, including $\Delta \psi$-dependent transport into mitochondria (3), sequestration by the endoplasmic reticulum via a SERCA-type $\mathrm{Ca}^{2+}$-ATPase (4), and delivery to acidocalcisome (5) or to the nucleus (6). (B) Electron micrograph of $T$. gondii, obtained after cryopreparation, showing the representative organelles of a tachyzoite form. Ac, acidocalcisome; Mn, micronemes; N, nucleus; arrowheads, rhoptries. Note the flat alveolar compartment, designated as the "inner membrane complex". Bar: $2 \mu \mathrm{m}$. Adapted from Moreno et al. [453]. Ilustrated by Dirceu Esdras Teixeira, Federal University of Rio de Janeiro, Brazil.

$[38,39]$. This question is of top relevance with Apicomplexa (Plasmodium/malaria, Toxoplasma/toxoplasmosis etc.).

The close relationship between ciliates and Apicomplexa is undisputed (Fig. 1), as it has been established in different studies on their molecular evolution [38,40,41]. In detail, this includes analysis of a variety of components, such as small ribosomal rRNA $[42,43], 268$ single copy genes [44], hsp70 proteins [45], proteins derived from cyanobacterial endosymbionts [46], ribosomal proteins (including Dinozoa as the largely neglected third group of Alveolata [47]), and a collection of first- and second-tier marker proteins [48]. This also includes phylum-specific proteins such as "alveolin" [49] that line the alveolar compartments below the cell membrane. All contain subplasmalemmal flattened sacs, the alveoli and the IMC, respectively (Figs. 2 and 3 ). The rather distinct freeze-fracture appearance of docking sites of dense core-secretory vesicles (particle "rings" and "rosettes") displays striking similarity between ciliates [50-52] and Apicomplexa [53]. Docking of trichocysts proceeds along basal body associated microtubules, in plus $\rightarrow$ minus direction [54] and, thus, resembles to positioning of lytic granules at the immunological synapse [55]. Similarly microtubules are arranged around the rhoptries and micronemes in the Apicomplexa (see above).

Another point in common is the association of cytoskeletal proteins with the alveoli and the IMC, which has been designated a membrane skeleton. Examples include the tetrins in Tetrahymena pyriformis, epiplasmins found in Paramecium and articulins in Pseudomicrothorax dubius [56]. In the case of Toxoplasma gondii, immunofluorescence microscopy has shown the presence of plateins, a subfamily of articulins. They form $10 \mathrm{~nm}$ thick filaments distributed throughout the protozoan body. Comparison with other protists has revealed considerable conservation [57]. In Apicomplexa the "inner membrane complex", IMC, is tightly bound to the cell membrane by a complex of proteins inserted in, or attached to the outer part of the IMC, in addition to actin and the thrombospondin-related anonymous (adhesive) protein, TRAP $[58,59]$. However, molecular links between alveoli and the 
cell membrane are not known from ciliates, although in the EM one can clearly recognize physical links, e.g. in Paramecium [50].

The appearance of recent ciliate clades is estimated to $\sim 800$ $[42,43]$ to 850 Mio years [60], with a common ancestry dating back considerably longer. This may have involved rather early signaling mechanisms on the basis of cyclic nucleotides [61] and of $\mathrm{Ca}^{2+}$ (this review), and thus may have developed in parallel to vesicle trafficking regulation by Rab and SNARE proteins already early in evolution [62-65]. The emergence of Apicomplexa, before becoming vertebrate parasistes, has been dated to $\sim 550$ Mio years ago for early forms and 400 Mio years ago for the genus Plasmodium [60], but radiation of mammal-hosted Plasmodium species started $\sim 13$ Mio years ago [66]. With ongoing specialization the genome may have undergone reduction and adaptations and, thus, diversification from the common ciliate/apicomplexan ancestors. How much similarity has there remained?

Experimental approaches to elucidate $\mathrm{Ca}^{2+}$ signaling are evidently easier with the non-pathogenic, large ciliate cells, while Apicomplexa (Plasmodium, Toxoplasma) deserve considerable medical interest. This is particularly due to the exocytosis of a battery of dense core-secretory organelles (apical rhopties, micronemes, and laterally positioned "dense granules") $[33,67]$. Among them, microneme secretion definitely requires a $\mathrm{Ca}^{2+}$ signal for exocytosis which is prerequisite to host cell infection $[20,68,69]$. These organelles are reminiscent of Paramecium's trichocysts and Tetrahymena's mucocysts which both are positioned over the entire cell cortex. To what extent may $\mathrm{Ca}^{2+}$ signaling be governed in different ways in the two main groups of alveolates?

In the past decade, work with either group has profited from the ongoing genome projects. The picture emerges that these two groups of alveolates not only share some similarities, but also exhibit considerable differences, as we outline in this survey. This may reflect the considerable reduction of apicomplexan genomes $[38,39]$ and the specific requirements for infection. However, comparison of the two main groups of Alveolata (with little data available on dinoflagellates) also reveals significant gaps of knowledge, often on specific, but widely different aspects. In practice, data obtained with one group are rarely taken into consideration for the other one. Therefore, this review is also intended to stimulate further work to fill such gaps. We want to stress, however, that it is not our intention to detail species specificities [39] or specific stages of the parasites, with their specific gene expression [70] and their specific $\mathrm{Ca}^{2+}$ requirements and signaling pathways [33], respectively. (These simplifications will help non-parasitologists; the facts we describe evidently refer to the stages where the respective structures and functions occur, as parasitologists will recognize.) Our main intention is to include proteomics data and experiments with cells and, thus, go beyond predictions and implications from genomic database mining. Restriction to comparative genomics can be misleading particularly when lower eukaryotes are compared with mammalian sequences; rather the analysis of specific domain sequences and protein function in situ are mandatory.

\subsection{Basic $\left.\mathrm{Ca}^{2+}\right]_{i}$ values and $\mathrm{Ca}^{2+}$ responses in Alveolata cells upon stimulation}

\subsubsection{Ciliates}

Much of our knowledge about $\mathrm{Ca}^{2+}$ in ciliates comes from Paramecium, mainly Paramecium tetraurelia. Because of their large size, they were preferably used over decades for electrophysiology $[71,72]$, mainly in the context of their swimming behavior. Another aspect analyzed to some extent in ciliates is vesicle trafficking (Paramecium: [64,65,73], Tetrahymena: [74]). All these phenomena are tightly coupled with $\mathrm{Ca}^{2+}$ signaling (Fig. 2).

As in mammalian and other cells, basic $\left[\mathrm{Ca}^{2+}\right]_{\mathrm{i}}$ is slightly below or near $10^{-7}$ molar in ciliates $[75,76]$ and values in apicomplexan cells are similar (Section 2.2.2). In ciliates, $\left[\mathrm{Ca}^{2+}\right]_{i}$ may increase at different sites of the cell in response to different stimuli, e.g. during depolarization-induced ciliary reversal/avoidance reaction or drug-induced exocytosis [10]. This includes secretagogs such as the RyR activators caffeine and 4-chloro-meta-cresol (4CmC) as well as the polyamine secretagogue, aminoethyldextran (AED) [10].

Remarkably, Paramecium cells can ward off attacks by some predators, such as Dileptus, by massive trichocyst exocytosis, as shown by Harumoto and Miyake [77] and confirmed by single cell analysis [78] which has revealed the function of unilaterally released (and decondensed) trichocyst contents as distance pieces. This cell-cell contact triggers $\mathrm{Ca}^{2+}$ signaling in the Paramecium cell [79] and similarly a local exocytotic response occurs with locally applied AED [80]. At the same time, ciliary beat is reversed - another aspect of the escape mechanism [78]. When Paramecium cells are stimulated by local heat generated by a pointed laser beam, this causes vigorous, synchronous trichocyst exocytosis and cells to move abruptly backward [81], as during chemical stimulation. Weaker heat stimulation causes ciliary reversal whose speed depends on the stimulation intensity. How this relates to $\mathrm{Ca}^{2+}$ remains to be established, but all this argues for a more or less restricted reaction, with limited spillover.

Normally ciliary reversal is induced by a depolarization/receptor potential generated in response to the activation of anteriorly enriched mechanoreceptor-type $\mathrm{Ca}^{2+}$-channels [82]. $\Delta \mathrm{V}$ dependent $\mathrm{Ca}^{2+}$ channels are restricted to ciliary membranes [83] and intraciliary $\mathrm{Ca}^{2+}$ signaling does not normally reach the cell soma. For instance, the $\mathrm{Ca}^{2+}$ signal generated in cilia via chemical depolarization by applying $20 \mathrm{mM} \mathrm{KCl}$ does not spread into the cell soma [84]. Repolarization after depolarization involves $\mathrm{Ca}^{2+}$-sensitive $\mathrm{K}^{+}$channels $[85,86]$. Exocytosis stimulation causes another, voltage-independent $\mathrm{Ca}^{2+}$ signal [75] which involves nonciliary ("somatic") channels and can entail spillover of $\mathrm{Ca}^{2+}$ into cilia, as shown by electrophysiological recordings [87] and by fluorochrome measurements [84]. This has also been shown to induce ciliary reversal in pawn mutants (non-reactive to depolarization [88]) - a clear consequence of $\mathrm{Ca}^{2+}$ spillover [80]. Large scale $\mathrm{Ca}^{2+}$ signals can spread from the cell soma into the macronucleus. This is illustrated by the fact that exocytosis stimulation induces increased transcription of specific genes in Tetrahymena [89] and Paramecium cells (see Paramecium database at http://paramecium.cgm.cnrsgif.fr and [90]). Finally, Paramecium also possesses $\mathrm{Ca}^{2+}$ channels sensitive to hyperpolarization [91].

Some of the $\mathrm{Me}^{+}-$and $\mathrm{Me}^{2+}$-influx channel activities in the cell membrane of ciliates are modified by the resulting increase of local $\left[\mathrm{Ca}^{2+}\right]_{i}$ or rather by formation of a $\mathrm{Ca}^{2+} / \mathrm{CaM}$ complex $[92,93]$. As known from numerous electrophysiological studies with Paramecium, anteriorly enriched enriched $\mathrm{Na}^{+}$and $\mathrm{Ca}^{2+}$ influx and posteriorly enriched $\mathrm{K}^{+}$efflux conductances in the somatic membrane are thus activated. This fact, in conjunction with the use of CaM inhibitors, has been exploited to register, by whole cellpatch electrophysiology, $\mathrm{Ca}^{2+}$ signals accompanying exocytosis stimulation [87]. Calmidazolium or W7 (n-[6-aminohexyl]-5chloro-1-naphthalenesulfonamide), powerful CaM inhibitors also in protozoa [30], have been used in this work. Also $\mathrm{K}^{+}$channels responsible for chemoattractant-induced conductances are regulated by $\mathrm{Ca}^{2+} / \mathrm{CaM}[94]$. The $\Delta \mathrm{V}$-dependent $\mathrm{Ca}^{2+}$ channels in the cilia are inactivated by the intraciliary $\left[\mathrm{Ca}^{2+}\right]$ increase [95]. Ironically the same mechanism has been identified, though much later, also in neuronal systems [96]. All this clearly demonstrates that basic mechanisms of $\mathrm{Ca}^{2+}$ signaling were invented early in evolution.

There are additional regulatory aspects of $\mathrm{Ca}^{2+}$ signaling in ciliates. In Paramecium the biogenesis of additional osmoregulatory system (=contractile vacuole complex, CVC) is induced when 
increased $\left[\mathrm{Ca}^{2+}\right]_{0}$ is applied in a hypoosmotic medium [97]. Also surface pattern formation in Paramecium depends on calcium (Section 5). All this suggests some morphogenetic plasticity in the context of "constitutive" $\mathrm{Ca}^{2+}$ signaling.

Encystment of some ciliates is another phenomenon which depends on an intracellular $\mathrm{Ca}^{2+}$ signal, as shown with dinoflagellates, where $\mathrm{Ca}^{2+} / \mathrm{CaM}$-activated adenylate cyclase may be involved [98]. Tetrahymena $[99,100]$, but not Paramecium, can form cysts, but participation of $\mathrm{Ca}^{2+}$ was mostly inferred only indirectly from the abundant secretory activity accompanying this process. The $\mathrm{Ca}^{2+}$ requirement was endorsed by more thorough work with Colpoda $[101,102]$. Excystment, analyzed in the ciliate, Sterkiella also depends on $\mathrm{Ca}^{2+}$ signal [103].

In summary, just as in higher eukaryotes, $\mathrm{Ca}^{2+}$ governs many functions also in ciliates. Some of the plasmalemmal $\mathrm{Ca}^{2+}$ channel types occurring in mammalian cells are also found in ciliates. Channel activities include some modulation mechanisms, e.g. activation or inhibition by $\mathrm{Ca}^{2+} / \mathrm{CaM}$ complex, as well as intracellular $\mathrm{Ca}^{2+}$ release channels (Section 4.1). $\mathrm{A} \mathrm{Ca}^{2+}$ signal accompanies, and is mandatory for a variety of ciliate activities, such as secretion and ciliary motion. Various aspects of $\mathrm{Ca}^{2+}$ signaling are rather old evolutionary achievements.

Less easy to identify is a potential $\mathrm{Ca}^{2+}$-sensor in the cell membrane, of the types discussed by Hofer [104]. In mammals, this is mostly a $\mathrm{Ca}^{2+}$ /polyvalent cation sensing receptor (also sensing appropriate aminoacids) coupled to trimeric G-proteins, but such a sensor has not been found in Paramecium. However, such a sensor function can also be executed by a non-selective, high conductivity, membrane potential-independent cation channel. For instance, in hippocampal neurons, such a channel immediately responds to stepwise changes in $\left[\mathrm{Ca}^{2+}\right]_{0}$, as analyzed by electrophysiology [105]. Similarly fluorochrome analysis in Paramecium has revealed an immediate, transient $\left[\mathrm{Ca}^{2+}\right]_{\mathrm{i}}$ increase upon abrupt in crease of $\left[\mathrm{Ca}^{2+}\right]_{0}[106]$, thus potentially fulfilling the criteria of a $\mathrm{Ca}^{2+} /$ polyvalent cation sensing receptor. See also Section 4.1 for a concise candidate.

\subsubsection{Apicomplexa}

In Apicomplexa, calibrated values of $\left[\mathrm{Ca}^{2+}\right]_{i}$ at rest also vary between 50 and $100 \mathrm{nM}[107,108]$. After isolation, depending on $\left[\mathrm{Ca}^{2+}\right]_{0},\left[\mathrm{Ca}^{2+}\right]_{\mathrm{i}}$ in Plasmodium falciparum may rise up to $700 \mathrm{nM}$ [11]. Thus, one may assume a rather high permeability, just as described for Paramecium (Sections 2.2.1 and 4.1). In the parasitophorous vacuole, the problem is to the opposite: here, the Plasmodium parasite is supplied with $\mathrm{Ca}^{2+}$ perhaps by the tubular connections to the outside medium and certainly by a $\mathrm{Ca}^{2+}$-pump contained in the host cell membrane [109]. The value for $\left[\mathrm{Ca}^{2+}\right]_{o}$ surrounding the parasite was thus determined as $\sim 40 \mu \mathrm{M}$. When one refers to experience with Paramecium (Section 3.2) this may suffice to drive a SOC mechanism. This may be assumed to occur in $P$. falciparum cells during host cell penetration, based on ${ }^{45} \mathrm{Ca}^{2+}$ flux measurements [110].

Host cell infection depends on an intracellular $\mathrm{Ca}^{2+}$ signal [111], including host cell penetration $[68,69,111]$. The conoid contains secretory organelles (rhoptries, micronemes) surrounded by a cytoskeletal structure (microtubules); in Apicomplexa the secretory activity of this name-giving complex is important for host cell penetration. (To anticipate, egression from the host cell also requires $\mathrm{Ca}^{2+}$, but from a different source [112]; see Section 3). The $\mathrm{Ca}^{2+}$ ionophore, $\mathrm{A} 23187$, by mediating secretion, can make parasite cells incapable of invasion, if incubated before seeing the host, but it also stimulate invasion and the exit of $T$. gondii tachyzoites from macrophages $[113,114]$. Generally, host cell penetration capacity has been probed with widely different $\mathrm{Ca}^{2+}$ activating and inhibitory compounds, respectively, including also the SERCA inhibitor thapsigargin ( $1 \mu \mathrm{M}$ concentration) and intracellular $\mathrm{Ca}^{2+}$ chelators, e.g. BAPTA-AM which is permeable and activated intracellularly by release of its acetoxymethylester moiety $[115,116]$. Fluorochrome recordings indicated the dependency of microneme secretion from a $\mathrm{Ca}^{2+}$ signal [117-119]. The molecular background, however, is poorly understood. One reason to compare the parasites with ciliates was the relatively easy accessibility of $\mathrm{Ca}^{2+}$ dynamics in the latter.

For the apicoplast, found as a vestigial plastid remnant in $T$. gondii [120] some plant-like functions have been suggested [112]. Abscisic acid synthesis causes CADPR formation and excystment in the infected tissue - a process requiring $\mathrm{Ca}^{2+}[112]$. Evidently cyst formation reduces virulence in $T$. gondii $[121,122]$. For cell cycle regulation in $P$. falciparum, a complete $\mathrm{Ca}^{2+}$ signaling pathway has been hypothetically envisioned [108], as outlined in Section 5.2.

\section{Calcium stores in alveolates and their activation}

\subsection{Identification of calcium stores in Alveolates}

From neuronal systems, mutual interaction of $\mathrm{Ca}^{2+}$ signals from different sources in a cell is well known [123]. This results from interdependence of $\mathrm{Ca}^{2+}$ mobilization from stores and from influx, as well as the interplay between a local $\left[\mathrm{Ca}^{2+}\right]_{i}$ increase and downregulation. How can we cope experimentally with such an intriguing situation?

$\mathrm{Ca}^{2+}$ stores may be identified by combinatorial approaches, e.g. by fluorochromes targeted to specific stores [6], energy-dispersive $\mathrm{X}$-ray microanalysis (EDX- see below) in the electron microscope (EM), as well as use of activators and inhibitors. Activators are discussed in the context of the different $\mathrm{Ca}^{2+}$-release channels (Section 4). Among inhibitors, those for sequestration may be typical of a store-specific uptake mechanism. For instance, the SERCAtype pump in the mammalian ER is inhibited by widely different compounds, including thapsigargin, cyclopiazonic acid, and tertbutylbenzohydrochinone, t-BHQ [124]. The binding sites for the latter are different from those of thapsigargin. As discussed below sensitivity of SERCA molecules in Alveolata differs considerably from that in mammals.

\subsubsection{Ciliates}

In Paramecium, alveolar sacs have been identified as cortical $\mathrm{Ca}^{2+}$ stores by Stelly et al. [125]; they isolated these compartments and followed ${ }^{45} \mathrm{Ca}^{2+}$ sequestration in an ATP regenerating regime. These studies were extended by Länge et al. [126] to find out more details about the kinetics of uptake and release. In fact, the activation mechanism remained elusive until very recently. Alveolar sacs were shown in situ EM studies using calibrated EDX [127] and, in addition, by electron-spectroscopic imaging, ESI [128] to contain $\mathrm{Ca}^{2+}$. Toward this goal, cells were rapidly inactivated by cryofixtion, i.e. by shooting into a cryogen [129]. Since this was combined with timed stimulation (quenched-flow analysis), store activation and refilling could be monitored. Note that EDX and ESI register local total concentrations (free and bound) of calcium, [Ca], while fluorochrome analyses register free $\mathrm{Ca}^{2+},\left[\mathrm{Ca}^{2+}\right]$.

Some other compartments harboring calcium were detected early on, with calcium deposited in specific electron dense or crystal-bearing vesicles, not only in Tetrahymena [130] but also in Paramecium. Here, crystals were identified by chemical and $\mathrm{X}$ ray diffraction analysis as struvite $(\mathrm{Mg} / \mathrm{Ca}$-ammonium phosphate) [131], a mineral also known from kidney stones.

In P. tetraurelia, it was recently possible to identify and localize a broad spectrum of different $\mathrm{Ca}^{2+}$ release channels (CRC) related to $\mathrm{IP}_{3} \mathrm{R} /$ RyR-type channels (PtCRC) [132-134]. Different types of such PtCRCs occur not only in dedicated stores, such as ER and alveolar sacs, but also in the CVC. Some occur in several of the manyfold vesicle types which are known to participate in vesicle trafficking, based 
either on morphological analyses [73] or on analyses of molecules relevant for the trafficking process. These include SNAREs (soluble $\mathrm{N}$-ethylmaleimide attachment protein receptors), specific actin isoforms and subunits of the $\mathrm{H}^{+}$-ATPase $[64,65]$. The multitude of such vesicles with specific PtCRCs suggests a rather local role for $\mathrm{Ca}^{2+}$ signaling in ciliates (Section 4.1). Evidence from mammalian cells also revealed that many, though not all, such vesicles are known to store $\mathrm{Ca}^{2+}[135]$ and - at least in part - to be endowed with $\mathrm{a} \mathrm{Ca}^{2+}$-sensor [136]. Such local $\mathrm{Ca}^{2+}$ signals may be prerequisite to the capacity of organelle specific membrane interaction and fusion. In summary, there is an intriguing mutual connection between local $\left[\mathrm{Ca}^{2+}\right]_{\mathrm{i}}$ and vesicle trafficking. Not only can $\mathrm{Ca}^{2+}$ modulate $\mathrm{Ca}^{2+}$ channel delivery; properly positioned CRCs in turn can regulate further vesicle trafficking. Furthermore, formation of trans-SNARE complexes per se can induce $\mathrm{Ca}^{2+}$ release in metazoan cells [137].

\subsubsection{Similarities and dissimilarities between ciliates and Apicomplexa}

In $T$. gondii immuno-gold EM localization of the SERCA-type $\mathrm{Ca}^{2+}$-ATPase has identified the ER as a prominent $\mathrm{Ca}^{2+}$ store [138]. Considering vesicle trafficking in Apicomplexa, one may also expect a spectrum of $\mathrm{Ca}^{2+}$ release channels to mediate the formation of local $\left[\mathrm{Ca}^{2+}\right]_{\mathrm{i}}$ signals. However, no data on the molecular identity of such CRCs are available at this time despite repeated efforts $([139,140]$; our own unpublished research). This makes clear identification and characterization of stores difficult. In particular no data are available on $\mathrm{Ca}^{2+}$ based signaling mechanism involving the IMC [141], the equivalent of ciliate alveolar sacs.

Is the IMC of the parasites a calcium store similar to alveolar sacs of ciliates? After preparation by standard EM protocols, the latter appear swollen and empty (Fig. 2C), but after fast freezing/freezesubstitution they appear flat [129], much like IMCs (Fig. 3B). The inner part of the IMC of $P$. falciparum and $T$. gondii is endowed with six-pass membrane proteins termed GAPM (glideosomeassociated protein with multiple-membrane spans) [142] and in freeze-fracture replicas these membranes are studded with $9 \mathrm{~nm}$ sized intramembranous particles/proteins arranged in register with underlaying microtubules ( $P$. gallinaceum: [143]; $T$. gondii: $[35,144])$. Therefore, GAPMs may cause this arrangement. In contrast, the inner part of the alveolar sacs of $P$. tetraurelia has no such microtubules attached, displays a rather different freeze-fracture appearance and houses densely clustered SERCA molecules [145]. (Note that SERCA is a 10-pass integral protein [32].) The inner part of the alveoli, therefore, is widely different between the two groups of Alveolata.

EDX analysis has been applied to cryofixed $T$. gondii cells [146]. There was no indication of a cortical store with any remarkable enrichment of Ca signals, in contrast to experiments conducted by the same group under comparable conditions with Paramecium cells [147], although the spatial resolution achieved did allow only to monitor calcium in the cell cortex, without assignment specifically to alveolar sacs. In contrast, EDX and ESI performed with $T$. gondii after $\mathrm{Ca}^{2+}$ precipitation by pyroantimonate resulted in reaction product not only in intracellular vacuoles and over the nuclear envelope (probably also in the ER), but also in association with the IMC [148]. Similar staining of IMC, ER and nuclear envelope was also found with this (less relialble) cytochemical approaches in $T$. gondii by others [149]. Thus, $\mathrm{Ca}^{2+}$ storage in the IMC has remained unsettled and repetition with cryomethods appears advised.

Alveolar sacs of Paramecium contain a SERCA-type $\mathrm{Ca}^{2+}$-pump $[145,150,151]$, a lumenal calsequestrin-(CaS-)like protein [152], and $\mathrm{Ca}^{2+}$-release channels related to RyRs [133]. Pumps and channels are located at opposite sides in a functionally useful manner: pumps facing the cell center, channels the pereiphery. No such components are known from the apicomplexan IMC (Fig. 3) whose dominant components are the gliding motor complex, the "glideosome" [33,67]. Considering that the relevant molecular components of both alveolar sacs and the IMC are well established, one is tempted to conclude that, in Apicomplexa, the original function as a $\mathrm{Ca}^{2+}$ store has been either reduced or abandoned in favor of a machinery dedicated to the mechanics of host cell penetration. To repeat, EDX analysis with advanced methodologies appears to be needed.

Recently, involvement of Rab11A [153] and Rab11B in the biogenesis of the IMC of $T$. gondii has been reported, assuming delivery of Golgi-derived vesicles by Rab11B [154]. In general terms, this GTPase is assumed to be associated with recycling endosomes [155] and also from the trans-Golgi network [156]. According to the intracellular distribution of a GFP fusion protein in Tetrahymena thermophila, Rab11B is associated with the oral apparatus [74] and, thus, possibly involved in some membrane recycling activities. As far as the biogenesis of alveolar sacs in Paramecium is concerned, we have evidence only for vesicles derived from the ER or downstream [151] and this could include the trans-Golgi network (not analyzed). Currently the dynamic processes described for $T$. gondii are unique indications of vesicular biogenesis of the IMC similar to that of alveolar sacs in Paramecium. Here, silencing of the SNAREspecific chaperone, NSF, results in vesicle attachment to alveolar sacs which otherwise has not been recognized [157]. Basically we assume vesicle trafficking for the biogenesis of alveolar sacs, rather than maturation, and a similar pathway may underlay ICM biogenesis.

$\mathrm{A} \mathrm{Ca}^{2+}$ storing organelle much better known in Apicomplexa than in ciliates is the acidocalcisome. These correspond to electron dense vesicles, as seen in whole mount EM preparations, containing a number of channels and transporters resposible for ion uptake, namely Mg, K, Ca, Fe and Zn (Fig. 4). They are endowed with a $\mathrm{Ca}^{2+}$-ATPase, $\mathrm{H}^{+}$-ATPase and a $\mathrm{H}^{+}$-pyrophosphatase, $\mathrm{H}^{+}$-PPase, characteristic (though not unique) for this organelle [19-21]. In the apicomplexan genus Eimeria, acidocalcisomes have been described as metachromatic volutin granules, as seen in the light microscope [158]. Acidocalcisomes store $\mathrm{Ca}^{2+}$ as insoluble pyro- and polyphosphates [20]. Ciliates probably contain acidocalcisomes, though up to now these have not been characterized, in contrast to the parasites. In Tetrahymena, chemical analysis of metachromatic volutin granules has documented the presence of $\mathrm{Ca}, \mathrm{Mg}$-pyrophosphate [159], thus resembling apicomplexan acidocalcisomes. They appear different fom the crystal vacuoles found in Paramecium cells whose molecular characteristics remains to be elucidated. $\mathrm{A} \mathrm{H}^{+}$-PPase has been identified by polymerase chain reaction (PCR) not only in Apicomplexa, but also in ciliates [160]. In Apicomplexa, chemical and cell biological analyses have assigned this pump to acidocalcisomes $[19,20,161]$. Acidocalcisomes exploit formation of a $\Delta \mathrm{H}^{+}$for $\mathrm{Me}^{2+}$ enrichment by $\mathrm{H}^{+} / \mathrm{Me}^{2+}$ or similar antiporter activity, as ascertained for Apicomplexa. Here, together with a $\mathrm{Ca}^{2+}$-ATPase (below), such exchangers serve the enrichment of $\mathrm{Ca}^{2+}$ largely in insoluble form (polyphosphate) and, thus, to control $\left[\mathrm{Ca}^{2+}\right]_{\mathrm{i}}$ homeostasis $[20,162]$.

The $\mathrm{Ca}^{2+}$-ATPase (TgA1) occurring in the acidocalcisomes (and reportedly in the cell membrane) of Toxoplasma, when compared with mammalian homologs, appears special with regard to several aspects: it has a size resembling that of mammalian PMCA, despite the reported absence of a CaM-binding domain; it is insensitive to thapsigargin $(1 \mu \mathrm{M})$ [20]. In fact, recent comparative genomic analysis classifies it as a P-type ATPase [163], similar to the established P-type ATPases, such as PMCA and SERCA. TgA1 knock-out $T$. gondii cells exhibited reduced pyro- and polyphosphate contents, altered $\mathrm{Ca}^{2+}$ homeostasis, and consequently reduced microneme secretion and host cell invasion capacity [20]. This may indicate a role of acidocalcisomes in $\mathrm{Ca}^{2+}$ signal transduction during host cell penetration, but further work appears to be required for more detailed specification, to exclude indirect effects of 


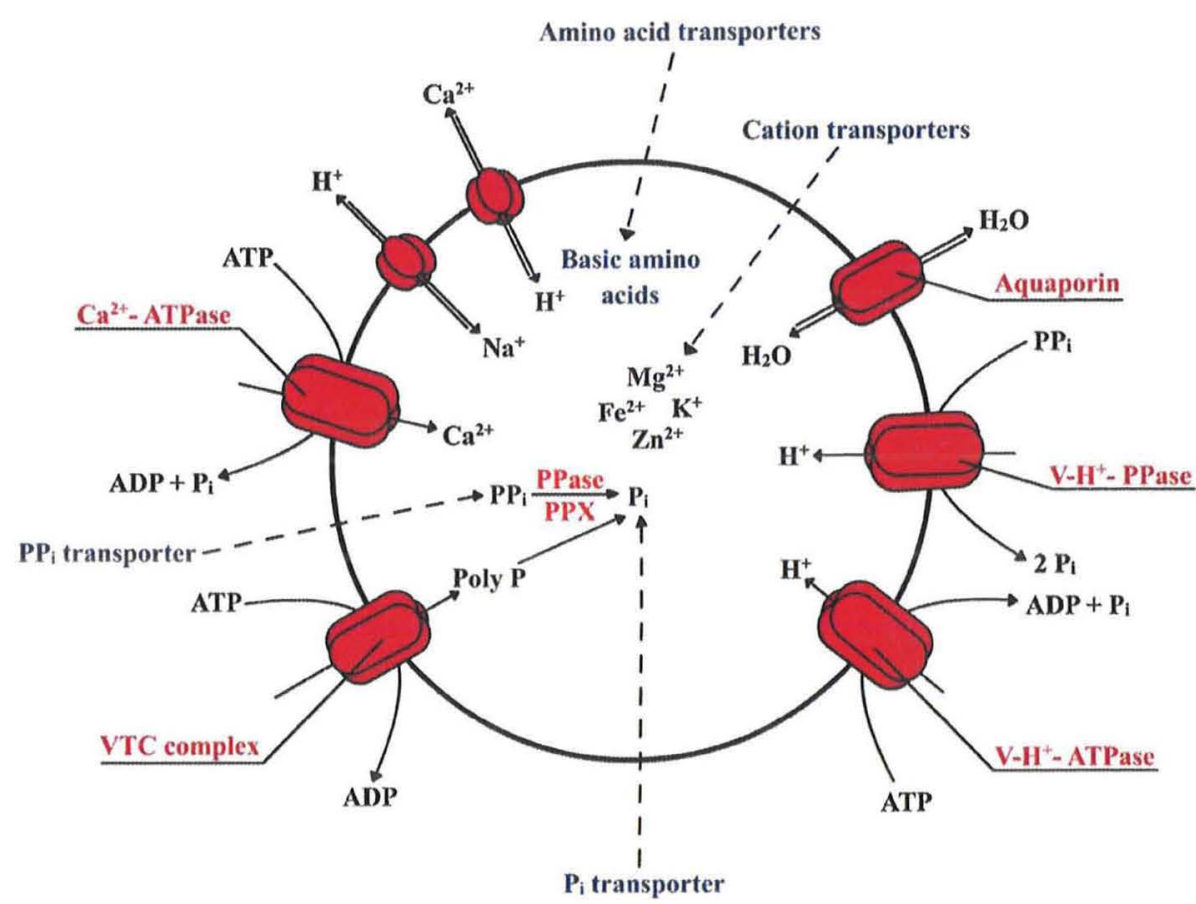

Fig. 4. Transport mechanisms across the acidocalcisomal membrane in Apicomplexa. Calcium uptake and release is mediated by a Ca ${ }^{2+}-\mathrm{ATPase}$ and $\mathrm{Ca}^{2+} / \mathrm{H}^{+}$exchanger, respectively. $\mathrm{A} \mathrm{H}^{+}$gradient is established by a $\mathrm{V}-\mathrm{H}^{+}$-ATPase and a $\mathrm{V}-\mathrm{H}^{+}$-PPase. An aquaporin channel is also present and a $\mathrm{Na}^{+} / \mathrm{H}^{+}$exchanger accounts for $\mathrm{H}^{+}$release. High concentrations of $\mathrm{PP}_{\mathrm{i}}$ and polyphosphates (Poly $\mathrm{P}$ ) are found in the matrix, requiring enzymes involved in their metabolism, such as exopolyphosphatase (PPX) and pyrophosphatase (PPase). In other organisms, the presence of a vacuolar transporter chaperone (VTC) presumably involved in synthesis and translocation of Poly P has been suggested. The transport of basic aminoacids and other cations $\left(\mathrm{Mg}^{2+}, \mathrm{Fe}^{2+}, \mathrm{K}^{+}\right.$and $\left.\mathrm{Zn}^{2+}\right)$ is still unclear. Adapted from Docampo and Moreno [21]. Illustrated by Dirceu Esdras Teixeira, Federal University of Rio de Janeiro, Brazil.

knock-out and to achieve more direct correlation with microneme exocytosis.

In Apicomplexa, $\mathrm{Ca}^{2+}$-ATPase activity is reported to be paralleled by $\mathrm{Ca}^{2+} / \mathrm{H}^{+}$counterflux [164]. However, this may not be an exchanger activity in the classical definition, but rather it may indicate electrogenicity of this pump, as known for the SERCA of mammalian cells $[165,166]$. A $\mathrm{Ca}^{2+}$-ATPase with rather similar properties also occurs in $P$. falciparum, but its localization is not indicated by the authors [167]. Clearly P. falciparum has a $\mathrm{Ca}^{2+}$ ATPase that is sensitive not only to thapsigargin (EC100 $\sim 25 \mu \mathrm{M}$, with some effects from micromolar concentrations on) but also to $5 \mu \mathrm{M}$ cylopiazonic acid [168]. Ultrastructural localization would be helpful, in such cases. Note that no equivalent is known from ciliates where the two SERCA molecules detected are of "standard" size, $\sim 100 \mathrm{kDa}[150,151]$, and insensitive even to $100 \mu \mathrm{M}$ thapsigargin [169]. Also the ciliate PMCA contrasts by the presence of a CaM-binding domain and a size of $\sim 130 \mathrm{kD}[170,171]$ as typical of PMCA in higher eukaryotic, including mammalian cells [31].

In the Paramecium DB - but not in Apicomplexa - TPC sequences can be found (unpubl. data), but they have not yet been assigned to any members of the endo-lysosomal axis. Since $\mathrm{Ca}^{2+}$ release can be activated by binding of NAADP ${ }^{+}$to TPCs of acidic stores $[25,26,172]$ we performed such binding studies with Paramecium homogenates (Section 4.2). The data obtained further support the occurrence of such channels in ciliates. However, for the following reasons this may concern acidic stores different to acidocalcisomes, of a type yet to be identified. Acidocalcisomes have been excluded as TPCendowed organelles in protozoa [26,173] and sea urchin eggs [174] Moreover, no consistent TPC sequences are found in the Apicomplexan databases (Section 4.2). Acidocalcisomes can participate in trafficking and merge with other organelles, so that theoretically widely different CRC types could coexist. In trypanosomes, fusion between acidocalcisomes and the CVC has been suggested [175].
There is also evidence that $\mathrm{Ca}^{2+}$ is released by $\mathrm{InsP}_{3}$ from apicomplexan acidocalcisomes [176,177], but this effect and organelle biogenesis is poorly understood. The molecular biology of the $\mathrm{Ca}, \mathrm{Mg}$-phosphate containing compartments found in Tetrahymena [130] still has to be established. Altogether, in ciliates, putative acidocalcisomes still require much more detailed analysis to achieve a level of knowledge comparable to that in Apicomplexa.

Additional $\mathrm{Ca}^{2+}$ storage organelles have been identified in apicomplexans. T. gondii possesses a "plant-like vacuole" endowed with a plant-like vacuolar $\mathrm{H}^{+}$-PPase, aquaporin and $\mathrm{Ca}^{2+} / \mathrm{H}^{+}$as well as $\mathrm{Na}^{+} / \mathrm{H}^{+}$exchange activity [178]. It serves to overcome stress in recently egressed tachyzoites when they reach their new extracellular medium. There are no indications of any $\mathrm{Ca}^{2+}$ activation mechanisms.

In Toxoplasma, acidocalcisomes [19] and the plant-like vacuole [178] are not only established $\mathrm{Ca}^{2+}$ stores, but they are also assumed to interact with each other [178]. Both compartments are able to store $\mathrm{Ca}^{2+}$ thanks to - among other mechanisms - a $\Delta \mathrm{H}^{+}$generated by $\mathrm{H}^{+}$-ATPase and $\mathrm{H}^{+}$-PPase activity, connected to a $\mathrm{Ca}^{2+} / \mathrm{H}^{+}$exchanger system [179]; Fig. 4. Whereas acidocalcisomes are widely distributed amongs Apicomplexa $[19,21,161,180]$, the plant-like vacuole does not belong to the general repertoire. In the latter, the storage form of $\mathrm{Ca}^{2+}$ is not yet clear.

Altogether there are large blackspots in either one of the protozoan groups under consideration here, not only regarding the $\mathrm{Ca}^{2+}$ storage compartments, but also $\mathrm{Ca}^{2+}$ signaling (Section 4.1).

\subsection{Activation of $\mathrm{Ca}^{2+}$ stores}

\subsubsection{Ciliates}

AED, the established secretagogue $[80]$ activates $\mathrm{Ca}^{2+}$ release from alveolar sacs [127] and also causes an influx of ${ }^{45} \mathrm{Ca}^{2+}$ in Paramecium [181]. AED is without any effect on the isolated cell 
Table 1

Characteristics of $\mathrm{Ca}^{2+}$ dynamics pertinent to stimulated exocytosis in Paramecium.

\begin{tabular}{|c|c|c|}
\hline & & Reference \\
\hline $\begin{array}{l}\text { Cytosolic free } \mathrm{Ca}^{2+} \text { concentration, }\left[\mathrm{Ca}^{2+}\right]_{\mathrm{i}} \text {, } \\
\text { before stimulation }\end{array}$ & $0.065-0.100 \mu \mathrm{M}$ & [75] \\
\hline $\begin{array}{l}\text { Total calcium concentration, [Ca], in alveolar } \\
\text { sacs }\end{array}$ & $\sim 40 \mathrm{mM}$ & [127] \\
\hline $\begin{array}{l}\mathrm{Ca}^{2+} \text { released from alveolar sacs upon } \\
\text { stimulation within } 1 \mathrm{~s}\end{array}$ & $\sim 80 \%$ & [127] \\
\hline Local $\left[\mathrm{Ca}^{2+}\right]_{i}$ at stimulation sites & $\sim 5 \mu \mathrm{M}$ & [75] \\
\hline \multicolumn{3}{|c|}{$\left[\mathrm{Ca}^{2+}\right]_{0}$ required for store-operated $\mathrm{Ca}^{2+}$-influx (SOC) } \\
\hline Threshold value (no SOC observed) & $0.25 \mu \mathrm{M}$ & [183] \\
\hline Half-maximal effect ( $50 \%$ exocytosis) & $0.7 \mu \mathrm{M}$ & [183] \\
\hline Maximal effect (threshold for $100 \%$ exocytosis) & $\sim 5 \mu \mathrm{M}$ & [75,183] \\
\hline \multicolumn{3}{|c|}{ Time required for alveolar sacs refilling with $\mathrm{Ca}^{2+}$} \\
\hline Eneregy-dispersive X-ray microanalysis & $\sim 60 \mathrm{~min}$ & {$[127]$} \\
\hline Timed double trigger experiments & $\sim 65 \mathrm{~min}$ & [436] \\
\hline${ }^{45} \mathrm{Ca}^{2+}$ uptake in vitro & $\sim 60 \mathrm{~min}$ & [126] \\
\hline
\end{tabular}

cortex fragments or with purified alveolar sacs [126], thus indicating the requirement of a kind of unknown signal transduction mechanism for store activation. A combination of timed activation (e.g. of exocytosis) with quenched-flow/cryofixation [129,182] allowed the analysis of $\mathrm{Ca}^{2+}$ fluxes with variable $\left[\mathrm{Ca}^{2+}\right]_{0}[183]$ within the subsecond time scale and EDX with high spatial resolution of $\sim 60-70 \mathrm{~nm}[127,184]$. As summarized in the scheme, below, and in Table 1, EDX revealed that mobilization from stores is the first step, causing a $\mathrm{Ca}^{2+}$ influx as a second step. This mechanism of store-operated $\mathrm{Ca}^{2+}$-influx, SOC, was further ascertained in different ways. (i) When during the subsecond stimulation time extracellular $\mathrm{Ca}^{2+}, \mathrm{Ca}^{2+}{ }_{0}$, was chelated to $\sim 30 \mathrm{nM}$, i.e. slighly below $\left[\mathrm{Ca}^{2+}\right]_{\mathrm{i}}$ at rest, $\sim 60 \%$ of the alveolar $\mathrm{Ca}^{2+}$ was released. (Note that total absence of $\mathrm{Ca}^{2+}{ }_{0}$ would increasingly damage Paramecium cells [128] and, therefore, was always avoided.) When $\mathrm{Ca}^{2+}{ }_{0}$ was replaced by $\mathrm{SrCl}_{2}$, again release of stored $\mathrm{Ca}^{2+}$ was visible, while $\mathrm{Sr}^{2+}$ followed from the outside [127]. Note that the K $\alpha$ energy lines of $\mathrm{Sr}$ and $\mathrm{Ca}$ are easily discernible. (ii) The response to $\mathrm{La}^{3+}$ in the medium and $\mathrm{Mn}^{2+}$-induced Fura-2 signal quenching, respectively, both characteristic of a SOC mechanism, also supported this mechanism [185]. (iii) Double mutants devoid of any $\mathrm{Ca}^{2+}$ influx could equally well be triggered by AED, with a similar decay of [Ca] in alveolar sacs as in wildtype cells [186]. Therefore, a $\mathrm{Ca}^{2+}$ induced $\mathrm{Ca}^{2+}$-release (CICR mechanism) from alveolar sacs can be excluded. The $\mathrm{Ca}^{2+}$-release channels involved are of the RyR-type, as discussed in Section 4.1. How mobilization from alveolar sacs and superimposed influx through the cell membrane is generated remains unknown. We refer to Section 1 for Orai/Stim linkers identified between cortical ER and the cell membrane, but none has been verified as yet (Stim and Orai being absent from the Paramecium DB). Remarkably, upon stimulation, a mass-transport of $\mathrm{Ca}^{2+}$ from the outside medium to the ER/SR (as we reported for alveolar sacs) was later described in an immune and a skeletal muscle cell line by totally different methods [187], just as in Paramecium [127].

Not only (unknown) chemical coupling but also conformational coupling between $\mathrm{Ca}^{2+}$ release channels in cortical compartments and plasmalemmal $\mathrm{Ca}^{2+}$ influx channels should be envisaged, in principle similar to - though not identical with - that known from skeletal muscle [17]. Physical linkers between cortical $\mathrm{Ca}^{2+}$ stores and the cell membrane different from Orai/Stim are also known. According to current knowledge, this includes (i) the protein Ist2p, known from yeast as an osmotic stress tolerance protein, which resembles coatamer protein type COPI [188]; when expressed in human cells it produces close ER-cell membrane attachments. (ii) In yeast cells, this is also achieved by the oxysterol-binding homology (Osh) protein family member Osh3, endowed with a pleckstrin homology domain [189]. (iii) Junctate protein is another candidate [190].

In Paramecium, activation of exocytosis and exocytosis-coupled endocytosis takes place according to the following flow chart:

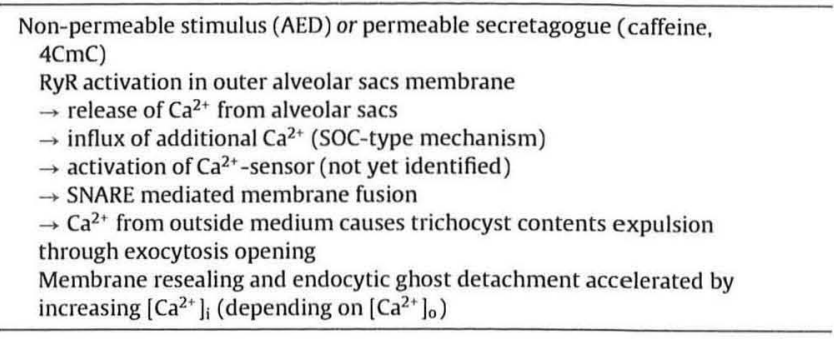

Whether crystal vacuoles of Paramecium represent acidic organelles related to acidocalcisomes in Apicomplexa (see above) has not been analyzed as yet, as is the case with the numerous acidic vesicles endowed with $\mathrm{H} \mathrm{H}^{+}$-pump [191]. An exception is the contractile vacuole complex (CVC) which is also endowed with a $\mathrm{H}^{+}$-ATPase, as shown in Paramecium [192-194]. In the absence of any overt $\mathrm{Ca}^{2+}$-pump, $\mathrm{Ca}^{2+}$ is probably sequestered by exploiting the chemiosmotic $\Delta \mathrm{H}^{+}$using an exchanger system. During systole this organelle releases, in a cyclic exocytotic process, substantial amounts of $\mathrm{Ca}^{2+}$ to the outside medium [195]. This may be a major mechanism of extruding an excess of $\mathrm{Ca}^{2+}$ after exocytosis stimulation [132]. Remarkably, according to ${ }^{45} \mathrm{Ca}^{2+}$ flux measurements $[181,196]$ and fluorochrome analyses [106], $\mathrm{Ca}^{2+}$ rapidly leaks into these cells. Such diffuse influx, even when provoked by pipetting high concentrations of $\mathrm{Ca}^{2+}$ onto cells, does not trigger any recognizable response. However, its downregulation will require permanent, efficient extrusion, notably by the CVC, which therefore does not act as a source during stimulation.

As in many other cells, the ER represents a significant calcium store also in ciliates, as outlined in Section 4.1.

\subsubsection{Apicomplexa}

Contact with a host cell is assumed to be the trigger for rapid $\mathrm{Ca}^{2+}$-dependent release of dense core vesicles and for penetration of the host cell by the parasites $[119,197]$. This recalls triggering of trichocyst exocytosis by contact with a predatory cell in Paramecium [77,78]. An essential difference is that, in Apicomplexa, material from the micronemes mediates intense contact $[68,198]$ (Section 6.1), whereas trichocysts keep attacking predatory cells at a distance [78].

The $\mathrm{Ca}^{2+}$ requirement for host cell penetration was originally derived from increased host cell interaction during $\mathrm{Ca}^{2+}$ ionophore treatment [68]. It was shown that incubation of tachyzoites of $T$. gondii in a solution containing A23187 or ionomycin leads to protrusion of the conoid $[115,199]$. Depletion of extracellular $\mathrm{Ca}^{2+}$ reduces tachyzoite invasion [200]. $\mathrm{Ca}^{2+}$ channel blockers, such as verapamil (whose channel effect in these cells is not established), and calmodulin antagonists also inhibit cell invasion [201]. As mentioned in Section 2.2, depletion of the parasite's intracellular calcium with the ionophore, A23187, inhibits invasion [115]. Tachyzoites preloaded with the $\mathrm{Ca}^{2+}$ chelator BAPTA/AM were unable to penetrate host cells [107]. Thus, $\mathrm{Ca}^{2+}$ requirement appears established for micronemes, but less for rhoptry, and not at all for constitutive dense granule secretion [202]. The requirement of extracellular $\mathrm{Ca}^{2+}$ for erythrocyte invasion has been documented with $P$. falciparum, as depletion of $\mathrm{Ca}^{2+}{ }_{0}$ inhibits infection [203] and other bivalent cations cannot substitute for $\mathrm{Ca}^{2+}{ }_{0}$ [204]

There is evidence of a SOC-type mechanism also in Apicomplexa, e.g. in P. falciparum [205], but the precise origin of $\mathrm{Ca}^{2+}$ and its mode of mobilization is not so clear, particularly since the IMC as the equivalent of alveolar sacs is more or less unlikely to be a 
$\mathrm{Ca}^{2+}$ store (Sections 3.1, 4.1 and 4.2). With T. gondii, a $\mathrm{Ca}^{2+}$ signal merely from internal sources, even without enforcement by a SOCtype mechanism, suffices for microneme activation [119]. A further complication is the heterogenous sensitivity of microneme secretion [206]. Clearly, precisely timed $\left[\mathrm{Ca}^{2+}\right]_{\mathrm{i}}$ signaling studies relative to the host cell penetration process would be of high value, but these are much more difficult to perform than with non-parasitic relatives.

To identify the origin of the $\mathrm{Ca}^{2+}$ signal, drugs which inhibit $\mathrm{Ca}^{2+}$ sequestration into specific stores may be useful; for $\mathrm{Ca}^{2+}$ mobilization, different activators have been probed with the two apicomplexan genera. The ER, but hardly acidocalcisomes have been envisaged in pilot studies by Billker et al. [12]. They found PLC-effects to activate $\mathrm{IP}_{3} \mathrm{Rs}$, or the effects of cADPR to activate RyR-like $\mathrm{Ca}^{2+}$-release channels in the context of secretion; in parallel experiments were done with thapsigargin. Microneme release is induced by cADPR in T. gondii [207] and in P. falciparum [208]. $\mathrm{Ca}^{2+}$ stores have been characterized in $P$. falciparum as sensitive to cyclopiazonic acid at usual concentrations, but not to thapsigargin [11], unless applied at concentrations much higher than efficient in mammalian cells $[109,168]$. Considering the difficulties in discriminating effects on ER and acidocalcisomes, there remains some additional uncertainty. Consider that, in apicomplexan cells, $\mathrm{InsP}_{3}$ is assumed to act not only on the ER, but also on acidocalcisomes (reviewed in $[176,177])$. Moreover, both organelles are functionally linked. $\mathrm{Ca}^{2+}$ released from the ER is cleared from the cytosol by uptake into acidocalcisomes [11] which, thus, may exert a function, beyond signal formation, as a sink.

Little is known about NAADP ${ }^{+}$effects and no useful TPC sequences can be found in the apicomplexan DBs. Although acidocalcisomes are abundant, particularly in Plasmodium and Toxoplasma $[111,179,180,209]$ the release channels have not been identified unambiguously as yet.

Such attempts do not necessarily identify these organelles as the only stores, since the Plasmodium food vacuole has also been considered a thapsigargin and cyclopiazonic acid sensitive store [210]. However, when fluorochrome trapping was eliminated, the $\mathrm{Ca}^{2+}$ concentration in this organelle was rather low, thus disqualifying it as a major source [211]. Judged on this basis, the ER and the acidocalcisomes may be the major $\mathrm{Ca}^{2+}$ stores in Apicomplexa. However, the latter contain $\mathrm{Ca}^{2+}$ mainly as polyphosphates and, thus, may not be easily mobilized [212]; accordingly a mechanism for rapid hydrolysis in the organelle lumen is discussed, as outline in the legend to Fig. 4.

Future work may profit from more subtle approaches. For instance, in yeast, homotypic vacuole fusion has been shown to depend on CaM and on $\mathrm{Ca}^{2+}$ released from the organelle [213]. This has been established by inhibition with the very fast $\mathrm{Ca}^{2+}$ chelator BAPTA (1,2-bis-[o-aminophenoxy]ethane tetraacetate). BAPTA binds $\mathrm{Ca}^{2+}$ with a $\tau=0.5 \mu$ s, i.e. within a very short distance from its release site, as previously summarized [10]. This recalls binding of CaM to food vacuoles in ciliates, as reported repeatedly, for Paramecium [214,215] and Tetrahymena [216]. Using different chelators, including membrane permeable derivatives as well as CaM inhibitors, one may scrutinize local effects also in Apicomplexa and other Alveolata more reliably.

\section{Calcium release channels in Alveolates}

\section{1. $\mathrm{IP}_{3} \mathrm{R}$ - and RyR-type $\mathrm{Ca}^{2+}$ release channels}

In unicellular organisms, including Dictyostelium and apicomplexan parasites, as well as in flowering plants, physiological effects by the application of the activators, $\operatorname{Ins}_{3}$ and caffeine, have been repeatedly reported. However, although $\mathrm{Ca}^{2+}$ channels in general are considered among the oldest channels emerging in evolution
[217], paradoxically CRCs have not yet been identified on a molecular scale to any sufficient degree, neither in multicellular plants [218] nor in any protozoan. Recent critical reviews, in fact, advocate for a more stringent characterization of the respective receptors $\left(\mathrm{IP}_{3} \mathrm{R}, \mathrm{RyR}\right)$ on a molecular level. Current reviews agree that this is not available for any protozoan species $[139,140]$ (except $I_{3} R s$ Paramecium [132] to which we could recently add RyRs [133]) and some related CRC forms [134].

The characteristic domain structure of $\mathrm{IP}_{3}$ Rs and RyRs [219-222] should make them amenable to identification also in lower eukaryotes. Beyond this, unequivocal identification has to include, on the one hand Ins $\mathrm{P}_{3}$ binding assays and in situ analysis of the effects of InsP $\mathrm{P}_{3}$ uncaging, and on the other hand the analysis of effects of CRC-activating messengers and drugs. Both receptor types are different in their molecular pharmacology [220,223,224], although considerable deviations occur at different levels of evolution [30]. Also manyfold modulatory effects exerted by interacting molecules and receptor modifications ([220,225]; for the RyR, see [24]; for the $\mathrm{IP}_{3} \mathrm{R}$, see $\left.[23,226]\right)$ would have to be taken into account in future analyses with protozoa. Considering the different pharmacology of some RyR mutations and concentration dependency of ryanodine effects, analysis by the alternative standard drugs, caffeine [227] and $4 \mathrm{CmC}$ [228], appears advised. With RyRs, the most likely physiological activator, cADPR [229], whose effect has been definitely established only quite recently [24], should also be probed. So far, the most essential criteria have been fulfilled only for some aspects, and only with the CRCs of Paramecium, PtCRC.

The compartment-specific delivery of all CRCs, as described for Paramecium below, is assumed to start in the cytosol, with incorporation into the ER membrane and subsequent "shipping" in vesicles to the respective membranes, based on poorly understood cues [225].

\subsubsection{Ciliates}

The Paramecium DB contains many scaffolds showing sequence similarities with all the types of $\mathrm{Ca}^{2+}$-release channels mentioned. According to the above criteria, $\mathrm{IP}_{3} \mathrm{R}$ - and RyR-type sequences have been analyzed in more detail [132-134]; see Fig. 5. Mainly the presence of some specific domains has been evaluated. This includes: (i) a near-aminoterminal Ins $\mathrm{P}_{3}$-binding domain (eventually with InsP $\mathrm{P}_{3}$-binding signatures, occurrence of $\mathrm{InsP}_{3}$ binding and physiological InsP $\mathrm{P}_{3}$ effects). (ii) Regions homologous to established RyRs. (iii) RIH (ryanodine-InsP $\mathrm{P}_{3}$-homology) domains homologous to both types of receptor channels. (iv) Organization of transmembrane domains including a pore domain with a selectivity filter. (v) Spotting a binding signature for $4 \mathrm{CmC}$ in the case of RyRs [230], whereas activation sites for caffeine are less well defined [224]. (vii) Domains appropriate for tetramerization $[17,220]$. Note that for $\mathrm{IP}_{3} \mathrm{Rs}$ and RyRs binding sites for activators other than $\mathrm{InsP}_{3}$ and $4 \mathrm{CmC}$ are less useful because of considerable variability [224].

Typically the $\mathrm{IP}_{3} \mathrm{R}$ contains in its $\mathrm{InSP}_{3}$-binding domain 10 residues for InsP $\mathrm{P}_{3}$ binding of which three are essential [231]. Also typically, the selectivity filter has the signature sequence GGGIGD in the RyR and GGGVGD in the $\mathrm{IP}_{3} \mathrm{R}[232,233]$; variations in these change ion conductance. In $P$. tetraurelia, we have combined these molecular analyses (Fig. 5) with AB localization and gene silencing studies in conjunction with functional tests. Due to their great number only individual PtCRC isoforms have been scrutinized paradigmatically.

We found in Paramecium six subfamilies of $\mathrm{Ca}^{2+}$-release channels (PtCRC) with more or less pronounced similarities to $\mathrm{IP}_{3} \mathrm{Rs}$ and RyRs, numerated I-VI [132-134]. To be considered for further analysis as putative $\mathrm{Ca}^{2+}$ release channels only those sequences were taken into account where the carboxy terminal part contains a channel domain corresponding to the criteria observed in mammalian cells. This includes six and four transmembrane 


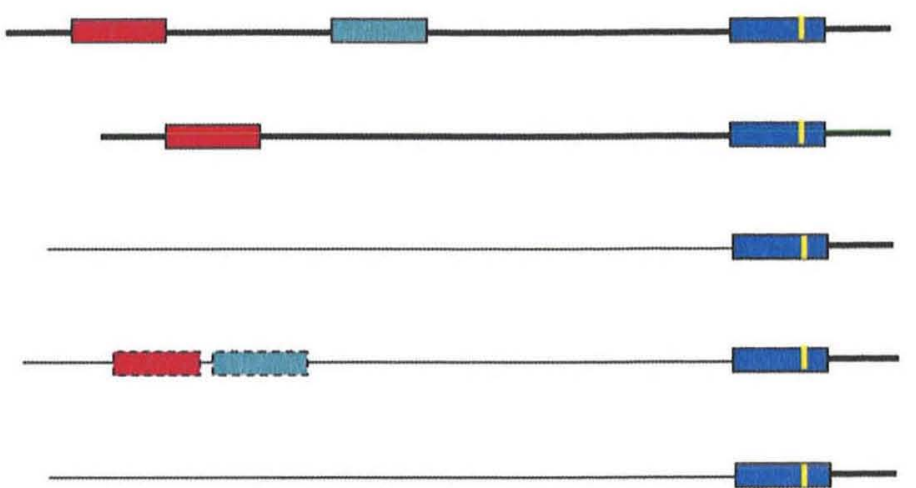

PtCRC-I

PICRC-II

PlCRC-III

PICRC-IV

\section{PICRC-V}

\section{PtCRC-VI}

Fig. 5. Molecular characterization of gene sequences encoding PtCRCs, type $I P_{3} R$ and RyR and related types. Only subfamily characteristics are depicted. Dark line: More (thick) or less (thin) conserved parts outside specific domains; red boxes: $\mathrm{IP}_{3}$-binding domain (dotted where variable within one subfamily). Turquois boxes: $\mathrm{RIH}$ (RyR/IP $\mathrm{R}$ ) homology domain (dotted when variable). Blue box: Domain with transmembrane regions, including the pore (yellow bar). Note large similarity of subfamilies I and II as well as of IV and VI; most subfamilies deviate in their overall similarity. For more details, see text. Based on data from Ladenburger and Plattner [134]. (For interpretation of the references to color in this figure legend, the reader is referred to the web version of the article.)

domains in the $\mathrm{IP}_{3} \mathrm{Rs}$ and RyRs, respectively, together with a putative pore domain $[220,224]$. (Note that for RyRs higher numbers of transmembrane domains are also discussed in the literature [24] - a matter to be settled even for mammalians). Most of the subfamilies of PtCRCs have several ohnologs [132-134] representing paralogs from whole genome duplications, including a quite recent one [234]. From a total of 34 PtCRCs, mostly only one or two characteristic subfamily members have been analyzed in more detail. Actually subfamily members may serve gene amplification, rather than individual differentiation for distinct effects. This presumption is in line with results obtained with other systems ([235], though in this work Paramecium evolution is plotted with much too short a time scale; see Section 2.1) and several studies with Paramecium $[64,65,236]$. The domain structure of the different paralogs/ohnologs is presented in Fig. 5, their subcellular distribution in Fig. 6, based on Ladenburger and Plattner [134]. Note that they predominantly possess a rather conserved carboxyterminal channel domain, while the other domains may be more or less variable.
Values of lumenal $\left[\mathrm{Ca}^{2+}\right]$ to be expected in organelles along the endo-lyso-phagosomal pathway are discussed in Section 4.2.

PtCRC-I-type channels are characterized by a putative InsP $_{3}$ binding domain and by sequences homologous to RyRs and an RIH domain. They are localized to the ER and, thus, correspond to the general distribution of $\mathrm{IP}_{3} \mathrm{R}$ and RyR channels in higher eukaryotes where such types are also found in the ER [1-4]. So far, only PtCRC subfamilies II and IV have been characterized in more detail according to the above criteria. PtCRC-II is a genuine $\mathrm{IP}_{3} \mathrm{R}$, which is unexpectedly localized to the CVC [132]. When the InsP $\mathrm{P}_{3}$-binding domain is overexpressed in Paramecium cells and probed with ${ }^{3} \mathrm{H}$-Ins $\mathrm{P}_{3}$, it clearly binds $\mathrm{InsP}_{3}$, in competition with cold InsP $\mathrm{P}_{3}$. The three aminoacids considered most crucial for InsP binding [231] are conserved. Ins $\mathrm{P}_{3}$ uncaging generates a distinct $\mathrm{Ca}^{2+}$ signal. Its localization and the general effects of gene silencing suggest a role in general $\left[\mathrm{Ca}^{2+}\right]$ homeostasis regulation. Under steady-state conditions, the CVC serves to balance the considerable $\mathrm{Ca}^{2+}$ influx by excretion of $\mathrm{Ca}^{2+}$ (Section 7.1). PtCRC-II channels may serve fine-tuning by allowing partial reflux into the cytosol.

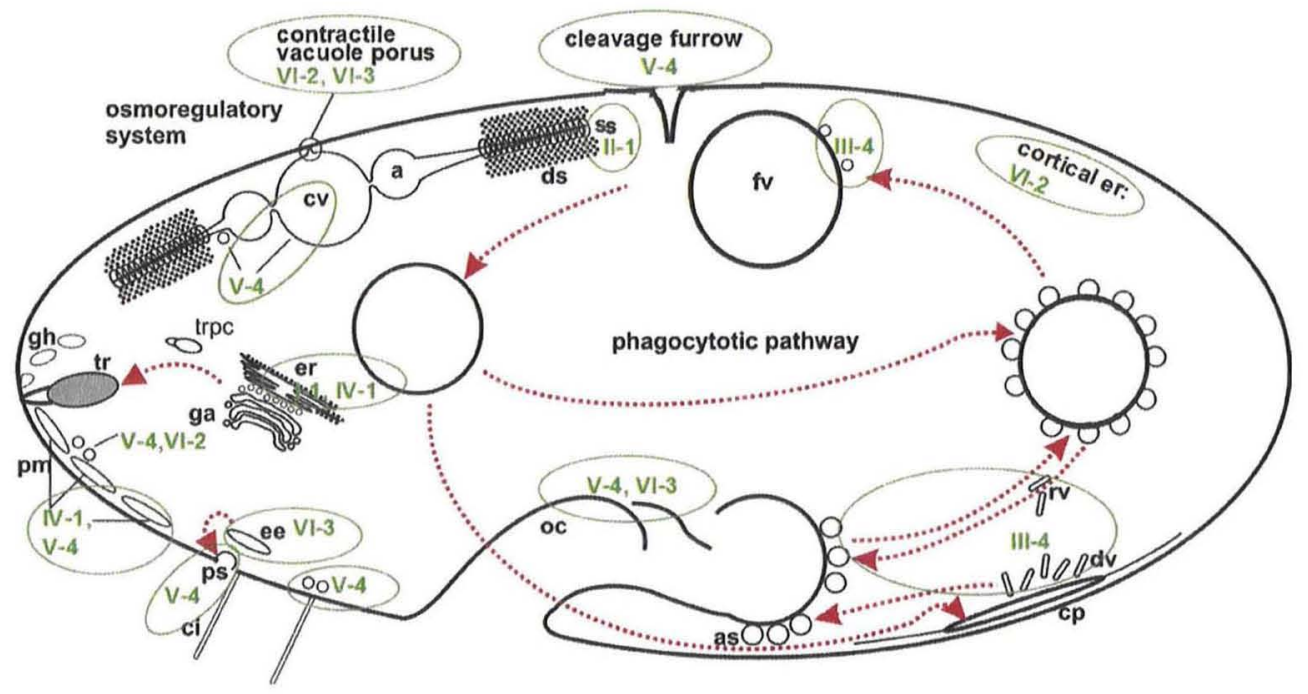

Fig. 6. Intracellular distribution of $\mathrm{Ca}^{2+}$-release channels in Paramecium (PtCRCs). Only selected representatives of the different groups are depicted. Abbreviations: $\mathrm{a}=$ ampullae (part of the $\mathrm{CVC}$ ), as = acidosomes (acidic recycling vesicles, different from acidocalcisomes), $\mathrm{ci}=\mathrm{cilia}, \mathrm{cp}=\mathrm{cytoproct}$ ( $\mathrm{cv}=$ contractile vacuole $(C V C), \mathrm{ds}=$ decorated spongiome (CVC part with $\mathrm{H}^{+}$-ATPase), $\mathrm{dv}=$ discoidal vesicles (special recycling vesicles), ee $=$ early endosomes, er $=$ endoplasmic reticulum, $\mathrm{fv}=$ food vacuole (phagosome), ga $=$ Golgi apparatus, $\mathrm{gh}=$ "ghosts" (from released trichocysts), oc $=$ oral cavity, pm $=$ plasma membrane ( olar sacs and nearby vesiclels at lower left), ps = parasomal sacs (clathrin-coated pits), $r v=$ recycling vesicles, $s s=$ smooth spongiome $(C V C)$, tr $=$ trichocysts, trpc $=$ trichocyst precursor. For further details, see text. According to Ladenburger and Plattner [134]. 
Concomitantly, fluorochrome analyses in Paramecium under resting conditions reveal spontaneous $\left[\mathrm{Ca}^{2+}\right]$ fluctuations along the extentions of the CVC [132]. Since this occurs without any overt stimulus, the phenomenon observed corresponds to what has more recently been described as constitutively active ${ } P_{3} R$ activity [237] in a chicken lymphocyte cell line where it is linked to basic bioenergetics. Compatible with this notion would be the observation that, in Tetrahymena, $\mathrm{PIns}_{2}$ displays considerable turnover without any stimulation [238]. Besides an RIH domain, these channels surprisingly also contain two or three regions homologous to RyRs, but they strictly fulfill the criteria for $\mathrm{IP}_{3} \mathrm{Rs}$.

In type PtCRC-III molecules no RIH domain could be identified, in contrast to types PtCRC-I and PtCRC-II. The InsP $P_{3}$-binding domain is present in PtCRC-III-1, -2 and -4 , but missing in subtype -3 ; the occurrence of RyR-related sequences is restricted. PtCRC-III-4 channels are contained in shuttle vesicles [134] that are different from discoidal vesicles and acidosomes [73]. These vesicles serve the transport of membrane materials from different stages of food vacuoles (phago[lyso]somes) to the site of nascent food vacuole [phagosome] formation; the channels evidently recycle from a secondary stage of the food vacuole development and from the expulsion site of old food vacuoles, the cytoproct (Fig. 6). Accordingly only some vacuoles are labeled by ABs against PtCRC-III-4. The following aspects support the feasibility of the occurrence of PtCRC-III-4 on some of the phagosomes. Synaptotagmin and, thus, $\mathrm{Ca}^{2+}$ are required for phagosome formation in human neutrophils [239] and macrophages [240]. Synaptotagmin is also required for lysosome/phagosome fusion [241]. Near-range $\mathrm{Ca}^{2+}$ signals will be required, as established for homotypic vacuole fusion in yeast [213], although, in Paramecium, the $\mathrm{Ca}^{2+}$-sensor will be different from synaptotagmin (Section 5.1).

Type PtCRC-IV-1 molecules are of the RyR-type; they are localized to the peripheral side of alveolar sacs [133]. Their sequence displays no RIH or InsP $\mathrm{P}_{3}$-binding domain, although some restricted regions resemble RyRs. Even though they are insensitive to ryanodine, when it is applied to cells or to the isolated organelles [126] (which were also shown not to bind labeled ryanodine in vitro [unpubl. res.]), PtCRC-IV-1 molecules are considered RyRs for the following reasons. Stimulation with caffeine and $4 \mathrm{CmC}$ generates a $\mathrm{Ca}^{2+}$ signal in parallel to massive trichocyst exocytosis; both phenomena are almost abolished when this channel is knockeddown. Previously these RyR agonists had been shown to induce a SOC-type mechanism in response to caffeine and to $4 \mathrm{CmC}[76,185]$, both established RyR activators. Note that $4 \mathrm{CmC}$ is known to activate RyRs with a point mutation also in mammals [228]. Accordingly, in the C-terminal part a binding site for $4 \mathrm{CmC}[230]$ has been found also in this Paramecium channel, PtCRC-IV, which enables $\mathrm{Ca}^{2+}$ release from alveolar sacs [133].

One of the channels characterized by patch-clamp analysis after reconstitution of isolated Paramecium cell cortex fragments (containing alveolar sacs) into lipid layers [242] showed properties compatible with the channels involved in AED stimulated $\mathrm{Ca}^{2+}$ release (and exocytosis), as analyzed by whole cell-patch analysis [87]. These channels were cation-nonspecific, but with highest permeability for $\mathrm{Ca}^{2+}$, and they did not respond to ligands then known [242]. In retrospect, they appear as the equivalent of PtCRCIV-1, i.e. RyRs whose poor $\mathrm{Me}^{2+}$ selectivity is notorious [243]. The fact that RyRs and $\mathrm{IP}_{3}$ Rs have high conductance and sufficiently long open times is prerequisite for efficient signaling. The reason is requirement of ion counter-currents to clamp the store membrane potential above the equilibrium/Nernst potential [244]. Low ion selectivity does not play a role for the selective release of $\mathrm{Ca}^{2+}$ as the organelle specific SERCA makes $\mathrm{Ca}^{2+}$ by far the predominant ion in the stores.

PtCRC types V and VI (of which subfamily members PtCRC-V-2 and PtCRC-VI-3 have been analyzed) are most heterogenous and most widely distributed among intracellular compartments. (This may suggest selective localization of individual ohnologs, but the ABs used did not allow us to ascertain this possibility). Type $V$ channels vary with regard to the presence/absence of an InsP $_{3}$-binding domain and a RIH domain, and both these domains are absent from Type VI channels. PtCRC-VI-4 is truncated. The wide intracellular distribution of different CRCs, also in higher eukaryotes, reflects requirement of local $\mathrm{Ca}^{2+}$ signaling and presence of $\mathrm{Ca}^{2+}$-sensor in many membranes participating in membrane flow in mammalian systems [136]. Evidently this is also the case in ciliates.

The localization of PtCRC-V-4 encompasses the parasomal sacs (clathrin-coated pits near ciliary basal bodies) and alveolar sacs. Here, these channels are confined to contact sites between adjacent sacs, as seen by immuno-gold EM. Since both alveolar sacs and coated pits also line the region around the cytostome, this explains labeling of this cell region, as has also been scrutinized by immunoEM analysis. This channel subpopulation also occurs in vesicles near the clefts between alveolar sacs and near ciliary basal bodies. Interestingly the latter sites do not coincide with early endosomes ("terminal cisternae") which in turn, contain PtCRC-VI-3. Just like PtCRC-II-1, PtCRC-V-4 is present in the contractile vacuole and the emanating radial canals of the CVC. Its porus region contains PtCRCVI-2 and PtCRC-VI-3. (The porus is a preformed site of exocytosis for the contractile vacuole and is also surrounded by alveolar sacs; the precise localization of these CRCs with regard to the vacuole extrusion site has not yet been identified). ABs against PtCRC-V-4 also stains the cleavage furrow, a site to where vesicles are delivered for cytokinesis, also in ciliates (Tetrahymena $[245,246])$. Heterogeneity of the ER is indicated by the enrichment of PtCRC-VI-2 type channels selectively in cortical structures, vesicles and/or ER, whereas we localized PtCRC-I-1 in the ER throughout the cell. Functional heterogeneity is known from mammalian cells [247-249] and has been observed in Paramecium during silencing of the SNARE-specific chaperone, NSF [65]. Thus, the distribution pattern of PtCRCs [134] is not really surprising.

How does this intriguing situation compare to higher eukaryotes? Here, within one cell, different parts of a single storage compartment, e.g. the ER, may contain different types of CRCs; this has also been found in sensory neurons $[250]$ and in smooth muscle cells [251]. Another possibility is the generation of different $\mathrm{Ca}^{2+}$ responses by two isoforms of $\mathrm{IP}_{3} \mathrm{Rs}$, e.g. in HeLa cells [252]. As far as cleavage furrow formation is concerned, this is paralleled by $\mathrm{Ca}^{2+}$ waves, as shown, for instance, with cleavage-stage Xenopus embryos [253]. Thus, similar findings with Paramecium are not without precedent.

The occurrence of CRC-V-4, endowed with a putative $\mathrm{InsP}_{3}$ binding domain, in parasomal sacs is a challenge. In some mammalian cells, the presence of only about two $\mathrm{InsP}_{3}$ receptor molecules in the cell membrane has been reported [254] and similarly only a small number of ryanodine receptors could be found in the plasma membrane of some cells [255]. The immuno-gold EMlabeling density we achieved (attached to the cytosolic side) on individual parasomal sacs is much higher than previously reported for any such channel in the cell membrane of any cell type. Is this the explanation of $\mathrm{Ca}^{2+}$ leakage conductances which has hardly been analyzed so far in Paramecium [71]? It recalls non-selective, high conductance, membrane potential-independent cation channels in hippocampal neurons; these can be activated by a stepwise increase of extracellular $\left[\mathrm{Ca}^{2+}\right][105]$. Under similar conditions, fluorochrome analyses in Paramecium indicate an abrupt increase of $\left[\mathrm{Ca}^{2+}\right]_{i}[106]$. Remarkably this induces no exocytosis - again indicating requirement of a focused $\left[\mathrm{Ca}^{2+}\right]_{i}$ increase (Section 1 ). Clearly it would now be worth while analyzing CRC-V-4 in the Paramecium cell membrane by electrophysiology.

CRC-V-4 harbors still another secret: it localizes selectively to the micronucleus, but not to the envelope of the macronucleus 

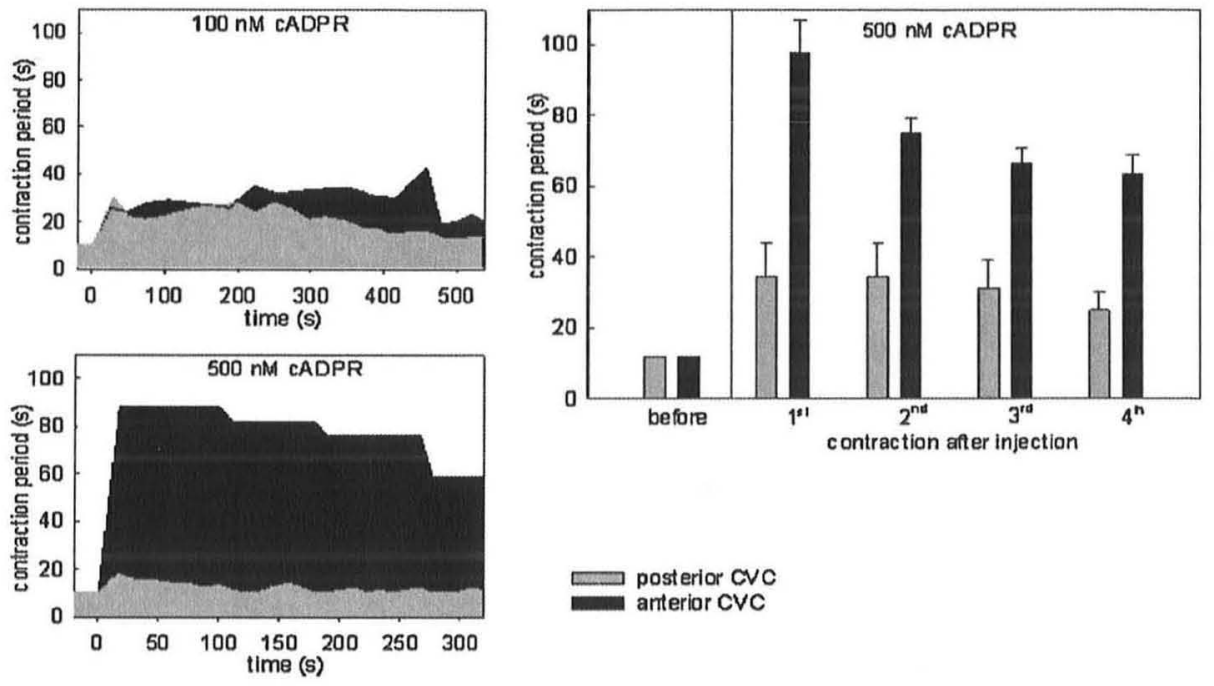

Fig. 7. Effect of injected CADPR on CVC contraction activity in Paramecium cells. In the experiments shown on the left, cells respond to cADPR concentrations from $\sim 100 \mathrm{nM}$ on, but higher concentrations cause increased reaction. Note that, for unknown reasons, the response is more pronounced in the anterior CVC, irrespective of the site of CADPR injection. Block diagram (right): statistical evaluation shows progressive decrease of the reaction, already within the four first activity cycles ( \pm SEM). Injection volume: $\sim 10 \%$ of cell volume, in all cases. Note that values before injection are identical in both CVCs, i.e., $\sim \mathbf{8}$. The effect on the CVC may be indirect (see text), but does not occur with mock-injections. Unpublished results.

[134]. Considering the multiple effects of $\mathrm{Ca}^{2+}$ signaling in the mammalian nucleus [256], one may now envisage a variety of functions, beyond the most discussed modulatory effect on transcription of genes encoding proteins since this does not take place in the micronucleus.

In summary, the plethora of differentially positioned PtCRCs (Fig. 6) strongly suggest a role of these $\mathrm{Ca}^{2+}$ channels in the regulation of basic $\mathrm{Ca}^{2+}$ housekeeping including $\mathrm{Ca}^{2+}$ homeostasis (PtCRC-I-1, PtCRC-II-1), of trichocyst biogenesis (PtCRC-II-1), exocytosis (PtCRC-IV-1) and trafficking of widely different vesicles (PtCRC-III-4, PtCRC-V-4 and PtCRC-VI-2/3) etc. Considering delivery of membrane components from different compartments to subsequent ones, one might expect occurrence of the very same channels in vesicle and target membranes. Since this is not always the case in our localization studies one may assume either organelle specific retention, or local enrichment within certain membranes, that remain undetected after dilution in a larger membrane area. This could conceal certain channels, so it would not be easily visible in all fusion partners.

Another challenge to be solved is the occurrence of two different types of CRCs in one organelle, e.g. of PtCRC-II- 1 and PtCRC-V-4 in the CVC, and of PtCRC-IV- 1 and PtCRC-V-4 in alveolar sacs. Possibly very local functional needs have to be matched, even within one organelle, by different types of CRCs. Such a situation is known, for example, from the ER of mammalian cells [249].

Several restrictions to our PtCRC analylsis should be stressed at this point. Mostly only one or two isoforms have been localized per subfamily (except group VI) and similarly functional analyses also have been restricted so far. Analyses of regulatory domains, such as the $\mathrm{Ca}^{2+}$-and CaM-dependent gatekeeper function in the $\mathrm{IP}_{3} \mathrm{R}[220]$ and of putative activator compounds would be advised. It should also be mentioned that not all of the PtCRCs display a typical pore signature and a selectivity filter mentioned above. Possibly this may vary in evolution. Work with mammalian cells suggests no pronounced selectivtity of RyRs as well as of $\mathrm{IP}_{3} \mathrm{Rs}$ and their isoforms for different cations $[220,224]$. In summary, at this time some of the molecules described above as PtCRCs may be considered only bona fide as $\mathrm{Ca}^{2+}$-release channels, whereas this appears rather certain for the PtCRC-II and PtCRC-IV types which have been analyzed in more detail $[132,133]$.
Taking into account that in animal cells RyRs are activated by CADPR [24] one may ask whether PtRyRs, e.g. those contained in alveolar sacs (CRC-IV-1), could be activated by CADPR? Up to now we have carried out only pilot experiments which suggest that some unspecified PtRyRs are activated. As Fig. 7 shows, CADPR microinjection causes a delay of the CVC contraction frequency, particularly of the anterior vacuole. (Note that this also occurs in response to NAADP ${ }^{+}$; Figs. 8 and 9, below). This effect, which occurred independently of the injection site, can be considered an indirect response to $\mathrm{Ca}^{2+}$ release at remote sites inside the cell. Taking into account the dominant role of the $\mathrm{CVC}$ in $\left[\mathrm{Ca}^{2+}\right]_{i}$ regulation [132] this response somehow reflects a physiological response to CADPR. The concentration values required for full activation are well comparable to those required for maximal $\mathrm{Ca}^{2+}$ release from cardiac microsomes [257]. More detailed analyses are required in order to find out which $\mathrm{Ca}^{2+}$ stores are activated by CADPR in ciliates.

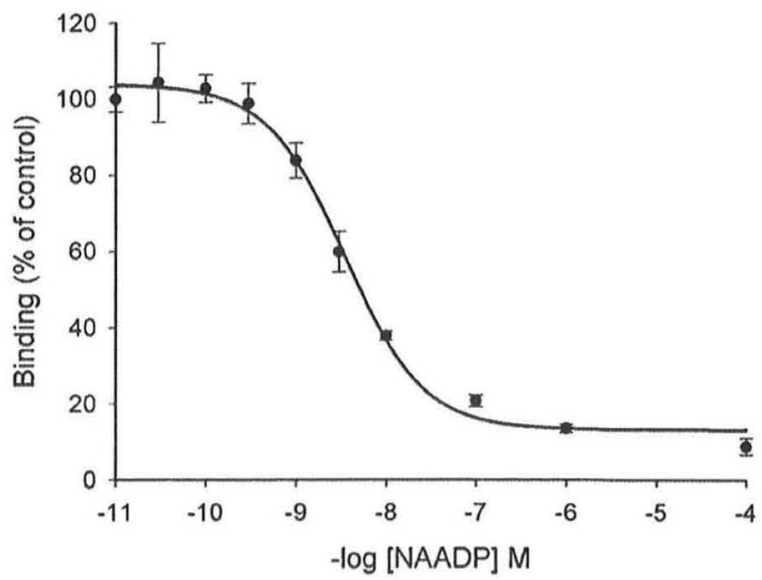

Fig. 8. ${ }^{32}$ PJNAADP binding in homogenate of whole $P$. tetraurelia cells under ionic conditions occurring in living Paramecium cells [279]; c.f. Bak et al. [257] for functional relevance. $200 \mathrm{pM}\left[{ }^{32}\right.$ PJNAADP was incubated with $0.1 \mathrm{mg}$ homogenate for $20 \mathrm{~min}$ before filtration. The $K_{\mathrm{d}}$ was found to be $3.31 \pm 0.05 \mathrm{nM}$ and the $B_{\mathrm{m} x}$ $335.4 \pm 9.9 \mathrm{fmol} / \mathrm{mg} ;(n=6)$. Unpublished results. 

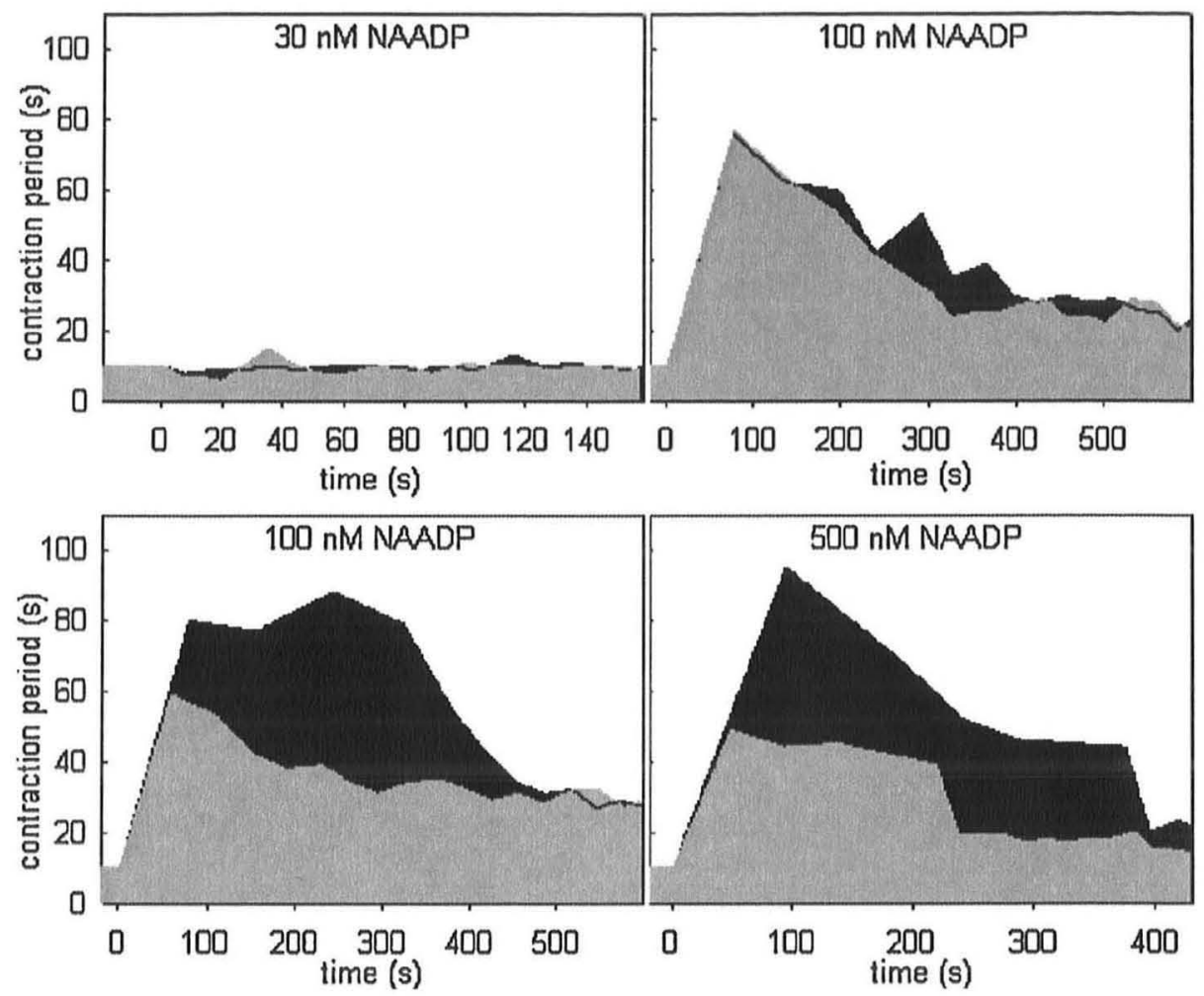

Fig. 9. Examples of the effect of microinjected NAADP ${ }^{+}$on the contraction activity of the CVC in Paramecium cells. Injection volume: $\sim 10 \%$ of cell volume. Note the different reaction in the anterior and posterior $\mathrm{CVC}$, respectively. Evidently $\mathrm{NAADP}^{+}$can yield more or less pronounced reactions when applied at a threshold concentration of $100 \mathrm{nM}$ concentration which eventually can reach already the same level as higher concentrations. Note that, for unknown reasons, the response is more pronounced in the anterior CVC, irrespective of the site of CADPR injection. Values before injection are identical in both CVCs, i.e., $\sim 8 \mathrm{~s}$. Consider the possibility of an indirect effect of NAADP' on CVC activity (see text). Unpublished results.

One may discuss which type of CRC is the oldest. From genomic analysis of the flagellate, Monosiga brevicollis, the impression emerges that this group may be rather close to ciliates as they are to metazoans also with respect to $\mathrm{Ca}^{2+}$ signaling. Remarkably Monosiga is reported to lack a RyR [16]. In contrast, we have found the occurrence of CRCs with features of either type, $\mathrm{IP}_{3} \mathrm{R}$ and RyR, in Paramecium [134]. All this points toward a common origin. The mechanisms appear pimeval, but they have been largely obliterated in the apicomplexan parasites (below).

\subsubsection{Apicomplexa}

Although $\mathrm{IP}_{3}$ - and RyR-related effects have been frequently described for apicomplexan parasites (Section 3.2) their molecular identity and even their occurrence remains enigmatic.

Addition of $\mathrm{Ins}_{3}$ in physiological concentrations to permeabilized Plasmodium chabaudi cells yields a $\mathrm{Ca}^{2+}$ signal [258]. Inhibitors of PLC, as applied with higher eukaryotes, inhibit stimulated $\left[\mathrm{Ca}^{2+}\right]_{i}$ increase in P. falciparum [205]. Functional analyses of Toxoplasma with InsP $\mathrm{P}_{3}$ and with different drugs suggested the occurrence of a mixed type of CRC [118]. In the databases available for $P$. falciparum and $T$. gondii, sequences with weak similarity to those in Paramecium have been found, but they lack transmembrane domains required for channel function and, therefore, do not fulfill any of the criteria outlined above. They do not allow us to recognize any characteristic domain structure. Moreover, only some sequences may indicate transmembrane regions of sufficient length and some of these are located at the aminoterminal side (unpublished data). Considering long lasting and ever increasing evidence of a physiological function of InsP $P_{3}$, recently demonstrated by $\operatorname{InsP}_{3}$ uncaging and $\mathrm{Ca}^{2+} /$ fluorochrome imaging in P. falciparum [259], one would definitely expect a genuine receptor for Ins $\mathrm{P}_{3}$. The same holds for the effects observed with the RyR activators, caffeine and cADPR $[207,208]$. Specifically Toxoplasma cells produce the abscission hormone, abscisic acid, which activates, via cADPR, a $\mathrm{Ca}^{2+}$ signaling pathway required for host cell egression $[112,122]$. However, neither an $\mathrm{IP}_{3} \mathrm{R}$ nor any RyR homolog could be detected in any of the Apicomplexa even in extensive search ([139,140,212]; own unpublished observations).

The general question arises as to what extent sequences lacking specific domains would qualify for $I_{3} R$ and RyR function. Without any doubt, an $\mathrm{IP}_{3} \mathrm{R}$ has to qualify for this function by binding $\mathrm{IP}_{3}$. In reality, up to now, only one other protozoan, Dictyostelium, has been assumed to possess an $\mathrm{IP}_{3} \mathrm{R}$-like protein (iplA) that has been identified by partial sequence homology and a number of transmembrane domains. However, no InsP $P_{3}$-binding domain has been characterized and also the putative selectivity filter region shows an aberrant aminoacid composition [260]. Deviation of iplA from Paramecium and animal CRCs is surprising also considering the close relationship of Dictyostelium to the animal kingdom [261]. As outlined above, even considerably less is known from Apicomplexa. This statement can be extended to candidates for RyRs and $\mathrm{IP}_{3} \mathrm{Rs}$ in all protozoa [262] as well as to multicellular plants [263,264] - a surprising uncertainty considering the frequent reports on effects of physiological activators and of drugs in both these systems.

\subsection{Two-pore $\mathrm{Ca}^{2+}$ release channels and acidic stores}

Among other channels, the two-pore channels (TPCs) are widely distributed from mosses to flowering plants and from Cenorhabditis elegans to man $[26,172,265]$. They owe their name 
to the tandem molecular structure consisting of $2 \times 6$ membranespanning regions in one molecule [26]. TPCs may be considered ancestral types of CRCs because of their structural similarity to voltage-gated $\mathrm{Ca}^{2+}$ - and $\mathrm{Na}^{+}$-channels $[25,26,265]$ which in turn possess four such domains, also each with six membranespanning regions. (Recall that RyRs are mostly assumed to have four membrane-spanning regions, in contrast to $\mathrm{IP}_{3} \mathrm{Rs}$ which possess six such regions [266]; see Section 4.1). Amazingly information about their possible occurrence in protozoa is practically absent. There is general agreement, however, that TPCs are absent from acidocalcisomes of the protozoa analyzed, including Apicomplexa [26,174]; we could also not find such sequences in the respective databases (unpublished data).

TPCS are activated by nicotinic acid adeninedinucleotide phosphate $\left(\mathrm{NAADP}^{+}\right)$, a metabolite formed by ADP-ribosyl cylase activity from NADP $[26,172,229]$. This cyclase is widely distributed and it can also produce cADPR from NAD [229]. The target of NAADP ${ }^{+}$is clearly different from that of CADPR [267]. Concomitantly, recent analysis of mammalian cells transfected with either RyRs or TPCs clearly revealed selectivity of these $\mathrm{Ca}^{2+}$ pool-activating second messengers [268]. Overall levels of NAADP ${ }^{+}$required to trigger $\mathrm{Ca}^{2+}$ release via TPCs in mammalian cells are only $1.5-8$-fold above basal levels [26], but local concentrations will be higher. Just as with $\mathrm{Ca}^{2+}$ and InsP $_{3}$, overall changes should not be considered a diagnostic of activation processes.

In all non-protozoan species analyzed TPCs are associated with acidic compartments, from early endosomes to lysosomes $[22,26]$, possibly including some unidentified vesicles [26]. TPCs have a selective, though not strict, conductivity for $\mathrm{Ca}^{2+}$. The $\mathrm{Ca}^{2+}$ released by TPCs can subsequently activate RyRs and $\mathrm{IP}_{3} \mathrm{Rs}[26,229]$. In mammalian cells, stimuli somehow resulting in TPC activation can be widely different and concomitantly this can contribute to signal transduction in a widely different context $[26,269]$. For ciliates and for Apicomplexan parasites [21], such analyses are not available.

Which specific functions may be envisaged? In "higher" animal cells, $\mathrm{Ca}^{2+}$ is required for vesicle trafficking and fusion, also along the endo-lysosomal pathway [270]. Here, a transient $\mathrm{Ca}^{2+}$ release is assumed to regulate membrane fusion/fission events in metazoans [137]. TPCs are known to contribute to these processes [26]. However, lumenal $\left[\mathrm{Ca}^{2+}\right]$ (or [Ca]) is generally reported to decrease already at the early endosome stage [271]. If one assumes a requirement of $\left[\mathrm{Ca}^{2+}\right]$ between 0.3 and $\leq 1 \mu \mathrm{M}$ for progressing in the endosomal pathway [272], would this $\mathrm{Ca}^{2+}$ have to come from other sources? This is not very likely the case, as in mammalian cells TPC1 channels are found in late endosomes, TPC2 in lysosomes, and - interestingly - TPC3 in the recycling endosomal compartment; only in early endosomes the presence of TPCs is less clear [273]. Also to be noted are reports on relatively high $\left[\mathrm{Ca}^{2+}\right]$, $37 \mu \mathrm{M}$, in endosomal compartments of some mammalian cells, such as pancreatic acinar cells [274]. In Arabidopsis thaliana, TPCs are localized to the big vacuole membrane [275]. Lysosomes in animal cells, e.g. in macrophages, contain substantial concentrations of $\mathrm{Ca}^{2+}(0.6 \mathrm{mM},[276])$ which theoretically could be made available for organelle interaction via TPCs whose occurrence in lysosomes of mammalian cells has been documented by patch-clamp analysis $[269,277]$. Whatever the relevant CRCs are, a measurable $\left[\mathrm{Ca}^{2+}\right]_{i}$ increase is long known to be required also for phago-lysosome fusion in macrophages [278]. What is the situation in alveolates?

\subsubsection{Ciliates}

In unpublished work with $P$. tetraurelia we find evidence for the presence of TPCs according to the following criteria. (i) The Paramecium DB contains sequences corresponding to TPCs; this is supported by partial cloning. (ii) We have used Paramecium whole cell homogenates to determine the $K_{\mathrm{d}}$ for $\mathrm{NAADP}^{+}$under physiological intracellular ionic conditions (which is important for such measurements [257]), as specified by Lumpert et al. [279]. We found a $K_{\mathrm{d}}$ of $3.31 \pm 0.05 \mathrm{nM}$ (Fig. 8), i.e. somewhat above that in sea urchin eggs (c.f. $200 \mathrm{pM}$ [280]) and almost identical to TPC type 2 in mouse liver [265]. This binding site was selective for NAADP over NAADPH and NADP(H). Also to be considered is that mammalian TPC2 possesses high and low affinity NAADP ${ }^{+}$binding sites [269]. (iii) We microinjected NAADP ${ }^{+}$into Paramecium cells. We observed that it alters the activity of the CVC (Fig. 9) which is known to be involved in the regulation of $\left[\mathrm{Ca}^{2+}\right]_{i}$ homeostasis $[132,195]$ Although Paramecium cells recognize $\mathrm{NAADP}^{+}$the effect achieved may be due to $\mathrm{Ca}^{2+}$ released from stores other than the CVC. The concentration values we had to use for full activation compare well with those required for maximal $\mathrm{Ca}^{2+}$ release from cardiac microsomes [257].

There are numerous acidic compartments in a Paramecium cell [191]. Nevertheless, their endowment with TPCs remains to be established. Some of the acidic compartments contain CRCs of the RyR-/IP ${ }_{3}$ R-type (Section 4.1 ). They could possibly coincide with TPCs within one organelle, accounting for different signaling pathways. (Recall that we find two types of $\mathrm{IP}_{3} \mathrm{Rs}$ alone in the CVC and two RyR-types in alveolar sacs.) So far, only for Dictyostelium is a cursory note on TPCs available [273]. Considering the change in lumenal pH within the phagosomes in Paramecium during cyclosis [191] and the capability of TPCs to sense the lumenal pH $[269,277]$ the endowment of vesicles with TPCs, if occurring, and their function may also change during intracellular trafficking. Since lumenal pH does change in Paramecium food vacuoles during cyclosis [73], one may expect different CRCs in different functional stages and possibly different types even in one stage.

Clearly more detailed studies are mandatory to establish in ciliates the occurrence of true TPCs, the type of $\mathrm{Ca}^{2+}$ stores which contain TPCs and which stores are activated by NAADP ${ }^{+}$.

\subsubsection{Apicomplexa}

Their acidocalcisomes are endowed with different means of sequestering $\mathrm{Ca}^{2+}$ and protons (Fig. 4). $\mathrm{A} \Delta \mathrm{H}^{+}$supports sequestration of $\mathrm{Ca}^{2+}$, as outlined in Section 3.1. Sequences resembling TPC1 of the $A$. thaliana vacuole reportedly occur in the genome of $T$. gondii, but not of Plasmodium or Cryptosporidium [212]. This may indicate progressive loss during evolution to parasitic life. Due to binding of $\mathrm{Ca}^{2+}$ as pyro- and polyphosphate [281] one could argue that $\mathrm{Ca}^{2+}$ mobilization could not take place sufficiently within adequate time, e.g. for serving host cell penetration (a rapidly hydrolyzing pyro/polyphosphatase is required). However, in Toxoplasma, depletion of acidocalcisomes of their $\mathrm{Ca}^{2+}$ storage capacity by $\mathrm{TgA} 1$ knock-out disturbs $\left[\mathrm{Ca}^{2+}\right]_{\mathrm{i}}$ homeostasis and micronemal secretion, and finally infectivity [20]. Nevertheless it would be useful to demonstrate that this is a direct, rather than a systemic effect of acidocalcisomes.

In P. falciparum, the food vacuole has previously been considered a significant $\mathrm{Ca}^{2+}$ store on the basis of fluorochrome analyses [210]. However, this view has been corrected, as $\mathrm{Ca}^{2+}$ fluorochrome signals collected from this organelle could be attributed to $\mathrm{pH}$ effects [211].

Altogether, in protozoa some aspects of vesicle trafficking and dynamic distribution of CRCs are not well understood. The interaction of acidocalcisomes with contractile vacuoles in Dictyostelium [282] and in trypanosomatides [180] may serve transfer of important membrane components. Interaction of acidocalcisomes with "lysosome-related organelles" is also reported [180], as it has been suggested for the plant-like vacuole in T. gondii [178]. In that case, vesicles with $\mathrm{IP}_{3} \mathrm{R} / \mathrm{RyR}$-type $\mathrm{Ca}^{2+}$-release channels and TPCs (if they exist) could merge. All this might imply multiple interactions of organelles somehow involved in $\left[\mathrm{Ca}^{2+}\right]_{\mathrm{i}}$ regulation.

The basic questions with apicomplexan parasites remain: which types of CRCs do they have, how much do they deviate from 
sequences known from other species, in which organelles are they located and how are they activated? These questions are of paramount importance and, hence, deserve detailed investigation.

\section{5. $\mathrm{Ca}^{2+}$-binding and $\mathrm{Ca}^{2+}$-activated proteins}

Ciliates contain a number of $\mathrm{Ca}^{2+}$-activated and of $\mathrm{Ca}^{2+}$-binding proteins (CaBPs), particularly in their cilia and in the cell cortex. Centrin and calmodulin (CaM) are among the most prominent CaBPs containing EF-hand $\mathrm{Ca}^{2+}$-binding loops [283-285]. As known from higher eukaryotes, each molecule has four such loops made of 12 aminoacids. In CaM these are suitable for high affinity/low capacity $\mathrm{Ca}^{2+}$-binding with hierarchial occupancy (loop I $\rightarrow$ IV). Recent high time resolution studies confirmed the aminoterminal loop as by far most efficient [286]. With centrin the situation is less clear as it also displays low affinity/high capacity $\mathrm{Ca}^{2+}$-binding capability [287]. (Related proteins in the SR lumen [288] are not known from Alveolates.) Therefore, CaM may more likely act as a $\mathrm{Ca}^{2+}$-sensor for dynamic processes $[286,289]$, whereas centrin can also act as a sink for $\mathrm{Ca}^{2+}$ due to low affinity/high capacity binding, as demonstrated with Paramecium [290]. CaM also activates many proteins, for instance, the mammalian [291] and ciliate [170] PMCA-type $\mathrm{Ca}^{2+}$-pump. The efficiency of $\mathrm{Ca}^{2+}$ pumping activity in downregulation of $\left[\mathrm{Ca}^{2+}\right]$ after stimulation may lag far behind inactivation of $\mathrm{Ca}^{2+}$ by binding to CaBPs [286], as we found with Paramecium [290]. In summary, CaBPs exert widely different, important functions, from activation to deactivation.

\subsection{Ciliates}

CaM has been characterized in Paramecium and Tetrahymena, but unexpectedly, P. tetraurelia contains 14 genes encoding CaM ( $R$. Kissmehl, unpubl. res.). Light microscopic localization of CaM has also been studied in Tetrahymena [292] and in Paramecium [92,293]. In EM immuno-localization studies CaM is posted at many strategic sites: in cilia, in the cell membrane-alveolar sacs interface, at trichocyst docking sites, at the CVC [214], as well as along different regions of microtubule guided vesicle transport [215].

Paramecium cells defective in CaM are unable to assemble functional exocytosis sites [294]. In fact, CaM can interact with specific SNARE proteins or SNARE-associated proteins, as has been ascertained for mammalian cells $[295,296]$. Thus, CaM, though frequently judged inappropriate to serve as a $\mathrm{Ca}^{2+}$-sensor for rapid signal transmission and membrane fusion during exocytosis, may at least indirectly serve this process by favoring the assembly of SNAREs. In neurons, the Q-SNARE, syntaxin $1 \mathrm{~A}$, together with $\mathrm{Qb} / \mathrm{c}$ SNARE, SNAP-25, associates with $\mathrm{Ca}^{2+}$ influx channels and thus can favor exocytosis [297]. Formation of a $\mathrm{Ca}^{2+} / \mathrm{CaM} / \mathrm{Munc} 13$ (auxiliary SNARE-interacting protein) sensor complex has also been reported, including neurons [298]. A more direct effect facilitating membrane fusion by transferring the lipid-binding domain of a v-SNARE from the cis- to the trans-side of juxtaposed membranes has also be shown [299]. The actual role of CaM precisely at exocytosis sites may differ from one cell type to another. In fact, in Paramecium, established CaM antagonists, such as W7 and trifluoperazine, do not inhibit AED-induced trichocyst exocytosis [87]. Therefore, $\mathrm{Ca}^{2+}$ sensors with $\mathrm{C} 2$ domains (see below), rather than EF-hand type CaBPs, remain favorites for future investigations along these lines.

As known from neurotransmitter release, CaM can serve as a $\mathrm{Ca}^{2+}$-sensor for exocytosis-coupled endocytosis [300]. Whether this is also true of endocytotic retrieval of trichocyst membranes is not known (although this step is also accelerated by increasing the $\mathrm{Ca}^{2+}$ gradient between the cell interior and the outside medium [183]). However, in ciliates involvement of CaM appears feasible for constitutive endocytosis via the parasomal sacs. In higher eukaryotes this is known to require dephosphorylation of dynamin by the $\mathrm{Ca}^{2+} / \mathrm{CaM}$ activated protein phosphatase 2B (PP2B, $\mathrm{CaN}=$ calcineurin) [301]. In fact, $\mathrm{CaN}$ is heavily enriched at such preformed sites of endocytosis in Paramecium [302]. In summary, different endocytotic processes in ciliates are $\mathrm{Ca}^{2+}$-dependent, just as in higher eukaryotes up to mammals [303-305].

A number of CaM-binding proteins (CaM-BPs) occur in Paramecium cells; among them are $\mathrm{Ca}^{2+}$-dependent and $\mathrm{Ca}^{2+}$-inhibitable CaM-binding proteins [306]. In whole cilia, ${ }^{45} \mathrm{Ca}^{2+}$ overlays revealed CaBP bands of 126, 96/95, 63 and $36 \mathrm{kDa}$; axonemes displayed bands of $126,96-105$ and $63 \mathrm{kDa}$, in ciliary membrane fractions bands are 120, 70 and $63 \mathrm{kDa}$ in size, whereas the $36 \mathrm{kDa}$ band was shared by axoneme and ciliary membranes. Cell bodies contained bands of about 120, 85 and $16-44 \mathrm{kDa}$ [306]. In isolated Paramecium cell cortices, a $\sim 120 \mathrm{kDa}$ large band [125] as well as bands of 126 , 63 and $58 \mathrm{kDa}$ have been recognized [10]. (Their molecular identity has not been established.) Other candidates are the PMCA (by its CaM-binding site [171]), the CaN-A subunit of $\sim 55 \mathrm{kDa}$ [307] and possibly the nd7 gene product with a sequence-derived size of $59 \mathrm{kDa}$ [308]. The manyfold cation conducting channels in the somatic and ciliary membrane of Paramecium also bind CaM. Here, $\mathrm{CaM}$ acts as a $\mathrm{Ca}^{2+}$-sensor [93], probably mediated by a multigene family of $\mathrm{Ca}^{2+}$-dependent CaM-BPs, between 60 and $70 \mathrm{kDa}$ in size and associated with the cell membrane [309]. A thorough analysis by systematic genetic screening is a task for future work.

In ciliates, phagosomes are also endowed with CaBPs. CaM-BPs $[216,310]$ and CaM $[214,215]$ bind already from an early stage on. Similar observations with higher eukaryotes suggest a role in the interaction with the numerous vesicle fusions and fissions during trafficking. Vacuole fusion in Saccharomyces cerevisiae requires CaM [213], in the absence of the $\mathrm{Ca}^{2+}$-sensors of the C2-type [311], as discussed below. Similarly, in Tetrahymena, $\mathrm{Ca}^{2+} / \mathrm{CaM}$ regulates cleavage furrow formation by vesicle delivery [312].

In mammalian cells, membrane fusion occurring during exocytosis and also at some intracellular sites is executed generally by interaction of SNAREs with the $\mathrm{Ca}^{2+}$-sensor protein, type synaptotagmin [313]. The synaptotagmin molecule is endowed with two $\mathrm{C2}$ domains. Binding constants for $\mathrm{Ca}^{2+}$ differ widely [314], depending on the isoform locally expressed, which meets local availability of $\left[\mathrm{Ca}^{2+}\right]$ for membrane-to-membrane interactions. This can be in the (sub-)micromolar (gland cell exocytosis [315]) to sub-millimolar range (transmitter release in nerve terminals [5]). Upon $\mathrm{Ca}^{2+}$ binding, its $\mathrm{C} 2$ domain most close to the aminoterminal membrane anchor [316] performs a lipophilic interaction with the lipid layers to be fused [317]. It thus qualifies for a $\mathrm{Ca}^{2+}$-sensor function and induction of membrane fusion by perturbation of the lipids. (For more details concerning ciliates, see [65] and below.) Constitutive exocytosis is considered independent of $\mathrm{Ca}^{2+}[135,318]$, or rather of a $\left[\mathrm{Ca}^{2+}\right]_{i}$ increase, as are some intracellular steps of membrane trafficking [136].

These proteins are different from two other families of CaBPs, the annexins and the copines, the latter endowed with $\mathrm{C} 2$ domains [319]. They bind to the phospholipids of biomembranes in a $\mathrm{Ca}^{2+}$-dependent manner. While annexins are discussed as being relevant for various aspects of membrane dynamics, copines may be involved in cell division and growth. Using ABs against common sequences, putative annexins have been localized in Paramecium to exocytosis sites, including trichocyst docking sites and the cytoproct [320]. Copines were actually first detected in Paramecium [321] before they were found, just like annexins, on a much broader scale [319].

The $\left[\mathrm{Ca}^{2+}\right]_{\mathrm{i}}$ generated locally at trichocyst exocytosis sites is $\sim 5 \mu \mathrm{M}[75]$ and, thus, rather similar to mammalian cells. In the Paramecium DB, gene sequences homologous to synaptotagmin occur, but they possess eight $\mathrm{C} 2$ domains (R. Kissmehl, pers. 
comm.). Similar proteins with up to six $\mathrm{C} 2$ domains are the exception in higher eukaryotic systems [322]. At least six proteins with C2 domains can participate in neurotransmission [323]. To account for the different $\mathrm{Ca}^{2+}$ sensitivities of different compartments a variety of $\mathrm{Ca}^{2+}$-sensors would have to be expected $[324,325]$. All these aspects await further elucidation in ciliates. However, the situation is intriguing even in some mammalian cells; for instance, in cochlear inner hair cells, exocytosis can occur also in the absence of synaptotagmin and/or of otoferlin, a multi-C2 domain CaBP with $\mathrm{Ca}^{2+}$-sensor properties [326].

Among the $\mathrm{Ca}^{2+}$-activated proteins in ciliates we find some that are directly and others that are indirectly activated by $\mathrm{Ca}^{2+}$, e.g. via $\mathrm{a} \mathrm{Ca}^{2+} / \mathrm{CaM}$ complex. Among the $\sim 2600$ protein kinases found in the Paramecium genome, the largest fraction is $\mathrm{Ca}^{2+} / \mathrm{CaM}$ regulated [327]. This includes kinases with a CaM-like domain integrated to the kinase molecule, CDPKs [328], as described from Paramecium [329]. No "CaM kinases" proper, i.e. kinases binding CaM, as occurring in higher eukaryotes, are known from ciliates. Inhibitory effects achieved with "anti-CaM" drugs (Section 2.2) may be due to inhibition of CaM or of CDPKs, as found in plants [330,331], but this has not always been scrutinized in protozoa. In Paramecium, CDPKs phosphorylate a set of ciliary CaBPs as well as centrin of the infraciliary lattice [332] and they closely resemble CDPKs in Apicomplexa [329]. In addition, in Paramecium, a casein kinase type 1, CK1, was found which is unconventionally inhibited by $\mathrm{Ca}^{2+}[333]$.

Calcineurin $(\mathrm{CaN})$ is a multifunctional Ser/Thr phosphatase, type 2B (PP2B), consisting of a $\sim 60 \mathrm{kDa}$ catalytic subunit (SU-A) and a $\sim 20 \mathrm{kDa}$ regulatory SU-B [334]. The catalytic SU requires binding of $\mathrm{CaM}$ and binding of the $\mathrm{Ca}^{2+}$-activated SU-B for its activation. This is the situation known for metazoan cells [335]. Evidence for CaN in Paramecium was based on detailed enzymatic analysis [336], on effects of microinjected monospecific ABs [337] and on immunoperoxidase [338] and quantitative immuno-EM gold localization studies [302]. This work was accompanied by a long lasting dispute about its existence in Paramecium (negation by $[13,339]$ ), until partial sequences were found [15]. Finally, the genes of this dimeric protein could be cloned and the two SUs, PtCaN-A and -B, characterized as very closely related to their mammalian counterparts [307].

In Paramecium, its localization to sites of notorious PP2B activity, as known from mammalian cells, is quite evident [302]. Its role during exocytosis performance, though also observed in mammalian systems, is not settled as yet [307]. Remarkably, in mammals, CaN has been shown to regulate the phosphorylation-dependent activity of the SNARE, SNAP-25, in chromaffin cells [340] and of the $\mathrm{Ca}^{2+}$-sensor, synaptotagmin VI, in spermatozoa [341]. As in mammals, apart from its other manyfold activities currently discussed $[334,342]$, CaN may also play a pivotal role during $\mathrm{Ca}^{2+}$-activated gene transcription in protozoa. Interestingly, massive exocytosis stimulation enhances the transcription and translation of a large number of genes in Tetrahymena [89] and Paramecium (J. Cohen and L. Sperling, data presented in the Paramecium DB), thus recalling activation of transcrisption factors in mammals [343]. Some of the upregulated proteins are themselves engaged in $\mathrm{Ca}^{2+}$-mediated effects.

$\mathrm{Ca}^{2+}$ is also involved in the secretion of trichocysts in Paramecium in a quite different way. $\mathrm{Ca}^{2+}{ }_{\mathrm{o}}$ is required for decondensation (severalfold stretching to needles longer than the cell diameter) [344]. Such a step is also essential for mucocyst release in Tetrahymena [345] where it also depends on $\mathrm{Ca}^{2+}{ }_{0}$ [346]. A mutant affecting the $\mathrm{Ca}^{2+}$-binding capacity of some trichocyst matrix proteins (derived from a pretrichynin precursor) are unable to perform exocytosis, although exocytotic membrane fusion takes place [347]. This can be mimicked with wildtype cells by stimulation at low $\left[\mathrm{Ca}^{2+}\right]_{0}[348]$. The same was shown with mast cells, using in parallel amperometry (to monitor contents release) and patch-clamp electrophysiology to monitor membrane fusion and fission [349]. In Paramecium, the complex exo-endocytosis process as a whole is accelerated by increasing $\left[\mathrm{Ca}^{2+}\right]_{o}$ due to increase influx [183] Also duration of these processes is within the range known from mammalian cells $[350,351]$.

In ciliates, centrin (= PCBP-25), like CaM, is endowed with four $\mathrm{EF}$-hand $\mathrm{Ca}^{2+}$-binding domains for varying intermolecular interactions and functions [352] and with an excess of negatively charged aminoacids, e.g. in Paramecium [332,353]. It is localized to the cell cortex where it forms the main component of the "infraciliary lattice" [354]. This is pivotal for downregulating high cortical $\left[\mathrm{Ca}^{2+}\right]_{\mathrm{i}}$ after massive exocytosis stimulation [290], as documented in Fig. 10. Centrin may be the most important immobile $\mathrm{Ca}^{2+}$-buffer since knock-out cells display an over 10 -fold delay in $\left[\mathrm{Ca}^{2+}\right]_{i}$ downregulation after trichocyst exocytosis stimulation. Centrin can be phosphorylated by the $\mathrm{Ca}^{2+}$-dependent PK-1 [332]. The colocalization of CaN together with centrin in the infraciliary [302] on the one hand and its assembly in dependency of the phosphorylation state on the other hand $[332,355]$ could indirectly regulate in ciliates the role of centrin in surface pattern formation, together with the different molecular interactions of the subdomains [352]. In fact, centrin is essential to achieve surface patterning in Paramecium [353], as it is for regulating duplication and maintenance of ciliary basal bodies in Paramecium [356] and Tetrahymena [352,357]. All this indicates long-time and far reaching constitutive effects of $\mathrm{Ca}^{2+}$ on epigenetically controled surface patterning in these cells.

The enzyme required to release $\mathrm{InsP}_{3}$ from $\mathrm{PIP}_{2}$, PLC, was identfied only very recently in Paramecium [358] and Tetrahymena $[238,359]$. If $\operatorname{InsP}_{3}$ is formed from PInsP $_{2}$ by the activity of PLC, this implies simultaneous formation of diacylglycerol (DAG), the activator of protein kinase C (PKC). There is only spurious evidence for the occurrence of PKC from sequence interference studies [360]. (A number of studies transferring inhibitors from mammalian to protist systems tacitly presumed equal efficacy and, thus, remains controversial for reasons discussed previously [30].) What other possible functions could DAG then execute? There is a paradigmatic situation in neuronal systems. Here, DAG binds the protein Munc13, a modulator of SNARE function [361]. Knowledge of SNARE-associated proteins in ciliates is very restricted, but a homolog of Munc18/Sec1, with six genes, can be found in the Paramecium DB (R. Kissmehl, unpubl. data). Although all this is hypothetic, an analogous effect of DAG on local lipid composition and function would appear feasible, particularly considering its modulatory effect on protein-based membrane interactions in higher eukaryotic systems [362].

In ciliates, knowledge about the occurrence of the high capacity/low affinity CaBPs, type calsequestrin ( $\mathrm{CaS}$ in SR) and calreticulin ( $\mathrm{CaR}$ in ER), which also exerts a chaperone function for protein folding [363], is fragmentary. Both have been identified bona fide by monospecific $\mathrm{ABs}$ (against the respective mammalian antigens) in homogenates from Paramecium. Thus, a CaR-like and a CaS-like protein have been localized at the EM level to the ER and to the alveolar sacs, respectively [152]. Molecular data are still missing (see also Section 8). Alone from the high [Ca] found by EDX in alveolar sacs of Paramecium and the rapid release upon stimulation [127] one has to postulate a high capacity/low affinity CaBP comparable to CaS in this organelle. For comparison, the ER chaperone, PDI (protein disulfide isomerase), has been cloned in Paramecium and clearly localized to the ER [133], just like the CR-like protein [152] and the ER tags $\mathrm{DiOC}_{6}$ [134] and $\mathrm{DiOC}_{18}$ [151].

\subsection{Apicomplexa}

To anticipate, the situation is principally rather similar to that in ciliates. Apicomplexan cells also contain CaM [111], CaN composed of a catalytic and a regulatory SU, CaN-A and CaN-B [364], and 

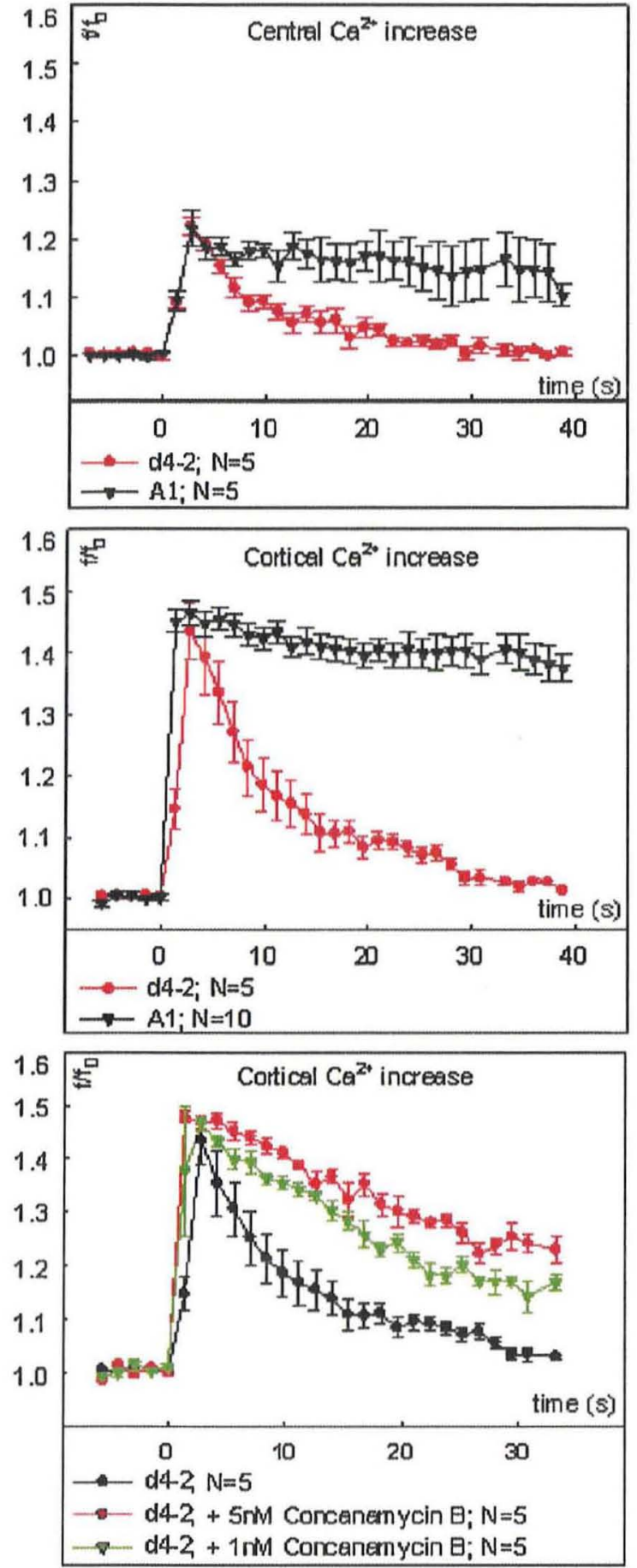

Fig. 10. Relevance of centrin, contained in the infraciliary lattice, and of $\mathrm{H}^{+}$-ATPase activity (inhibited by concanamycin $\mathrm{B}$ ) for downregulation of $\left[\mathrm{Ca}^{2+}\right]_{i}$ in cortical and central regions of the Paramecium cell following exocytosis stimulation by AED. Strains used: d4-2, wildtype cells; A1, cells deficient in infraciliary lattice. The top and middle diagram are reproduced from Sehring et al. [290], the bottom diagram shows unpublished results.

centrin ( $T$. gondii [365]; P. falciparum [366]). T. gondii possesses a $\mathrm{Ca}^{2+}$-ATPase, described as $\mathrm{TgA} 1$, complemented by a paralog called $\operatorname{Tg} 44 . \mathrm{mo2812}$ [140]. It is localized to the cell surface and to the acidocalcisomal membrane and contributes to $\mathrm{Ca}^{2+}$ homeostasis [162]. TgA1 is $130 \mathrm{kDa}$ large, but no CaM-binding has been reported [20] - in contrast to PMCA (Sections 3.1 and 7.1).
Altogether, the Plasmodium genome contains over 30 proteins with EF-hand modules [38]. Only one CaM gene may exist in P. falciparum, with $92 \%$ protein sequence identity to $T$. gondii and $H$. sapiens [367]. In P. falciparum, CaM has been localized to the cell apex by immuno-fluorescence [201] and immuno-gold EM analysis [368], just as in Paramecium. Anti-CaM drugs inhibit host cell invasion by $T$. gondii tachyzoites [201] and differentiation of stages of $P$. falciparum in vitro [369]. Reliability of such drugs at different levels of evolution can be attributed to high sequence conservation in CaM [30]. The situation clearly reminds that in Paramecium, not only regarding localization $[214,338]$ but also the requirement for the assembly of exocytosis sites [294] and drug effects on exocytosis in Tetrahymena [370].

In a phylogenetic analysis, CaN-A of T. gondii, Plasmodium yoelii, and Cryptosporidium parvum form clusters close to, but separate from the ciliates, $P$. tetraurelia and $T$. thermophila [307]. CaN and $\mathrm{CaN}$-interacting proteins have been considered important for medical use of cyclosporin A (CSA) against Plasmodium infection [364,371,372].

In T. gondii, centrin is enriched in patches near the cell surface within the conoid [365] in a situation which may qualify it as a sink for $\mathrm{Ca}^{2+}$. This is comparable to the cortical centrin in the Paramecium cell cortex ([290]; see above).

The $P$. falciparum genome contains only $\sim 100$ sequences encoding protein kinases (PKs) or PK-related proteins [373,374] which is far below the number in ciliates [327]. Thus, diversification is very much smaller in the parasites than in their free-living relatives. As in ciliates, genuine CaM kinases have not been found in Apicomplexa [374]. P. falciparum, T. gondii and other Apicomplexa are also endowed with $\mathrm{Ca}^{2+}$-dependent protein kinases, type CDPKs $[12,328,375]$, which otherwise are considered typical of plants [330,331] and ciliates (Paramecium [329]). These include a CDPK4 in Plasmodium vivax, which displays a well conserved $\mathrm{N}$-terminal kinase domain and a C-terminal CaM-like structure with $4 \mathrm{EF}$-hand motifs for $\mathrm{Ca}^{2+}$-binding. This protein is expressed in the mature schizont, thus suggesting a role in the process of proliferation [376]. CDPK4 also seems to be essential for the process of exflagellation of the male gametocytes, a key event during the life cycle of malaria parasites in the insect [377]. A CDPK3 has also been identified [378]. CDPK1 in T. gondii is essential for its exocytotic activity. Its suppression blocks exocytotic release of micronemal contents, thus interfering with tachyzoite motility, host cell invasion and egression from the host cell at the end of the intracellular cycle [379]. It is inhibited by nanomolar concentrations of the kinase inhibitors called "bumped" - compounds which are inactive against mammalian kinases. Since these kinase inhibitors inhibit an early stage of $T$. gondii infection they open the possibility to use these compounds against toxoplasmosis [380].

In P. falciparum, a $\mathrm{Ca}^{2+} / \mathrm{CaM}$-activated protein kinase B-like enzyme, $P f \mathrm{PKB}$, may be important for host cell penetration, by affecting the actomyosin motor of the glidosome attached to the inner membrane complex [12] (Section 6.1.2), in conjunction with upstream CaM and PLC activation [381]. Vaid and Sharma [382] were the first to identify non-GPI-specific PLC in any Alveolata member, i.e. P. falciparum. No protein kinase C (PKC), but putative kinase-like sequences (PKLSs) with some similarity, has been detected in the $P$. falciparum genome; rather untypically, however, these lack a $\mathrm{Ca}^{2+}$-binding and a phospholipid-binding domain [373]. In summary, the situation is quite similar to that in ciliates, with the exception of InsP $\mathrm{P}_{3}$ signaling which has been established in Paramecium (above), but not in any of the Apicomplexa.

Cell cycle regulation in $P$. falciparum is also reported to include several activities related to $\mathrm{Ca}^{2+}$ signaling: a PLC activity, an atypical $\mathrm{Ca}^{2+} / \mathrm{CaM}$-regulated protein kinase $\mathrm{B}$ (PKB; see above), a CDPK, and a PKG involved in $\mathrm{Ca}^{2+}$ mobilization; an $\mathrm{IP}_{3} \mathrm{R}$ in the ER and 
plasmalemmal Ca ${ }^{2+}$ influx channels are also assumed to be involved in cell cycle regulation [108], although $\mathrm{IP}_{3} \mathrm{Rs}$ have not been identified in any of the Apicomplexa as yet (Section 4.1). Some of these proteins are also discussed in the context of "glidosome" function for host cell penetration ([12]; Section 6.1).

The analysis of the $P$. falciparum genome does not allow one to identify the ER-specific lumenal $\mathrm{Ca}^{2+}$-dependent and glycosylation-sensitive chaperones, calnexin and $\mathrm{CaR}$, as known from mammalian cells $[363,383]$. This was endorsed by chaperone network analysis [366]. The latter paper differs in its opinion about the occurrence of ER-resident glycosylation from a paper by Hirtzlin et al. [371] which was based on an analysis of cyclophilin/peptidylprolyl cis-trans isomerase. If the $\mathrm{Ca}^{2+}$ dependent chaperones would prove to be absent, other proteins with highly negative charge may bind $\mathrm{Ca}^{2+}$ sequestered in the ER lumen which is considered a rapidly releasable pool in these cells (Section 3.1). For instance, PfERC/reticulocalbin, a CaBP of lower $\mathrm{Ca}^{2+}$ affinity than CaR family members, is assumed to be an ERresident component due to its ER retention signal [384]. Also in $P$. falciparum, such a signal is absent from a CaBP, type hsp90; although it otherwise resembles much more CaS, e.g. by a 68 aminoacid stretch with an excess of acidic residues, it is assumed to be cytosolic [385]. In summary, ER-resident $\mathrm{Ca}^{2+}$-BPs in Apicomplexa are insufficiently known and require more detailed investigation just as in ciliates.

\section{Calcium for motility and bioenergetics}

\section{1. $\mathrm{Ca}^{2+}$ for cell motility and cytokinesis}

These phenomena encompass rather heterogenous mechanisms, including ciliary beat regulation and parasite movement. Among them are gliding and penetration into, and liberation from host cells. Cytokinesis is also regulated by $\mathrm{Ca}^{2+}$. In addition, in ciliates, local increase of cortical $\left[\mathrm{Ca}^{2+}\right]$ also entails local cell contraction due to contraction of the centrin-based infraciliary lattice ([386]; Section 5).

\subsubsection{Ciliary activity regulation}

$\mathrm{Ca}^{2+}$ is required for basic activity of flagella [387] and cilia [388]. This also holds for ciliates [71,72]. A cyclic switch based on CaMassociated and CaM-dissociated states of target molecules may operate by cyclic changes in the concentration of intraciliary $\left[\mathrm{Ca}^{2+}\right]$ [387]. In ciliates, accelerated foreward swimming can be induced by hyperpolarization. This is accompanied by an increase in cAMP formation [389], though with some delay over several beats [390]. A drop of $\left[\mathrm{Ca}^{2+}\right]_{i}$ in cilia by 3 -fold may be closer to the latter basic regulation mechanism [391]. Some aspects of the underlaying mechanism, though not fully established as yet, differ from those assumed for mammalian cilia [392].

In ciliates, a stimulated increase of $\left[\mathrm{Ca}^{2+}\right]$ in cilia induces a change in ciliary beat direction (ciliary reversal [389]), as shown by injection of EGTA-buffered $\mathrm{Ca}^{2+}$ solutions into Paramecium cells [393] and also with Triton-extracted Paramecium models [394]. In both cases ciliary reversal was complete at $\left[\mathrm{Ca}^{2+}\right]=10^{-6} \mathrm{M}$. In vivo, this reaction takes place as an avoidance reaction when a cell hits an obstacle (see scheme, below). Then, mechanoreceptors with $\mathrm{Ca}^{2+}$-channel characteristics, concentrated in the anterior somatic membrane, are activated [82]. Database searches suggest Piezo as a candidate for mechanosensitive $\mathrm{Ca}^{2+}$ channels, also in Paramecium [395]. The receptor potential is mediated by depolarization due to $\mathrm{Ca}^{2+}$ influx [396] and activates voltage-dependent $\mathrm{Ca}^{2+}$-channels that are localized exclusively in the cilia [83]. Their activation is regulated by ciliary centrin [397]. Depolarization is counterbalanced by $\mathrm{K}^{+}$efflux [396].
In ciliates, the intraciliary $\left[\mathrm{Ca}^{2+}\right]$ increase thus produced activates a $\mathrm{Ca}^{2+} / \mathrm{CaM}$-stimulated guanylate cyclase, so that cyclic guanosine monophosphate(cGMP) levels increase [13,14,398]. This $\mathrm{Ca}^{2+}$-activated step is followed by activation of protein kinase $\mathrm{G}$ (PKG) activity. PKG mediated phosphorylation of some ciliary proteins [399] is reversed by a protein phosphatase type 1, PP1 [339]. Since the cGMP increase goes on over considerably more time than the rise of the $\mathrm{Ca}^{2+}$ signal [390] the coupling of the two processes does not appear very clear. In summary, the situation seems as follows: whereas $\mathrm{Ca}^{2+}$ appears as the first second messenger, cGMP may exert a modulatory effect over longer times [400].

In Paramecium, ciliary reversal takes place according to the following flow chart:

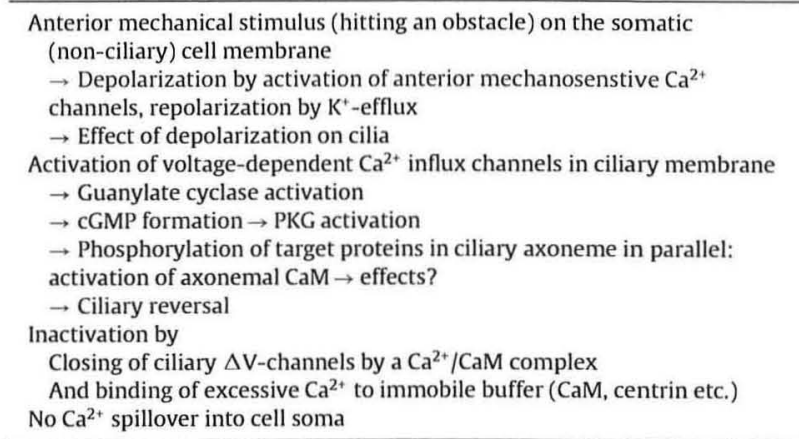

The immediate reversal response may be induced by the swift rise of intraciliary $\left[\mathrm{Ca}^{2+}\right]$ in interaction with CaM. This is associated with the axoneme in Paramecium $[214,215]$ and Tetrahymena [401]. How may CaM be integrated in the machinerey of ciliary activity? The hierarchial occupancy of the four $\mathrm{Ca}^{2+}$-binding loops of $\mathrm{CaM}$ is well established; considering increased liability for $\mathrm{Mg}^{2+}$ binding toward the C-terminal loop IV, Machemer and Teunis [402] hypothesized a $\mathrm{Ca}^{2+} / \mathrm{CaM}$ switch for ciliary activity, i.e. for backand foreward swimming. As recently found, differential occupancy of the four binding loops by $\mathrm{Ca}^{2+}$ in fact suffices to significantly change the effects on target molecules [403]. Biochemical experiments have shown the occurrence in cilia of further candidates for the interaction with $\mathrm{Ca}^{2+}$, including $\mathrm{CaBPs}$ and $\mathrm{Ca}^{2+}$-activated proteins [404]; Section 5. One of them is a heteropolymeric radial spoke protein, as found in Chlamydomonas; it associates with CaM in $\mathrm{Ca}^{2+}$-dependent manner and disposes of a phosphate transfer capacity as well [405]. Despite all these details, the precise mechansim of $\mathrm{Ca}^{2+}$-based regulation of ciliary activity in ciliated protozoa is not yet fully understood.

Subsequent to activation, further $\mathrm{Ca}^{2+}$ influx is abolished by a feedback exerted by the very same $\mathrm{Ca}^{2+}$ that has activated the ciliary reversal process [95]. This involves a $\mathrm{Ca}^{2+} / \mathrm{CaM}$ complex [92], just as found much later in different neuronal channels [96]. In general terms, $\mathrm{CaM}$ is an established $\mathrm{Ca}^{2+}$-sensor also in ciliates [92,93], in conjunction with $\mathrm{Ca}^{2+}$-dependent $\mathrm{CaM}$-BPs associated with the cell membrane [309].

The number of $\mathrm{Ca}^{2+}$ ions per cilium required for ciliary reversal activation may be of the estimated order of only $\sim 10^{3}$ [84]. These data are compatible with values etimated from the concentration required for activating ciliary reversal in permeabilized models [394], from $\mathrm{Ca}^{2+} /$ EGTA injected cells [393], and from electrophysiology. For further discussion, including electrophysiology, see Plattner and Klauke [10].

As shown by EDX, $\mathrm{Ca}^{2+}$-mediated activation of ciliary reversal in Paramecium entails no $\mathrm{Ca}^{2+}$ spillover into somatic regions underneath [84], unless cells are overstimulated [406]. This makes a cilium a functionally defined compartment with regard to $\mathrm{Ca}^{2+} \mathrm{sig}$ naling. By contrast, exocytosis stimulation can entail $\mathrm{Ca}^{2+}$ spillover from the soma, where the signal is generated by a SOC mechanism 
(Section 3.2), deep into cilia [84]. This has been recognized not only in EDX analyses but also by fluorochrome analysis. By this mechanism $P$. tetraurelia pawn mutants (which are defective in ciliary $\mathrm{Ca}^{2+}$ influx channels [88]) are also enabled to perform ciliary reversal [84].

Could centrin play a role in $\mathrm{Ca}^{2+}$ signaling in cilia? Using immuno-gold labeling centrin is found not only in ciliary basal bodies but also in the basis of cilia of human nasal cells [407]. No such data are available for ciliates and proteome analysis of isolated ciliary fractions gave no evidence along these lines [408]. If more scrutinized analysis would detect centrin in the ciliary basis of ciliates, it could contribute to the phenomenon often cited in electrophysiological recordings, that is a hypothetical "pump" which should be basally located and which would normally impede $\mathrm{Ca}^{2+}$ spillover from cilia into the soma. Alternatively the equivalent of this "pump" could be centrin associated with basal bodies (Section 5). In contrast, the PMCA-type pump is very likely too slow to produce such effects.

In Paramecium, exogenously added guanosine trisphosphate (GTP) can trigger alternating foreward and backward swimming in $\sim 8$ s periods without the characteristics of ciliary reversal [409]; see scheme, below. Electrophysiological recordings have documented oscillating depolarizations which do not occur in response to other nucleotides. A role for $\mathrm{Ca}^{2+}$ has been verified with a microinjected fluorochrome which showed a strong first peak, followed by smaller ones $[410]$. When $\left[\mathrm{Ca}^{2+}\right]_{0}$ was quenched to near resting $\left[\mathrm{Ca}^{2+}\right]_{i}$ levels, the first peak was reduced to the size of the subsequent ones, but otherwise signaling and behavior was as with normal $\left[\mathrm{Ca}^{2+}\right]_{0}$. The fact that signaling was altered by application of thapsigargin was considered as evidence of $\mathrm{Ca}^{2+}$ release from alveolar sacs [411]. Considering that this store is definitely insensitive to thapsigargin ([150,185]; see also Section 7.2) and that depletion of this store from $\mathrm{Ca}^{2+}$ by other, more specific means had no effect on the GTP response [410], one may well have to consider one of the other manyfold intracellular stores [134].

Cyclic backward/forward swimming induced in Paramecium by exogenous GTP follows the following scheme:

\footnotetext{
Exogenous GTP $(15 \mu \mathrm{M})$

$\rightarrow$ The first $\left[\mathrm{Ca}^{2+}\right]_{i}$ peak, larger than subsequent ones, requires $\mathrm{Ca}^{2+}{ }_{0}$

$\rightarrow$ Further (smaller) cyclic activity peaks in $\sim 8 \mathrm{~s}$ intervals supported by

$\mathrm{Ca}^{2+}$ from internal stores (type of store for internal $\mathrm{Ca}^{2+}$ mobilization

during GTP activation is unknown)

$\rightarrow$ Periodic activation and downregulation, followed by desensitization

(mechanism unknown), decaying $\mathrm{Ca}^{2+}$ signal etc.
}

\subsubsection{Gliding, host cell penetration and parasite liberation}

$\mathrm{Ca}^{2+}$ plays a fundamental role in the process of motility of tachyzoites, merozoites, sporozoites and ookinetes of members of the Apicomplexa phylum. This special type of cell motility is initiated by the secretion of rhoptry and microneme proteins. In this motility process the parasite membrane is captured unilaterally, the parasite itself is pushed forward. Initially a "moving junction" complex is formed by rhoptry exocytosis, RON protein being integrated into the host cell membrane and then serving as a receptor for micronemal protein AMA1, all arranged in a ring [412]. Gliding then depends on the binding of thrombospondin-like proteins (TRAP) to the protozoan surface where it interacts on the one hand with a host cell-receptor and on the other hand, via aldolase, with an actin-myosin complex. All this is located in the parasites subplasmalemmal space in close association with the IMC. Examples of TRAPs include TgMIC2 in T. gondii, circumsporozoite protein (CSP) of Plasmodium, CTPR of Plasmodium ookinetes and the merozoite TRAP homolog in Plasmodium (reviewed in [67]). Some of these steps depend on $\mathrm{Ca}^{2+}$ in an intriguing manner.

$\mathrm{A}\left[\mathrm{Ca}^{2+}\right]_{\mathrm{i}}$ increase in the parasites is considered crucial for host cell penetration $[68,69,111]$. How precisely does $\mathrm{Ca}^{2+}$ act and from which pools is it mobilized in the parasites? In the $T$. gondii cell cortex, CaM interacts with myosin light chains (MLC) and, thus, forms part of the invasion machinery. TgMLC1 is associated with the inner membrane complex, in contrast to TgMLC2 which is associated with the cell membrane [413]. Some of the "glidosome" components are probably a target for $\mathrm{Ca}^{2+}$, as one may assume for MLC activation. However, recently the involvement of a $\mathrm{Ca}^{2+}$ signal in activating glidosome function has been disputed [208]. If so, the function of $\mathrm{Ca}^{2+}$ could be more associated with the effects of secretory activity accompanying host cell penetration ([68,119,414]; see also Section 3). As mentioned above, inhibition of TgCDPK1 inhibited micronome secretion and inhibited progress in the life cycle [379]. $\mathrm{Ca}^{2+}$ imaging during $T$. gondii-host cell interaction has shown the following. First, $\mathrm{Ca}^{2+}$ is required for the exocytotic processes in the context of establishing of parasite-host contact (prerequisite to formation of the "moving junction"; above). Then, still during invasion, $\left[\mathrm{Ca}^{2+}\right]_{\mathrm{i}}$ goes down abruptly [119], possibly to avoid an overshooting reaction which otherwise could entail egression from the host cell.

With Plasmodium, $\mathrm{Ca}^{2+}$ is also involved in the formation of microgametes [415]. Release of microgametocytes of $P$. falciparum for transformation into mature microgametes ("exflagellation") requires $\mathrm{Ca}^{2+}$, as it is inhibited by the CaM inhibitor, W7 [415].

Interestingly $T$. gondii has recently been reported to contain voltage-gated $\mathrm{Ca}^{2+}$-channels (VGCCs). Three genes encoding VGCCs have been detected in $T$. gondii, clustering with a group of three, out of a total of eight, VGCCs in T. thermophila [140]. They were found neither in $P$. falciparum, nor in $C$. parvum. For $T$. gondii the authors suggest a role for $\mathrm{Ca}^{2+}$ influx upon $\mathrm{Ca}^{2+}$ release from internal stores. Concomitantly, a SOC-type mechanism has also been described in P. falciparum [205]; see Section 3.2.2.

\subsubsection{Cytokinesis}

In vertebrates, cell division requires a $\left[\mathrm{Ca}^{2+}\right]_{i}$ increase near the cleavage furrow on a time scale of minutes, as seen during early cell divisions in zebrafish and Xenopus development $[253,416]$. In both cases $\mathrm{Ca}^{2+}$ was from internal, InsP $\mathrm{P}_{3}$-sensitive pools. Ins $\mathrm{P}_{3}$ formation is essential also for the progression of cytokinesis in Drosophila spermatocytes [417]. This coincides with the local enrichment of recycling endosomes characterized by Rab11 and FIP3 (family of Rab11-interacting proteins) $[418,419]$. In HeLa cells, such vesicles also contain the R-SNARE, VAMP8; some other vesicles associated with the cleavage furrow are devoid of the endosomal markers and are considered as constitutive secretory vesicles [420]. Which one of these vesicles contributes the $\mathrm{Ca}^{2+}$ required for cytokinesis progression is not known. Among them, recycling endosomes are known to contain channels for $\mathrm{Ca}^{2+}$ release (Section 4.2). What is known about alveolates?

In Tetrahymena, the situation may be comparable. Similar to HeLa cells, two types of vesicles containing Cda12p and Cda13p were seen to be engaged in cytokinesis [246]. They are functionally related to Rab11-interacting proteins and, thus, connected to recycling endosomes (Sections 3.1 and 4.2 ). Both vesicle types travel along microtubules to the cleavage furrow. Antisense studies revealed the relevance of Cda12p vesicles for endocytosis and cytokinesis, and of Cda13p vesicles for conjugant separation and for cytokinesis [246]. As in higher eukaryotes, $\mathrm{a} \mathrm{Ca}^{2+}$ signal is likely needed for the progress of cytokinesis, but its origin remains to be determined. In Paramecium we found PtCRC-V-4, associated with the cleavage furrow ([134]; Fig. 6).

\section{2. $\mathrm{Ca}^{2+}$ for bioenergetics}

Upon stimulation, mitochondria of mammalian cells take up $\mathrm{Ca}^{2+}$ very rapidly, as has been established using Rhodamine-2 as an organelle specific fluorochrome. Rapid $\mathrm{Ca}^{2+}$ uptake into 


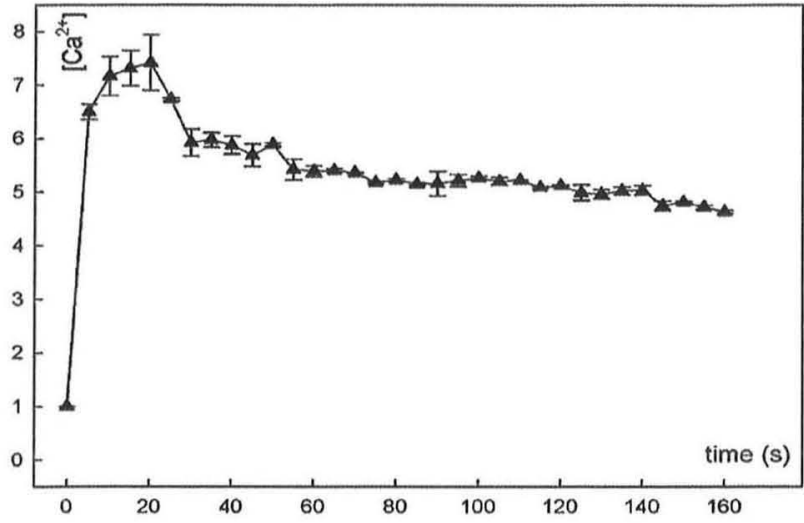

Fig. 11. $\left[\mathrm{Ca}^{2+}\right]$ increase in cortical mitochondria after exocytosis stimulation in Paramecium cells by AED, analyzed with Rhodamine-2. Unpublished results.

mitochondria depends on a locally generated $\left[\mathrm{Ca}^{2+}\right]_{i}$ increase [421] and requires a uniporter. Release into the cytosol is mediated by a $\mathrm{Na}^{+} / \mathrm{Ca}^{2+}$ exchanger, but other mechanisms are also discussed [422]. An increase in mitochondrial $\left[\mathrm{Ca}^{2+}\right]$ activates mitochondrial dehydrogenases and consequently ATP production [423].

$\mathrm{Ca}^{2+}$ interferes with energetics also in Paramecium. A $63 \mathrm{kDa}-$ phosphoprotein, pp63, is dephosphorylated during synchronous trichocyst exocytosis in parallel with ATP decay $(\leq 5 \mathrm{~s})$ and rephosphorylated during ATP recovery ( $\geq 20 \mathrm{~s}$ ), as summarized previously [424]. This protein was identified in Paramecium as phosphoglucomutase, PGM [425]; it was also found in Toxoplasma [426]. Based on its sensitivity to PP2B/CaN and to a $\mathrm{Ca}^{2+}$-inhibitable protein kinase we derived a $\mathrm{Ca}^{2+}$-sensitive de-/rephosphorylation cycle for pp63/PGM in connection with the mobilization of glucose for glycolysis $[424,427]$ in spatially restricted cortical areas where pp63/PGM is enriched [428]. Since AED stimulation, by $\mathrm{Ca}^{2+}$ spillover, also induces ciliary reversal $[84,182]$ some of the increased ATP production may be consumed in cilia. Considering the structural and functional similarity of alveolar sacs with muscular SR it is interesting to see that, in human skeletal muscle, a considerable proportion of glycogen moblization, that also involves PGM activity, is significantly correlated with $\mathrm{Ca}^{2+}$ release from the SR [429]

During AED-induced synchronous trichocyst exocytosis, analyzed by quenched-flow/cryofixation [129,430], local total calcium, [Ca], also increases in mitochondria. By EDX analysis, mitochondrial [Ca] increase was detected within a subsecond time scale, followed by decay within seconds [127]. In contrast, when mitochondrial $\left[\mathrm{Ca}^{2+}\right]$ was followed by the fluorochrome, Rhodamine-2, a rapid increase was registered, to 7.5 -fold within a second time scale, but decay was much slower, lasting $\geq 5 \mathrm{~min}$ (Fig. 11). Thus, according to the comparison of $[\mathrm{Ca}]$ and $\left[\mathrm{Ca}^{2+}\right]$ in mitochondria, only a small fraction of $\mathrm{Ca}^{2+}$ is retained after stimulation. As mentioned, this may serve in the activation of dehydrogenases in the mitochondrial matrix and, thus, increase mitochondrial energy supply, as known from mammalian cells $[423,431,432]$.

The frequently observed enrichment of mitochondria in Paramecium's cell cortex could also exert a "vacuum cleaner" effect, enforcing the influx of $\mathrm{Ca}^{2+}$, when mitochondria sequester much of it upon stimulation. Such an effect has been discussed for the immune synapse [433].

In a genomic survey of Paramecium, neither a mitochondrial $\mathrm{Ca}^{2+} / \mathrm{H}^{+}$exchanger nor a $\mathrm{Ca}^{2+}$-sensor regulating the mitochondrial $\mathrm{Ca}^{2+}$ uniporter was indicated, and no data were presented for such a uniporter [434], probably because its sequence had not yet been determined. It remains open whether these molecules differ too much from known sequences or whether other molecules are in use.

\section{Downregulation of calcium}

\subsection{Extrusion of $\mathrm{Ca}^{2+}$ from the cytosol and from the cell}

As mentioned, Paramecium cells have a PMCA-type $\mathrm{Ca}^{2+}$-pump in their cell membrane $[171,435]$, probably not only in the somatic region, but also in cilia. Not only its molecular size ( $\sim 130 \mathrm{kDa})$, but also occurrence of a CaM-binding site helps identifying this pump [171], as does inhibition by calmidazolium [170]. (Note: Partial sequences of another $\mathrm{Ca}^{2+}$-pump which we identified as a SERCA-type [150] have been erroneously annotated as a PMCA in the Paramecium DB). According to our balance calculations, PMCA activity may be much too slow to account for the rapid decay of $\left[\mathrm{Ca}^{2+}\right]_{\mathrm{i}}$ observed, e.g. after exocytosis stimulation $[10,132]$. Also the SERCA localized to the inner area of alveolar sacs $[145,151]$ sequesters $\mathrm{Ca}^{2+}$ with a $t_{1 / 2}$ of only $\sim 60 \mathrm{~min}$ ([436]; Table 1 ).

Downregulation of $\left[\mathrm{Ca}^{2+}\right]_{i}$ under steady-state conditions (passive diffusion) and after exocytosis stimulation in Paramecium can be summed up as follows (see also Fig. 2A):

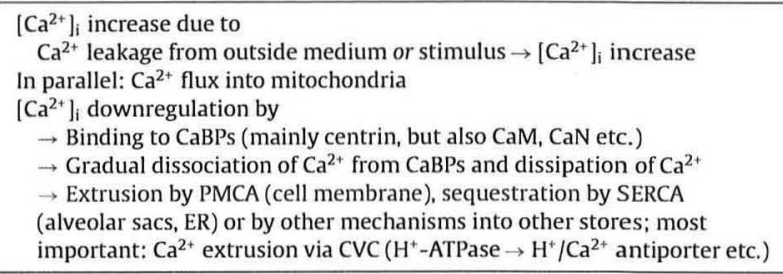

As an alternative, rapid extrusion by a $\mathrm{Na}^{+} / \mathrm{Ca}^{2+}$ exchanger in the cell membrane (as operating in cardiomyocytes between heart beats [437]) has been proposed, based on experiments with the ciliate, Euplotes crassus [438]. This was founded on the application of an exchanger inhibitor, although the specific efficacy of the drug effect has not been analyzed directly with a ciliate. In fact, one has to consider the low specificity of many drugs borrowed from mammalian cell biology for use in ciliates [30]. Restricted specificity is particularly a general problem with antiporter inhibitors [439]. Therefore, more direct evidence of any antiporter systems in the ciliate cell membrane, as well as anywhere else, appears mandatory.

By contrast, non-mitochondrial antiporters are well established functionally in Apicomplexa, particularly in their acidocalcisomes [21,179]; Fig. 4. Much less is known about antiporters in the cell membrane. Scrutinized analysis of apicomplexan databases suggests the occurrence of several $\mathrm{Ca}^{2+} / \mathrm{H}^{+}$antiporter orthologs, in the absence of $\mathrm{Na}^{+} / \mathrm{Ca}^{2+}$ exchangers [140]. In contrast, a $\mathrm{Na}^{+} / \mathrm{Ca}^{2+}$ exchanger is known from choanoflagellates [16] - protists that are much closer to higher eukaryotes than any other unicellular organism.

Currently we judge, in ciliates under steady-state or stimulation conditions, the recovery of $\left[\mathrm{Ca}^{2+}\right]_{i}$ as follows (Fig. 2). Cytosolic CaBPs, such as cortically enriched centrin, rapidly bind and, thus, inactivate $\mathrm{Ca}^{2+}$ in a first step, followed by desorption and dissipation. Pilot calculations evidenced that the CVC may be the crucial organelle guaranteeing recovery within a short time period [132]. The CVC possesses a $\mathrm{H}^{+}$-ATPase for sequestration of water and ions [192-194]. Here, extrusion of $\mathrm{Ca}^{2+}$ can be operated by the chemiosmotic $\Delta \mathrm{H}^{+}$-based $\mathrm{H}^{+} / \mathrm{Ca}^{2+}$ (or similar) exchange system in a second step. In fact, using microelectrodes Stock et al. [195] have measured extrusion of substantial concentrations of $\mathrm{Ca}^{2+}$ by the organelle, in the absence of a $\mathrm{Ca}^{2+}$-pump (our data). Concomitantly, application of the established inhibitor of the Paramecium $\mathrm{H}^{+}$-ATPase, concanamycin $\mathrm{B}$ [440], before stimulation delays the recovery of $\left[\mathrm{Ca}^{2+}\right]_{i}$ to resting levels after AED stimulation of exocytosis by 
$\sim 10$-fold (Fig. 10). Therefore, in Paramecium, a $\Delta \mathrm{H}^{+}$-based secondary active $\mathrm{Ca}^{2+}$ transport in acidic compartments, notably the $\mathrm{CVC}$, is a most realistic mechanism for rapid downregulation of $\left[\mathrm{Ca}^{2+}\right]_{\mathrm{i}}$.

As mentioned, T. gondii possesses a plasmalemmal-type $\mathrm{Ca}^{2+}$ ATPase, described as $\operatorname{TgA} 1$, complemented by a paralog called $\mathrm{Tg} 44 . \mathrm{mo} 2812$ [140]. It is localized not only to the cell surface, but also to the acidocalcisomal membrane and, thus, contributes to $\mathrm{Ca}^{2+}$ homeostasis [162].

\subsection{Store (re)filling}

In mammalian cells, re-uptake of $\mathrm{Ca}^{2+}$ by the ER, mediated by its SERCA pump, takes place on the scale of minutes, as summarized by Verkhratsky [441]. For mammalian cells, thapsigargin is the diagnostic of SERCA activity; its binding site has been specified by affinity labeling [442]. In protists, this pump may work much more slowly and several additional uptake mechanisms have been established for non-ER type stores in Apicomplexa. Also drug sensitivity can differ from mammalian cells.

\subsubsection{Ciliates}

Sequestration of ${ }^{45} \mathrm{Ca}^{2+}$ by alveolar sacs isolated from Paramecium cells in an ATP-regenerating system [125] was the first hint to the occurrence of an organellar $\mathrm{Ca}^{2+}$-pump. Two genes encode closely related paralogs of a sarcoplasmic/endoplasmic reticulum $\mathrm{Ca}^{2+}$-ATPase, SERCA, in Paramecium $[150,151]$. The green fluorescent protein-(GFP-)tagged SERCA protein passes from the ER, by vesicle flow, selectively to the alveolar sacs [151]. The fact that hardly any SERCA-GFP remains visible in the ER can be explained by rapid throughput. The PtSERCA-type pump is not sensitive to the classical inhibitor, thapsigargin, and this drug does not cause a SOC in Paramecium $[10,30]$. This failure can be attributed to the lack of conservation of eight aminoacids in the putative binding site [150]. Paramecium is also little, if at all, sensitive to the other standard SERCA inhibitors, cyclopiazonic acid $[10,30]$ and tBHQ when used in concentrations which are effective in mammalian cells [30]. The SERCA of Tetrahymena has also been cloned [443], but inhibitor studies are lacking. $\mathrm{Ca}^{2+}$ storage by the ER in ciliates must be important also for some signaling events because of the presence of PtCRC-I channels in the ER [134].

The CVC can also be considered a $\mathrm{Ca}^{2+}$ store because of the sequestration of $\mathrm{Ca}^{2+}$ into the CVC lumen [195]. As outlined above, in the absence of a Ca ${ }^{2+}$-pump, a $\mathrm{Ca}^{2+} / \mathrm{H}^{+}$or similar exchanger system may lumenally enrich $\mathrm{Ca}^{2+}$. As mentioned in Section 4.1, there also occurs a partial reflux via constitutively active $\mathrm{IP}_{3} \mathrm{Rs}$, thus producing stochastic $\mathrm{Ca}^{2+}$ sparks along the outlines of the organelle [132]. For all other components endowed with CRCs, the mechanism of $\mathrm{Ca}^{2+}$ sequestration has not been analyzed in ciliates.

\subsubsection{Apicomplexa}

The SERCA molecule is encoded by only one gene in $T$. gondii [167] and in P. falciparum [140]. The SERCA activity of Apicomplexa is reported to be inhibited by thapsigargin at concentrations applied to mammalian cells $[138,258]$, although the thapsigargin binding site in P. falciparum also differs - though less than in Paramecium from that in mammals. Other studies refute thapsigargin sensitivity in the apicomplexan parasites, but indicate a response to usual tBHQ concentrations in Plasmodium [258]. With cyclopiazonic acid a 10 times higher concentration has to be applied to inhibit PfATP6 [444]. Such differences may also be a problem of accessibility and the actual concentration "seen" by the target [445]. Furthermore, there is some polymorphism of the SERCA molecule concerning sensitivity to inhibitors in natural $P$. falciparum populations, as well as in some laboratory lines [446]. See also Section 3.1.2. Artemisinin has been considered a SERCA inhibitor of therapeutic interest for Plasmodium and Toxoplasma infection [138,445,447]. Apart fom its usefulness, artemisinin was recently found not to bind to the Plasmodium SERCA molecule, PfATP6, and not to inhibit its activity. Concomitantly it may exert another effect on these parasites [444,448].

\section{3. $\mathrm{Ca}^{2+}$ oscillations}

Spontaneous $\left[\mathrm{Ca}^{2+}\right]_{\mathrm{i}}$ oscillations have been analyzed only with P. tetraurelia, though not systematically. Prajer et al. [449] were the first to recognize spontaneous $\left[\mathrm{Ca}^{2+}\right]_{i}$ oscillations with a period of $t=\geq 2 \mathrm{~min}\left(\left[\mathrm{Ca}^{2+}\right]_{0}=1.5 \mathrm{mM}\right.$; fluorochrome: calcium Green-1). Oscillations with much shorter periods of $\sim 8 \mathrm{~s}$ were seen by Plattner and Klauke [10] to emanate spontaneously from the oral region $\left(\left[\mathrm{Ca}^{2+}\right]_{0}=0.05 \mathrm{mM}\right.$; fluorochrome: Fluo-3). Ladenburger et al. [132] observed spontaneous oscillations with a period of 8-20 s $\left(\left[\mathrm{Ca}^{2+}\right]_{0}=1 \mathrm{mM}\right.$; dextran-coupled Fluo-4). These oscillations were significantly altered upon uncaging $\operatorname{Ins}_{3}$ (though this does not indicate the source of $\mathrm{Ca}^{2+}$ ). For unknown reasons, in other extensive experimental series, we did not recognize any sponateous $\left[\mathrm{Ca}^{2+}\right]_{i}$ oscillations.

Oscillations of a periodicity of $\sim 8 \mathrm{~s}$ can be induced by exogenous application of GTP ([410]; $\left[\mathrm{Ca}^{2+}\right]_{0}=1 \mathrm{mM}$; fluorochrome: Fura Red), as first recognized by electrophysiological recordings [409]. Exogenous BAPTA, calculated to reduce $\left[\mathrm{Ca}^{2+}\right]_{\mathrm{o}}$ to slightly below $\left[\mathrm{Ca}^{2+}\right]_{\mathrm{i}}$ at rest $[75,185]$, reduced the first peak which otherwise was larger than the subsequent ones. Over some minutes, the $\mathrm{Ca}^{2+}$ response to GTP runs in a self-sustaining manner until it decays [410].

Since all fluorochromes used in these experiments have comparable $K_{\mathrm{d}}$ values of $\leq 1 \mu \mathrm{M}$ and time constants of around $1 \mu \mathrm{s}$ (summarized in [10]), data appear roughly comparable, even though obtained in a different context under variable experimental conditions $\left(\left[\mathrm{Ca}^{2+}\right]_{0}\right.$, fluorochrome). The $\left[\mathrm{Ca}^{2+}\right]_{i}$ oscillations observed must involve internal stores. Since we could not normally observe such $\left[\mathrm{Ca}^{2+}\right]_{i}$ oscillations, even under comparable conditions [75], the oscillations described may collectively suggest different physiological states of the cells, with unknown parameters, except GTP stimulation. Prajer et al. [449] discussed their data hypothetically in the context of surface structure modulation. Specifically for GTP induced oscillations we believe that they can serve near-range signaling between cells [410]. More detailed analyses will have to consider that the $\mathrm{Ca}^{2+}$ involved may come from different stores, with different kinds of mobilization as well as feedback mechanisms [450,451]. See also doi: $10.4249 /$ scholarpedia. 1576 for mechanisms currently discussed for $\mathrm{Ca}^{2+}$ oscillations in mammalian cells.

\section{Conclusions}

In Table 2 we summarize some of the essential similarities and differences currently known about $\mathrm{Ca}^{2+}$ stores and $\mathrm{Ca}^{2+}$ signaling in ciliates and in some of the evolutionarily closely related apicomplexan parasites.

- Cell membrane channels. Over a long time period, ciliates, notably Paramecium, have served electrophysiologists as a model to analyze plasmalemmal ion fluxes. A plethora of channels has been characterized, some conducting $\mathrm{Ca}^{2+}$, other with $\mathrm{Ca}^{2+}$ regulated conductances. $\Delta \mathrm{V}$-dependent $\mathrm{Ca}^{2+}$ channels are clearly restricted to cilia which, thus, represent a specific $\mathrm{Ca}^{2+}$ sensitive compartment. $\Delta \mathrm{V}$-dependent $\mathrm{Ca}^{2+}$ channels are known from Apicomplexa [212], their precise role requiring further work. To our knowledge nothing is known about transient receptor potential (TRP) channels in alveolates, though sequences occur in the 
Table 2

$\mathrm{Ca}^{2+}$-stores and $\mathrm{Ca}^{2+}$-signaling in Ciliates (Paramecium, Tetrahymena) and Apicomplexa (Plasmodium, Toxoplasma).

\begin{tabular}{|c|c|c|c|c|}
\hline & Ciliates & Reference (selection) & Apicomplexa ${ }^{a}$ & Reference (selection) ${ }^{a}$ \\
\hline $\begin{array}{l}\text { Basic }\left[\mathrm{Ca}^{2+}\right]_{i} \\
\text { Cytosolic CaBPs }\end{array}$ & $\begin{array}{l}50-100 \mathrm{nM} \\
\text { CaM } \\
\text { Centrin } \\
\text { CaN-B }\end{array}$ & $\begin{array}{l}{[75]} \\
{[92,292]} \\
{[354]} \\
{[307]}\end{array}$ & $\begin{array}{l}50-100 \mathrm{nM} \\
\text { Ditto } \\
\text { Ditto } \\
\text { Ditto }\end{array}$ & $\begin{array}{l}{[107,108]} \\
{[111]} \\
{[365,366]} \\
{[364]}\end{array}$ \\
\hline PMCA & Present & {$[170,435]$} & $\begin{array}{l}\text { Ditto } \\
\text { TgA1 (mainly classified as acidocalcisomal) }\end{array}$ & $\begin{array}{l}{[140,162]} \\
{[20]}\end{array}$ \\
\hline $\begin{array}{l}\mathrm{Ca}^{2+} \text {-influx channels } \\
\text { Cortical } \mathrm{Ca}^{2+} \text {-stores }\end{array}$ & $\begin{array}{l}\text { Many types } \\
\text { Alveolar sacs }\end{array}$ & $\begin{array}{l}{[71,72,93]} \\
{[10,87,106,125-127,150]}\end{array}$ & $\begin{array}{l}\text { No details available } \\
\text { Inner membrane complex? } \\
{\text { (Unknown } \mathrm{Ca}^{2+} \text {-storage) }}^{\mathrm{a}}\end{array}$ & $\overline{-}$ \\
\hline Type of $\mathrm{Ca}^{2+}$-pump & SERCA & {$[150,169]$} & $\begin{array}{l}\text { SERCA, T. gondii } \\
\text { P. chabaudi } \\
\text { P. falciparum }\end{array}$ & $\begin{array}{l}{[138,167]} \\
{[258]} \\
{[140]}\end{array}$ \\
\hline $\begin{array}{l}\text { CaBP } \\
\text { Mobilization by }\end{array}$ & $\begin{array}{l}\text { Calsequestrin-LPb } \\
\text { Caffeine } \\
\text { 4-Cl-m-cresol }\end{array}$ & $\begin{array}{l}{[152]} \\
{[76]} \\
{[185]}\end{array}$ & $\begin{array}{l}\text { Not clear; see Section } 5.2 \\
\text { Unknown } \\
\text { Unknown }\end{array}$ & - \\
\hline $\begin{array}{l}\text { Type of release channel } \\
\text { Type of structural coupling }\end{array}$ & $\begin{array}{l}\text { Ryanodine receptor } \\
\text { Unknown (no Orai/Stim) }\end{array}$ & {$[133,134]$} & $\begin{array}{l}\text { Unknown } \\
\text { For IMC/cell membrane } \\
\text { Connection, see Section } 6.1\end{array}$ & - \\
\hline Type of functional coupling & SOC/trichocyst release & {$[10,127,185]$} & - & - \\
\hline $\begin{array}{l}\text { SERCA-type } \mathrm{Ca}^{2+} \text {-ATPase } \\
\mathrm{Ca}^{2+} \text {-ATPase activity } \\
\text { Drug sensitivity }\end{array}$ & $\begin{array}{l}\text { SERCA-type } \\
\text { TG insensitive } \\
\text { tBHQ insensitivity } \\
\text { CPA insensitivity }\end{array}$ & $\begin{array}{l}{[151]} \\
{[30,150,169]} \\
\\
{[169]} \\
{[169]}\end{array}$ & $\begin{array}{l}\text { Various species } \\
\text { P. chabaudi: insensitive } \\
\text { P. falciparum: TG insensitive } \\
\text { T. gondii: TG sensitive } \\
\text { tBHQ sensitive } \\
\text { P. falciparum: more CPA sensitive }\end{array}$ & $\begin{array}{l}\text { See subsequent refs. } \\
{[258]} \\
{[444]} \\
{[12]} \\
{[258,444]} \\
{[444]}\end{array}$ \\
\hline $\begin{array}{l}\text { Localization } \\
\text { CaBP (chaperone) } \\
\text { Dense core vesicles } \\
\text { Stimulation by }\end{array}$ & $\begin{array}{l}\text { ER and alveolar sacs } \\
\text { CaR-LPb } \\
\text { Trichocysts } \\
\text { AED } \\
\text { Predator contact }\end{array}$ & $\begin{array}{l}{[150,151]} \\
{[152]} \\
{[80,129]} \\
{[77,78]}\end{array}$ & $\begin{array}{l}\text { ER } \\
\text { Not detectable in PfDB } \\
\text { Micronemes, rhoptries } \\
\text { Ethanol } \\
\text { Host cell contact }\end{array}$ & $\begin{array}{l}{[138]} \\
{[374]} \\
{[117]} \\
{[119,197]}\end{array}$ \\
\hline $\mathrm{Ca}^{2+}{ }_{0}$-requirement & Multiple steps & See Section 3.2 & $\begin{array}{l}P . \text { falciparum } \\
\text { None: } T \text {. gondii }\end{array}$ & $\begin{array}{l}{[203,205]} \\
{[119]}\end{array}$ \\
\hline Source & $\begin{array}{l}\text { Release from alveolar } \\
\text { Sacs + influx (SOC) }\end{array}$ & {$[127,185,186]$} & $\begin{array}{l}\text { P. falciparum: } \mathrm{SOC} \text { assumed } \\
\mathrm{Ca}^{2+}{ }_{i} \text { source uncertain }\end{array}$ & [205] \\
\hline $\begin{array}{l}\text { Plant vacuole-like comp. } \\
\mathrm{Ca}^{2+} \text {-storage } \\
\text { Other acidic compartments } \\
\mathrm{Ca}^{2+} \text { uptake mechanism }\end{array}$ & $\begin{array}{l}\text { Unknown } \\
\text { Unknown } \\
\text { Many } \\
\text { Unknown }\end{array}$ & $\begin{array}{l}- \\
- \\
{[191]}\end{array}$ & $\begin{array}{l}\text { T. gondii } \\
\text { T. gondii } \\
\text { Acidocalcisomes } \\
\mathrm{Ca}^{2+} \text {-ATPase }(\mathrm{TgA} 1) \text {, } \\
\mathrm{Ca}^{2+} \text {-PPase, } \mathrm{Ca}^{2+} / \mathrm{H}^{+} \text {and other exchangers }\end{array}$ & $\begin{array}{l}{[178]} \\
{[178]} \\
{[453]} \\
{[179]}\end{array}$ \\
\hline $\begin{array}{l}\mathrm{Ca}^{2+}-\text { release mechanism } \\
\text { Crystal vacuoles } \\
\text { TPCs }\end{array}$ & $\begin{array}{l}\text { NAADP }^{+} \text {(not localized) } \\
\text { Struvite (Ca,Mg phosphate) } \\
\text { Present in Paramecium DB } \\
\text { (Not localized) }\end{array}$ & $\begin{array}{l}\text { Binding studies (Fig. 9) } \\
\text { [131] } \\
\text { Unpubl. data }\end{array}$ & $\begin{array}{l}\text { Not known } \\
\text { Not known } \\
\text { Acidic compartments } \\
\text { Except acidocalcisomes } \\
\text { No TPCs in databases }\end{array}$ & $\begin{array}{l}{[173]} \\
{[212]}\end{array}$ \\
\hline $\begin{array}{l}\text { InsP } P_{3} \text { effects } \\
I_{3}-\mathrm{R} \\
\text { RyR-LPs } \\
\text { cADPR effects }\end{array}$ & $\begin{array}{l}\text { Yes (InsP } P_{3} \text { uncaging) } \\
\text { Cloned (subfamilies) } \\
\text { Cloned (subfamilies) } \\
\text { Yes (not localized) }\end{array}$ & $\begin{array}{l}{[132]} \\
{[132]} \\
{[133]} \\
\text { Microinjection (Fig. 7) }\end{array}$ & $\begin{array}{l}\text { P. falciparum } \\
\text { Unknown } \\
\text { Unknown } \\
\text { T. gondii } \\
\text { P. falciparum }\end{array}$ & $\begin{array}{l}\text { [259]; also see text } \\
- \\
- \\
{[207]} \\
{[208]}\end{array}$ \\
\hline
\end{tabular}

For more details, see text.

b $-\mathrm{LP}=-$ like protein.

Paramecium DB. Their localization could be plasmalemmal and/or intracellular [452].

- $\mathrm{Ca}^{2+}$-dependent and $\mathrm{Ca}^{2+}$-binding proteins. CaM is largely conserved in the two groups of Alveolata. Similarly CaN and centrin appear to play important roles. Among protein kinases, both groups contain CDPKs with an inherent CaM-like domain, rather than kinases activated by CaM as a separate molecule.

- Overall $\mathrm{Ca}^{2+}$ regulation. In both groups of Alveolata, molecular mechanisms underlaying intracellular $\mathrm{Ca}^{2+}$ sequestration and $\mathrm{Ca}^{2+}$ extrusion are probably largely comparable to those in metazoans. This includes participation of PMCA, SERCA, and exploitation of $\Delta \mathrm{H}^{+}$(generated either by $\mathrm{H}^{+}$-ATPases) in the context of antiporter systems. $\Delta \mathrm{H}^{+}$-dependent mechanisms of $\mathrm{Ca}^{2+}$ regulation have been analyzed in much more detail in the parasites. In detail, acidocalcisomes abound in Apicomplexa, whereas they are not identified as yet in ciliates, where they probably also occur. In the parasites they may serve to clear an excess of $\mathrm{Ca}^{2+}$ from the cell, and some evidence suggests a role in $\mathrm{Ca}^{2+}$ signaling during host cell penetration

- $\mathrm{Ca}^{2+}$ stores. In ciliates, $\mathrm{Ca}^{2+}$ stores are represented by the alveolar sacs, the ER and probably by the numerous endo-lysosomal and phagosomal compartments (as one may derive from the distribution of putative CRCs). The CVC also contains $\mathrm{Ca}^{2+}$ which it regularly extrudes from the cell during each systole in $\sim 10 \mathrm{~s}$ time intervals. Release of $\mathrm{Ca}^{2+}$ from alveolar sacs via RyR-type CRCs during exocytosis stimulation is superimposed by a SOC 
mechanism. In contrast, the inner membrane complex of Apicomplexa apparently has lost - fully or partially - the capability of storing substantial amounts of $\mathrm{Ca}^{2+}$ - if any - and the SOC mechanism recently described [205] would have to originate from another store. Ciliates contain numerous types of RyRs and $\mathrm{IP}_{3} \mathrm{Rs}$ - two of them are now molecularly and functionally clearly defined according to criteria valid for mammalian cells. Ciliates very likely also contain TPCs in compartments yet to be identified. In the genomic databases available for Apicomplexa, there occur only short fragments of sequences from similar channels, RyRs, $\mathrm{IP}_{3}$ Rs and TPCs. Nevertheless, when InsP $\mathrm{P}_{3}$ is introduced into the parasites, it clearly exerts some effects. However, the molecular equivalents of these potential channels have resisted identification in a variety of attempts. Altogether, with the exception of Paramecium, information about such CRCs in protozoa is only fragmentary. For instance, gene sequences attributed to $\mathrm{IP}_{3} \mathrm{Rs}$ in the amoeba, Naegleria [41], and in Dictyostelium [260] have never been supplemented by proteomic analysis, localization and functional studies. As far as lower eukaryotes are concerned, one speculation says that, wherever InsP $\mathrm{P}_{3}$ effects have been ascertained in the absence of a true $\mathrm{IP}_{3} \mathrm{R}$, such effects may operate in a (not yet identified) way different from receptor activation. An exception would be the true $\mathrm{IP}_{3}$ Rs described in Paramecium $[132,134]$. Therefore, the identification of $\mathrm{Ca}^{2+}$ release mechanisms and the underlaying channels in the stores of Apicomplexa remain a problem of paramount importance. Here - in contrast to ciliates - acidocalcisomes are well analyzed [453], although $\mathrm{InsP}_{3}$ effects remain enigmatic.

- Evolutionary aspects of signaling. According to comparative genomics, $\mathrm{IP}_{3}$ Rs are assumed to have emerged in evolution before RyRs [434]. However, in contrast to this view derived from database information then available, the Paramecium cell clearly contains RyRs and $\mathrm{IP}_{3} \mathrm{Rs}$, as we have shown [132-134]. (Accordingly a PInsP $\mathrm{P}_{2}$ hydrolyzing PLC occurs in ciliates $[238,358,359]$.) The temporal sequence of the emergence of RyRs and $\mathrm{IP}_{3} \mathrm{Rs}$, as well as of TPCs (like RyRs not identified in the genomic analysis by Collins and Meyer [434]) requires more detailed analysis. No comparable data are available from Apicomplexa. Considering the clear identification of RyR- and of $\mathrm{IP}_{3} \mathrm{R}$-type CRCs in Paramecium, the argument that in Apicomplexa they may be undetectable because of evolutionary distance is no longer maintainable. Rather, these may have lost such channels from a common ancestor during transition to parasitic life. In the course of genome reduction, they may have switched to other mechanisms more appropriate for such life style. Many genes pertinent to $\mathrm{Ca}^{2+}$ handling and signaling, which are contained in the Paramecium DB have been annotated by the group in Konstanz. In their recent comparative genomic analysis using the Paramecium DB Collins and Meyer [434] find a mitochondrial $\mathrm{Na}^{+} / \mathrm{Ca}^{2+}$ exchanger and a polycystic $\mathrm{Ca}^{2+}$-channel of the transient receptor potential- (TRP-)type $\mathrm{Ca}^{2+}$ channel. Any other TRP-type channels also await elucidation in Paramecium. In their evolutionary survey, these authors detected no sequences of a plasmalemmal-type of $\mathrm{Na}^{+} / \mathrm{Ca}^{2+}$ (whose existence we questioned in Section 7.1) or $\mathrm{Na}^{+} / \mathrm{K}^{+} / \mathrm{Ca}^{2+}$ exchanger, and neither plasmalemmal Orai-related or -associated $\mathrm{Ca}^{2+}$ channels, nor Stim-related ER-type sensors involved in sensory signal transduction can be found (as we confirm by our own data mining).

- A set of basic questions awaiting solutions. Interestingly, no trimeric G-proteins, e.g. for the regulation of PLC activity, have been safely established as yet in alveolates (except fragmentary information for ciliates; see [30]). However, PLC for the hydrolysis of PIns $\mathrm{P}_{2}$ occurs in ciliates $[238,358,359]$. We confirm the absence of $\mathrm{CaR}$ and $\mathrm{CaS}$ sequences in the Paramecium $\mathrm{DB}$, as indicated by Collins and Meyer [434], in contrast to our immuno-localization to the ER and alveolar sacs of Paramecium, respectively, using monospecific ABs (see Sections 3.1 and 5.1). However, in this case, when so widely different evolutionary levels are compared, an excess of acidic aminoacids may be more important than primary sequence. We consider this question open for further work. If this assumption is correct similar reasons may have impeded the identification of the ER-type $\mathrm{Ca}^{2+}$-dependent chaperones in Apicomplexa, although other work suggests core glycosylation (Section 6.1) which in higher eukaryotes is normally paralleled by such chaperone functions. Similar uncertainty exists in both groups concerning annexins, as characterized in higher eukaryotes $[454,455]$.

- Consequences of parasitic life. In summary, it appears that components relevant for $\mathrm{Ca}^{2+}$ handling and signaling are much more complex in ciliates than in Apicomplexa. These may have reduced several functions inherited from common evolutionary precursor forms or transformed them into other functions. This concerns the alveoli, where the equivalents (inner membrane complex) in the parasites cannot be safely considered as overt $\mathrm{Ca}^{2+}$ stores. They may rather serve as an abutment for glidosome activity during host cell entry. In the parasites, the main store of $\mathrm{Ca}^{2+}$ amenable to rapid mobilizations, e.g. during host cell penetration, could be the acidocalcisomes and/or the ER, although the molecular mechanism of $\mathrm{Ca}^{2+}$ release is not yet sufficiently clear for neither one of these compartments. In addition, acidocalcisomes may serve disposing of an excess of $\mathrm{Ca}^{2+}$, or storage for eventual availability over longer times. While characteristic TPCs cannot be found and apparently have been lost, mechanisms for rapid $\mathrm{Ca}^{2+}$ handling via $\mathrm{H}^{+}$gradients and exchanger mechanisms have become preponderant in Apicomplexa. Prerequisites are $\mathrm{H}^{+}$-ATPases, $\mathrm{Ca}^{2+}$-ATPases and $\mathrm{H}^{+}$-pyrophosphatase, as well as several $\mathrm{Ca}^{2+}$ exchanger activities. Acidocalcisomes as a whole and some of their transport activities have not been characterized in ciliates as yet, where they may also occur.

Generally the number of proteins involved in $\mathrm{Ca}^{2+}$ regulation increases during evolution. This is true not only for the comparison of Archaea with Eubacteria, but also for the transition to higher plants and to mammals [456]. It is also evident for the transition from protozoa to metazoa [434]. Nevertheless, we realize that a great part of the standard reperoire available in "higher" organisms can already be identified in ciliates. This is also in contrast to the younger branch of alveolates represented by the apicomplexan parasites whose $\mathrm{Ca}^{2+}$ regulation appears secondarily greatly reduced. The finding in Paramecium of CRCs closely related to the RyR is striking, considering their reported absence from choanoflagellates, the roots of metazoan evolution $[16,457]$. Here, however, detailed domain analyses are still missing.

\section{Acknowledgements}

Work by H.P. cited herein has been supported by the Deutsche Forschungsgemeinschaft. Work by K.M. and W.S. cited herein has been supported by the Brazillian agencies CNPq, CAPES and FAPERJ.

\section{References}

[1] M.J. Berridge, P. Lipp, M.D. Bootman, The versatility and universality of calcium signalling, Nat. Rev. Mol. Cell Biol. 1 (2000) 11-21.

[2] M.J. Berridge, M.D. Bootman, H.L. Roderick, Calcium signalling: dynamics, homeostasis and remodelling, Nat. Rev. Mol. Cell Biol. 4 (2003) 517-529.

[3] D.E. Clapham, Calcium signaling, Cell 131 (2007) 1047-1058.

[4] A.N. Dodd, J. Kudla, D. Sanders, The language of calcium signaling, Annu. Rev. Plant Biol. 61 (2010) 593-620.

[5] E. Neher, Vesicle pools and $\mathrm{Ca}^{2+}$ microdomains: new tools for understanding their roles in neurotransmitter release, Neuron 20 (1998) 389-399.

[6] R. Rizzuto, T. Pozzan, Microdomains of intracellular $\mathrm{Ca}^{2+}$ : molecular determinants and functional consequences, Physiol. Rev. 86 (2006) 369-408. 
[7] A.J. Laude, A.W. Simpson, Compartmentalized signalling: $\mathrm{Ca}^{2+}$ compartments, microdomains and the many facets of $\mathrm{Ca}^{2+}$ signalling, FEBS J. 276 (2009) 1800-1816.

[8] M.J. Berridge, Calcium microdomains: organization and function, Cell Calcium 40 (2006) 405-412.

[9] O.H. Petersen, M. Michalak, A. Verkhratsky, Calcium signalling: past, present and future, Cell Calcium 38 (2005) 161-169.

[10] H. Plattner, N. Klauke, Calcium in ciliated protozoa: sources, regulation, and calcium-regulated cell functions, Int. Rev. Cytol. 201 (2001) 115-208.

[11] L.M. Alleva, K. Kirk, Calcium regulation in the intraerythrocytic malaria parasite Plasmodium falciparum, Mol. Biochem. Parasitol. 117 (2001) $121-128$.

[12] O. Billker, S. Lourido, L.D. Sibley, Calcium-dependent signaling and kinases in apicomplexan parasites, Cell Host Microbe 5 (2009) 612-622

[13] J.E. Schultz, S. Klumpp, R.D. Hinrichsen, Calcium and membrane excitation in Paramecium, in: D.H. O'Day (Ed.), Calcium as Intracellular Messenger in Eucaryotic Microbes, Am. Soc. Microbiol., Washington (DC), 1990, pp. 124-150.

[14] J.E. Schultz, S. Klumpp, Cyclic nucleotides and calcium signaling in Paramecium, Adv. Sec. Mess. Phosphoprot. Res. 27 (1993) 25-46.

[15] R.D. Hinrichsen, D. Fraga, C. Russell, The regulation of calcium in Paramecium, Adv. Sec. Mess. Phosphoprot. Res. 30 (1995) 311-338.

[16] X. Cai, Unicellular $\mathrm{Ca}^{2+}$ signaling 'toolkit' at the origin of metazoa, Mol. Biol. Evol. 25 (2008) 1357-1361

[17] C.C. Yin, L.G. D'Cruz, F.A. Lai, Ryanodine receptor arrays: not just a pretty pattern? Trends Cell Biol. 18 (2008) 149-156.

[18] A.V. Yeromin, S.L. Zhang, W. Jiang, Y. Yu, O. Safrina, M.D. Cahalan, Molecular identification of the CRAC channel by altered ion selectivity in a mutant of Orai, Nature 443 (2006) 226-229.

[19] R. Docampo, W. de Souza, K. Miranda, P. Rohloff, S.N. Moreno, Acidocalcisomes - conserved from bacteria to man, Nat. Rev. Microbiol. 3 (2005) 251-261.

[20] S. Luo, F.A. Ruiz, S.N. Moreno, The acidocalcisome $\mathrm{Ca}^{2+}$-ATPase (TgA1) of Toxoplasma gondii is required for polyphosphate storage, intracellular calcium homeostasis and virulence, Mol. Microbiol. 55 (2005) 1034-1045.

[21] R. Docampo, S.N. Moreno, Acidocalcisomes, Cell Calcium 50 (2011) 113-119.

$22]$ S. Patel, R. Docampo, Acidic calcium stores open for business: expanding the potential for intracellular $\mathrm{Ca}^{2+}$ signaling, Trends Cell Biol. 20 (2010) 277-286.

[23] R.L. Patterson, D. Boehning, S.H. Snyder, Inositol 1,4,5-trisphosphate receptors as signal integrators, Annu. Rev. Biochem. 73 (2004) 437-465.

[24] R. Zalk, S.E. Lehnart, A.R. Marks, Modulation of the ryanodine receptor and intracellular calcium, Annu. Rev. Biochem. 76 (2007) 367-385.

[25] A. Galione, A.M. Evans, J. Ma, et al., The acid test: the discovery of twopore channels (TPCS) as NAADP-gated endolysosomal $\mathrm{Ca}^{2+}$ release channels, Pflugers Arch. - Eur. J. Physiol. 458 (2009) 869-876.

[26] A. Galione, A.J. Morgan, A. Arredouani, et al., NAADP as an intracellular messenger regulating lysosomal calcium-release channels, Biochem. Soc. Trans. 38 (2010) 1424-1431.

[27] S. Patel, L. Ramakrishnan, T. Rahman, et al., The endo-lysosomal system as an NAADP-sensitive acidic $\mathrm{Ca}^{2+}$ store: role for the two-pore channels, Cell Calcium 50 (2011) 157-167.

[28] G.A. Rutter, E.A. Bellomo, $\mathrm{Ca}^{2+}$ signalling: a new route to NAADP, Biochem. J. 411 (2008) e1-e3.

[29] J.L. Sutko, J.A. Airey, W. Welch, L. Ruest, The pharmacology of ryanodine and related compounds, Pharmacol. Rev. 49 (1997) 53-98.

[30] H. Plattner, I.M. Sehring, C. Schilde, E.M. Ladenburger, Pharmacology of ciliated protozoa - drug (in)sensitivity and experimental drug (ab)use, Int. Rev. Cell Mol. Biol. 273 (2009) 163-218.

[31] E. Carafoli, J. Krebs (Eds.), Calcium Homeostasis, Springer-Verlag, Heidelberg, New York, Berlin, 2000

[32] M.G. Palmgren, P. Nissen, P-type ATPases, Annu. Rev. Biophys. 40 (2011) 243-266.

[33] D. Soldati, B.J. Foth, A.F. Cowman, Molecular and functional aspects of parasite invasion, Trends Parasitol. 20 (2004) 567-574.

[34] J.F. Dubremetz, G. Torpier, Freeze fracture study of the pellicle of an eimerian sporozoite (Protozoa, Coccidia), J. Ultrastruct. Res, 62 (1978) 94-109.

[35] W.M. Cintra, W. de Souza, Distribution of intramembranous particles and filipin-sterol complexes in the cell membranes of Toxoplasma gondii, Eur. J. Cell Biol. 37 (1985) 63-69.

[36] F. Scheckenbach, K. Hausmann, C. Wylezich, M. Weitere, H. Arndt, Large-scale patterns in biodiversity of microbial eukaryotes from the abyssal sea floor, Proc. Natl. Acad. Sci. U.S.A. 107 (2010) 115-120.

[37] J. Pawlowski, R. Christen, B. Lecroq, et al., Eukaryotic richness in the abyss: insights from pyrotag sequencing, PLoS One 6 (2011) e 18169.

[38] L. Aravind, L.M. Iyer, T.E. Wellems, L.H. Miller, Plasmodium biology: genomic gleanings, Cell 115 (2003) 771-785.

[39] D.S. Roos, Themes and variations in apicomplexan parasite biology, Science 309 (2005) 72-73

40] S.L. Baldauf, The deep roots of eukaryotes, Science 300 (2003) 1703-1706.

41] L.K. Fritz-Laylin, S.E. Prochnik, M.L. Ginger, et al., The genome of Naegleria gruberi illuminates early eukaryotic versatility, Cell 140 (2010) 631-642.

[42] A.-D. Wright, D.H. Lynn, Maximum ages of ciliate lineages estimated using a small subunit rRNA molecular clock: crown eukaryotes date back to the paleoproterozoic, Arch. Protistenk. 148 (1997) 329-341.
[43] C. Berney, J. Pawlowski, A molecular time-scale for eukaryote evolution recalibrated with the continuous microfossil record, Proc. Biol. Sci. 273 (2006) 1867-1872.

[44] C.H. Kuo, J.P. Wares, J.C. Kissinger, The Apicomplexan whole-genome phylogeny: an analysis of incongruence among gene trees, Mol. Biol. Evol. 25 (2008) 2689-2698.

[45] K. Budin, H. Philippe, New insights into the phylogeny of eukaryotes based on ciliate Hsp70 sequences, Mol. Biol. Evol. 15 (1998) 943-956.

[46] A. Reyes-Prieto, A. Moustafa, D. Bhattacharya, Multiple genes of apparen algal origin suggest ciliates may once have been photosynthetic, Curr. Biol. 18 (2008) 956-962.

[47] T.R. Bachvaroff, S.M. Handy, A.R. Place, C.F. Delwiche, Alveolate phylogeny inferred using concatenated ribosomal proteins, J. Eukaryot. Microbiol. 58 (2011) 223-233.

[48] Y.I. Tekle, J.R. Grant, A.M. Kovner, J.P. Townsend, L.A. Katz, Identification of new molecular markers for assembling the eukaryotic tree of life, Mol. Phylogenet. Evol. 55 (2010) 1177-1182.

[49] S.B. Gould, W.H. Tham, A.F. Cowman, G.I. McFadden, R.F. Waller, Alveolins, a new family of cortical proteins that define the protist infrakingdom Alveolata, Mol. Biol. Evol. 25 (2008) 219-1230.

[50] H. Plattner, F. Miller, L. Bachmann, Membrane specializations in the form of regular membrane-to-membrane attachment sites in Paramecium. A correlated freeze-etching and ultrathin-sectioning analysis, J. Cell Sci. 13 (1973) 687-719.

[51] J. Beisson, M. Lefort-Tran, M. Pouphile, M. Rossignol, B. Satir, Genetic analysis of membrane differentiation in Paramecium. Freeze-fracture study of the trichocyst cycle in wild-type and mutant strains, J. Cell Biol. 69 (1976) 126-143.

[52] C.F. Bardele, Mapping of highly ordered membrane domains in the plasma membrane of the ciliate Cyclidium glauccoma. J. Cell Sci. 61 (1983) 1-30.

[53] E. Porchet, G. Torpier, Etude du germe infectieux de Sarcocystis tenella et Tox oplasma gondii par la technique du cryodécapage. [Freeze fracture study of Toxoplasma and Sarcocystis infective stages (author's transl.)], Z. Parasitenkd. 54 (1977) 101-124.

[54] H. Plattner, C. Westphal, R. Tiggemann, Cytoskeleton-secretory vesicle interactions during the docking of secretory vesicles at the cell membrane in Paramecium tetraurelia cells, J. Cell Biol. 92 (1982) 368-377.

[55] G.M. Griffiths, A. Tsun, J.C. Stinchcombe, The immunological synapse: a foca point for endocytosis and exocytosis, J. Cell Biol. 189(2010) 399-406.

[56] J.A. Kloetzel, A. Baroin-Tourancheau, C. Miceli, S. Barchetta, J. Farmar, D. Banerjee, A. Fleury-Aubusson, Plateins: a novel family of signal peptide-containing articulins in euplotid ciliates, J. Eukaryot. Microbiol. 50 (2003) 19-33.

[57] L. Lemgruber, J.A. Kloetzel, W. de Souza, R.C. Vommaro, Toxoplasma gondii: further studies on the subpellicular network, Mem. Inst. Oswaldo Cruz 104 (2009) 706-709.

[58] K. Wengelnik, R. Spaccapelo, S. Naitza, et al., The A-domain and the thrombospondin-related motif of Plasmodium falciparum TRAP are implicated in the invasion process of mosquito salivary glands, EMBO J. 18 (1999) 5195-5204.

[59] A. Keeley, D. Soldati, The glideosome: a molecular machine powering motility and host-cell invasion by Apicomplexa, Trends Cell Biol. 14 (2004) 528-532

[60] E.J. Douzery, E.A. Snell, E. Bapteste, F. Delsuc, H. Philippe, The timing of eukaryotic evolution: does a relaxed molecular clock reconcile proteins and fossils? Proc. Natl. Acad. Sci. U.S.A. 101 (2004) 15386-15391.

[61] J.L. Johnson, M.R. Leroux, CAMP and CGMP signaling: sensory systems with prokaryotic roots adopted by eukaryotic cilia, Trends Cell Biol. 20 (2010) 435-444.

[62] J.B. Dacks, M.C. Field, Evolution of the eukaryotic membrane-trafficking system: origin, tempo and mode, J. Cell Sci. 120 (2007) 2977-2985.

[63] J.B. Dacks, P.P. Poon, M.C. Field, Phylogeny of endocytic components yields insight into the process of nonendosymbiotic organelle evolution, Proc. Natl. Acad. Sci. U.S.A. 105 (2008) 588-593.

[64] H. Plattner, How to design a highly organized cell: an unexpectedly high number of widely diversified SNARE proteins positioned at strategic sites in the ciliate, Paramecium tetraurelia, Protist 161 (2010) 497-516

[65] H. Plattner, Membrane trafficking in protozoa SNARE proteins, $\mathrm{H}^{+}$-ATPase, actin, and other key players in ciliates, Int. Rev. Cell Mol. Biol. 280 (2010) 79-184.

[66] R.E. Ricklefs, D.C. Outlaw, A molecular clock for malaria parasites, Science 329 (2010) 226-229.

[67] J. Baum, T.W. Gilberger, F. Frischknecht, M. Meissner, Host-cell invasion by malaria parasites: insights from Plasmodium and Toxoplasma, Trends Parasitol. 24 (2008) 557-563.

[68] V.B. Carruthers, L.D. Sibley, Mobilization of intracellular calcium stimulates microneme discharge in Toxoplasma gondii, Mol. Microbiol. 31 (1999) 421-428

[69] H.M. Ngo, H.C. Hoppe, K.A. Joiner, Differential sorting and post-secretory targeting of proteins in parasitic invasion, Trends Cell Biol. 10 (2000) 67-72.

[70] L. Li, B.P. Brunk, J.C. Kissinger, et al., Gene discovery in the apicomplexa as revealed by EST sequencing and assembly of a comparative gene database, Genome Res. 13 (2003) 443-454

[71] H. Machemer, Electrophysiology, in: H.-D. Görtz (Ed.), Paramecium, SpringerVerlag, Berlin, Heidelberg, New York, London, Paris, Tokyo, 1988, pp. 185-215.

[72] H. Machemer, Motor control of cilia, in: H.-D. Görtz (Ed.), Paramecium, Springer-Verlag, Berlin, Heidelberg, New York, London, Paris, Tokyo, 1988, pp. 216-235. 
[73] R.D. Allen, A.K. Fok, Membrane trafficking and processing in Paramecium, Int, Rev. Cytol. 198 (2000) 277-318.

[74] L.J. Bright, N. Kambesis, S.B. Nelson, B. Jeong, A.P. Turkewitz, Comprehensive analysis reveals dynamic and evolutionary plasticity of Rab GTPases and membrane traffic in Tetrahymena thermophila, PLoS Genet. 6 (2010) e1001155.

[75] N. Klauke, H. Plattner, Imaging of $\mathrm{Ca}^{2+}$ transients induced in Paramecium cells by a polyamine secretagogue, J. Cell Sci. 110 (1997) 975-983.

[76] N. Klauke, H. Plattner, Caffeine-induced $\mathrm{Ca}^{2+}$ transients and exocytosis in Paramecium cells. A correlated $\mathrm{Ca}^{2+}$ imaging and quenched-flow/freezefracture analysis, J. Membr. Biol. 161 (1998) 65-81

[77] T. Harumoto, A. Miyake, Defensive function of trichocysts in Paramecium, J. Exp. Zool. 260 (1991) 84-92.

[78] G. Knoll, B. Haacke-Bell, H. Plattner, Local trichocyst exocytosis provides an efficient escape mechanism for Paramecium cells, Eur. J. Protistol. 27 (1991) 381-385.

[79] Y. Iwadate, K. Katoh, H. Asai, M. Kikuyama, Simultaneous recording of cytosolic $\mathrm{Ca}^{2+}$ levels in Didinium and Paramecium during a Didinium attack on Paramecium, Protoplasma 200 (1997) 117-127.

[80] H. Plattner, R. Stürzl, H. Matt, Synchronous exocytosis in Paramecium cells. IV. Polyamino compounds as potent trigger agents for repeatable triggerredocking cycles, Eur. J. Cell Biol. 36 (1985) 32-37.

[81] A. Hamel, C. Fisch, L. Combettes, P. Dupuis-Williams, C.N. Baroud, Transition between three swimming gaits in Paramecium escape, Proc. Natl. Acad. Sci. U.S.A. 108 (2011) 7290-7295

[82] H. Machemer, A. Ogura, lonic conductances of membranes in ciliated and deciliated Paramecium, J. Physiol. 296 (1979) 49-60.

[83] A. Ogura, K. Takahashi, Artificial deciliation causes loss of calcium-dependent responses in Paramecium, Nature 264 (1976) 170-172.

[84] M.R. Husser, M. Hardt, M.-P. Blanchard, J. Hentschel, N. Klauke, H. Plattner One-way calcium spill-over during signal transduction in Paramecium cells: from the cell cortex into cilia, but not in the reverse direction, Cell Calciun 36 (2004) 349-358.

[85] D. Oertel, S.J. Schein, C. Kung, Separation of membrane currents using a Paramecium mutant, Nature 268 (1977) 120-124.

[86] Y. Satow, C. Kung, Ca-induced $\mathrm{K}^{+}$-outward current in Paramecium tetraurelia J. Exp. Biol. 88 (1980) 293-303.

[87] C. Erxleben, H. Plattner, $\mathrm{Ca}^{2+}$ release from subplasmalemmal stores as a primary event during exocytosis in Paramecium cells, J. Cell Biol. 127 (1994) 935-945.

[88] N. Haga, M. Forte, Y. Saimi, C. Kung, Microinjection of cytoplasm as a test of complementation in Paramecium, J. Cell Biol. 92 (1982) 559-564.

[89] A. Haddad, A.P. Turkewitz, Analysis of exocytosis mutants indicates close coupling between regulated secretion and transcription activation in Tetrahymena, Proc. Natl. Acad. Sci. U.S.A. 94 (1997) 10675-10680

[90] O.Arnaiz, L. Sperling, ParameciumDB in 2011: new tools and new data for functional and comparative genomics of the model ciliate Paramecium tetraurelia, Nucleic Acids Res. 39 (2011) D632-D636.

[91] R.R. Preston, Y. Saimi, C. Kung, Calcium current activated upon hyperpolar ization of Paramecium tetraurelia, J. Gen. Physiol. 100 (1992) 233-251.

[92] C. Kung, R.R. Preston, M.E. Maley, et al., In vivo Paramecium mutants show that calmodulin orchestrates membrane responses to stimuli, Cell Calcium 13 (1992) 413-425.

[93] Y. Saimi, C. Kung, Calmodulin as an ion channel subunit, Annu. Rev. Physiol. 64 (2002) 289-311.

[94] W.E. Bell, R.R. Preston, J. Yano, J.L. Van Houten, Genetic dissection of attractant-induced conductances in Paramecium, J. Exp. Biol. 210 (2007) 357-365.

[95] P. Brehm, R. Eckert, Calcium entry leads to inactivation of calcium channel in Paramecium, Science 202 (1978) 1203-1206.

[96] I.B. Levitan, It is calmodulin after all! Mediator of the calcium modulation of multiple ion channels, Neuron 22 (1999) 645-648.

[97] M. Iwamoto, R.D. Allen, Y. Naitoh, Hypo-osmotic or $\mathrm{Ca}^{2+}$-rich external conditions trigger extra contractile vacuole complex generation in Paramecium multimicronucleatum, J. Exp. Biol. 206 (2003) 4467-4473.

[98] S.T. Tsim, J.T. Wong, Y.H. Wong, Calcium ion dependency and the role of inositol phosphates in melatonin-induced encystment of dinoflagellates, J. Cell Sci. 110 (1997) 1387-1393.

[99] E.W. McArdle, B.L. Bergquist, C.F. Ehret, Structural changes in Tetrahy mena rostrata during induced encystment, J. Protozool. 27 (1980) 388-397.

[100] J.C. Gutierrez, E. Orias, Genetic characterization of Tetrahymena thermophila mutants unable to secrete capsules, Dev. Genet. 13 (1992) 160-166.

[101] T. Matsuoka, A. Kondoh, K. Sabashi, N. Nagano, T. Akematsu, A. Kida, R. lino, Role of $\mathrm{Ca}^{2+}$ and cAMP in a cell signaling pathway for resting cyst formation of ciliated protozoan Colpoda, cucculus, Protistology 6 (2009) 103-110.

[102] Y.Sogame, E. Kinoshita, T. Matsuoka, $\mathrm{Ca}^{2+}$-dependent in vivo protein phosphorylation and encystment induction in the ciliated protozoan Colpoda cucullus, Eur. J. Protistol. 47 (2011) 208-213.

[103] R. Lescasse, J. Grisvard, G. Fryd, A. Fleury-Aubusson, A. Baroin-Tourancheau, Proposed function of the accumulation of plasma membrane-type $\mathrm{Ca}^{2+}$ ATPase mRNA in resting cysts of the ciliate Sterkiella histriomuscorum Eukaryot. Cell 4 (2005) 103-110.

[104] A.M. Hofer, Another dimension to calcium signaling: a look at extracellular calcium, J. Cell Sci. 118 (2005) 855-862.
[105] Z. Xiong, W. Lu, J.F. MacDonald, Extracellular calcium sensed by a novel cation channel in hippocampal neurons, Proc. Natl. Acad. Sci. U.S.A. 94 (1997) $7012-7017$

[106] C. Erxleben, N. Klauke, M. Flötenmeyer, M.-P. Blanchard, C. Braun, H. Plattner, Microdomain $\mathrm{Ca}^{2+}$ activation during exocytosis in Paramecium cells. Superposition of local subplasmalemmal calcium store activation by local $\mathrm{Ca}^{2+}$ influx, J. Cell Biol. 136 (1997) 597-607.

[107] M.C. Vieira, S.N. Moreno, Mobilization of intracellular calcium upon attachment of Toxoplasma gondii tachyzoites to human fibroblasts is required for invasion, Mol. Biochem. Parasitol. 106 (2000) 157-162

[108] F.C. Koyama, D. Chakrabarti, C.R. Garcia, Molecular machinery of signal transduction and cell cycle regulation in Plasmodium, Mol. Biochem. Parasitol. 165 (2009) $1-7$

[109] M.L. Gazarini, A.P. Thomas, T. Pozzan, C.R. Garcia, Calcium signaling in a low calcium environment: how the intracellular malaria parasite solves the problem, J. Cell Biol. 161 (2003) 103-110.

[110] M. Wasserman, J. Chaparro, Intraerythrocytic calcium chelators inhibit the invasion of Plasmodium falciparum, Parasitol. Res. 82 (1996) 102-107.

[111] S.N. Moreno, R. Docampo, Calcium regulation in protozoan parasites, Curr. Opin. Microbiol. 6 (2003) 359-364.

[112] K. Nagamune, L. M. Hicks, B. Fux, F. Brossier, E.N. Chini, LD. Sibley, Abscisic acid controls calcium-dependent egress and development in Toxoplasma gondii, Nature 451 (2008) 207-210

[113] T. Endo, K.K. Sethi, G. Piekarski, Toxoplasma gondii: calcium ionophore A23187-mediated exit of trophozoites from infected murine macrophages, Exp. Parasitol. 53 (1982) 179-188.

[114] G. Arrizabalaga, F. Ruiz, S. Moreno, J.C. Boothroyd, lonophore-resistant mutant of Toxoplasma gondii reveals involvement of a sodium/hydrogen exchanger in calcium regulation, J. Cell Biol. 165 (2004) 653-662.

[115] R. Mondragon, E. Frixione, $\mathrm{Ca}^{2+}$-dependence of conoid extrusion in Toxoplasma gondii tachyzoites, J. Eukaryot. Microbiol. 43 (1996) 120-127.

[116] X.M. Chen, S.P. O'Hara, B.Q. Huang, et al., Apical organelle discharge by Cryptosporidium parvum is temperature, cytoskeleton, and intracellular calcium dependent and required for host cell invasion, Infect. Immun. 72 (2004) $6806-6816$.

[117] V.B. Carruthers, S.N. Moreno, L.D. Sibley, Ethanol and acetaldehyde elevate intracellular $\left[\mathrm{Ca}^{2+}\right]$ and stimulate microneme discharge in Toxoplasma gondii, Biochem. J. 342 (1999) 379-386

[118] J.L. Lovett, N. Marchesini, S.N. Moreno, L.D. Sibley, Toxoplasma gondii microneme secretion involves intracellular $\mathrm{Ca}^{2+}$ release from inositol 1,4,5triphosphate $\left(\mathrm{IP}_{3}\right) /$ ryanodine-sensitive stores, J. Biol. Chem. 277 (2002) 25870-25876.

[119] J.L. Lovett, L.D. Sibley, Intracellular calcium stores in Toxoplasma gondiigovern invasion of host cells, J. Cell Sci. 116 (2003) 3009-3016.

[120] S. Sato, The apicomplexan plastid and its evolution, Cell. Mol. Life Sci. 68 (2011) 1285-1296.

[121] M.S. Behnke, A. Khan, J.C. Wootton, J.P. Dubey, K. Tang L.D. Sibley, Virulence differences in Toxoplasma mediated by amplification of a family of polymorphic pseudokinases, Proc. Natl. Acad. Sci. U.S.A. 108 (2011) 9631-9636.

[122] K. Nagamune, L. Xiong, E. Chini, L.D. Sibley, Plants, endosymbionts and parasites: abscisic acid and calcium signaling, Commun. Integr. Biol. 1 (2008) 62-65.

[123] J. García-Sancho, A. Verkhratsky, Cytoplasmic organelles determine complexity and specificity of calcium signalling in adrenal chromaffin cells. Act Physiol. (Oxf.) 192 (2008) 263-271.

[124] F. Michelangeli, J.M. East, A diversity of SERCA Ca ${ }^{2+}$ pump inhibitors, Biochem. Soc. Trans. 39 (2011) 789-797.

[125] N. Stelly, J.P. Mauger, M. Claret, A. Adoutte, Cortical alveoli of Paramecium: a vast submembranous calcium storage compartment, J. Cell Biol. 113 (1991) $103-112$.

[126] S. Länge, N. Klauke, H. Plattner, Subplasmalemmal Ca ${ }^{2+}$ stores of probable relevance for exocytosis in Paramecium. Alveolar sacs share some but not all characteristics with sarcoplasmic reticulum, Cell Calcium 17 (1995) 335-344.

[127] M. Hardt, H. Plattner, Sub-second quenched-flow/X-ray microanalysis show rapid $\mathrm{Ca}^{2+}$ mobilization from cortical stores paralleled by $\mathrm{Ca}^{2+}$ influx during synchronous exocytosis in Paramecium cells, Eur. J. Cell Biol. 79 (2000) 642-652.

[128] G. Knoll, A. Grässle, C. Braun, W. Probst, B. Höhne-Zell, H. Plattner, A calcium influx is neither strictly associated with nor necessary for exocytotic membrane fusion in Paramecium cells, Cell Calcium 14 (1993) 173-183.

[129] G. Knoll, C. Braun, H. Plattner, Quenched flow analysis of exocytosis in Paramecium cells: time course, changes in membrane structure, and calcium requirements revealed after rapid mixing and rapid freezing of intact cells, J. Cell Biol. 113 (1991) 1295-1304.

[130] J.R. Coleman, J.R. Nilsson, R.R. Warner, P. Batt, Qualitative and quantitative electron probe analysis of cytoplasmic granules in Tetrahymena pyriformis, Exp. Cell Res. 74 (1972) 207-219.

[131] J.E. Grover, A.F. Rope, E.S. Kaneshiro, The occurrence of biogenic calcian struvite, $(\mathrm{Mg}, \mathrm{Ca}) \mathrm{NH}_{4} \mathrm{PO}_{4}, 6 \mathrm{H}(2) \mathrm{O}$, as intracellular crystals in Paramecium, J. Eukaryot. Microbiol. 44 (1997) 366-373.

[132] E.-M. Ladenburger, I. Korn, N. Kasielke, T. Wassmer, H. Plattner, An Ins $(1,4,5) \mathrm{P}_{3}$ receptor in Paramecium is associated with the osmoregulatory system, J. Cell Sci. 119 (2006) 3705-3717

[133] E.-M. Ladenburger, I.M. Sehring, I. Korn, H. Plattner, Novel types of $\mathrm{Ca}^{2+}$ release channels participate in the secretory cycle of Paramecium cells, Mol. Cell. Biol. 29 (2009) 3605-3622. 
[134] E.-M. Ladenburger, H. Plattner, Calcium-release channels in Paramecium. Genomic expansion, differential positioning and partial transcriptional elimination, PLoS One 6 (2011) e27111.

[135] R.D. Burgoyne, M.J. Clague, Calcium and calmodulin in membrane fusion, Biochim. Biophys. Acta 1641 (2003) 137-143.

[136] J.C. Hay, Calcium: a fundamental regulator of intracellular membrane fusion? EMBO Rep. 8 (2007) 236-240.

[137] D. Shen, X. Wang, H. Xu, Pairing phosphoinositides with calcium ions in endolysosomal dynamics: phosphoinositides control the direction and speci-
ficity of membrane trafficking by regulating the activity of calcium channels in the endolysosomes, Bioessays 33 (2011) 448-457.

[138] K. Nagamune, W.L. Beatty, L.D. Sibley, Artemisinin induces calciumdependent protein secretion in the protozoan parasite Toxoplasma gondii, Eukaryot. Cell 6 (2007) 2147-2156.

[139] T. Nagata, S. lizumi, K. Satoh, et al., Comparative analysis of plant and animal calcium signal transduction element using plant full-length cDNA data, Mol. Biol. Evol. 21 (2004) 1855-1870.

[140] K. Nagamune, L.D. Sibley, Comparative genomic and phylogenetic analyses of calcium ATPases and calcium-regulated proteins in the apicomplexa, Mol Biol. Evol. 23 (2006) 1613-1627.

[141] V.B. Carruthers, J.C. Boothroyd, Pulling together: an integrated model of Toxoplasma cell invasion, Curr. Opin. Microbiol. 10 (2007) 83-89.

[142] H.E. Bullen, C.J. Tonkin, R.A. O'Donnell, et al., A novel family of Apicomplexan glideosome-associated proteins with an inner membrane-anchoring role, J. Biol. Chem. 284 (2009) 25353-25363.

[143] A. Raibaud, P. Lupetti, R.E. Paul, et al., Cryofracture electron microscopy of the ookinete pellicle of Plasmodium gallinaceum reveals the existence of novel pores in the alveolar membranes, J. Struct. Biol. 135 (2001) 47-57.

[144] N.S. Morrissette, J.M. Murray, D.S. Roos, Subpellicular microtubules associate with an intramembranous particle lattice in the protozoan parasite Toxoplasma gondii, J. Cell Sci. 110 (1997) 35-42.

[145] H. Plattner, M. Flötenmeyer, R. Kissmehl, et al., Microdomain arrangement of the SERCA-type $\mathrm{Ca}^{2+}$ pump $\left(\mathrm{Ca}^{2+}\right.$-ATPase $)$ in subplasmalemmal calcium stores of Paramecium cells, J. Histochem. Cytochem. 47 (1999) 841-854.

[146] A. Bouchot, K. Zierold, A. Bonhomme, et al., Tachyzoite calcium changes during cell invasion by Toxoplasma gondii, Parasitol. Res. 85 (1999) 809-818.

[147] K.Zierold, Cryofixation methods for ion localization in cells by electron probe microanalysis: a review, J. Microsc. 161 (1991) 357-366.

[148] A. Bonhomme, L. Pingret, P. Bonhomme, et al., Subcellular calcium localization in Toxoplasma gondii by electron microscopy and by $\mathrm{X}$-ray and electron energy loss spectroscopies, Microsc. Res. Tech. 25 (1993) 276-285.

[149] E.J. de Melo, W. de Souza, A cytochemistry study of the inner membrane complex of the pellicle of tachyzoites of Toxoplasma gondii, Parasitol. Res. 83 (1997) 252-256

[150] K. Hauser, N. Pavlovic, R. Kissmehl, H. Plattner, Molecular characterization of a sarco(endo)plasmic reticulum $\mathrm{Ca}^{2+}$-ATPase gene from Paramecium tetraurelia and localization of its gene product to sub-plasmalemmal calcium stores, Biochem. J. 334 (1998) 31-38.

[151] K. Hauser, N. Pavlovic, N. Klauke, D. Geissinger, H. Plattner, Green fluorescent protein-tagged sarco(endo)plasmic reticulum $\mathrm{Ca}^{2+}-\mathrm{ATPase}$ overexpression in Paramecium cells: isoforms, subcellular localization, biogenesis of cortical calcium stores and functional aspects, Mol. Microbiol. 37 (2000) 773-787.

[152] H. Plattner, A. Habermann, R. Kissmehl, N. Klauke, I. Majoul, H.D. Söling, Differential distribution of calcium stores in Paramecium cells. Occurrence of a subplasmalemmal store with a calsequestrin-like protein, Eur. J. Cell Biol. 72 (1997) 297-306.

[153] C. Agop-Nersesian, B. Naissant, F. Ben Rached, et al., Rab11A-controlled assembly of the inner membrane complex is required for completion of apicomplexan cytokinesis, PLoS Pathog. 5 (2009) e 1000270

[154] C. Agop-Nersesian, S. Egarter, G. Langsley, B.J. Foth, D.J. Ferguson, M. Meissner, Biogenesis of the inner membrane complex is dependent on vesicula transport by the alveolate specific GTPase Rab11B, PLoS Pathog. 6 (2010) transport

[155] O. Ullrich, S. Reinsch, S. Urbe, M. Zerial, R.G. Parton, Rab11 regulates recycling through the pericentriolar recycling endosome, J. Cell Biol. 135 (1996) 913-924

[156] M. Zerial, H. McBride, Rab proteins as membrane organizers, Nat. Rev. Mol. Cell Biol. 2 (2001) 107-117.

[157] R. Kissmehl, M. Froissard, H. Plattner, M. Momayezi, J. Cohen, NSF regulates membrane traffic along multiple pathways in Paramecium, J. Cell Sci. 115 (2002) 3935-3946.

[158] L.C. Soares Medeiros, F. Gomes, L.R. Maciel, et al., Volutin granules of Eimeria parasites are acidic compartments and have physiological and structura characteristics similar to acidocalcisomes, J. Eukaryot. Microbiol. 58 (2011) $416-423$.

[159] H. Rosenberg, The isolation and identification of "volutin" granules from Tetrahymena, Exp. Cell Res. 41 (1966) 397-410.

[160] J.R. Perez-Castineira, J. Alvar, L.M. Ruiz-Perez, A. Serrano, Evidence for a wide occurrence of proton-translocating pyrophosphatase genes in parasitic and free-living protozoa, Biochem. Biophys. Res. Commun. 294 (2002) 567-573.

[161] K. Miranda, W. de Souza, H. Plattner, et al., Acidocalcisomes in Apicomplexan parasites, Exp. Parasitol. 118 (2008) 2-9.

[162] S. Luo, M. Vieira, J. Graves, L. Zhong, S.N. Moreno, A plasma membrane-type $\mathrm{Ca}^{2+}$-ATPase co-localizes with a vacuolar $\mathrm{H}^{+}$-pyrophosphatase to acidocalcisomes of Toxoplasma gondii, EMBO J. 20 (2001) 55-64.

[163] J.K. Pittman, Vacuolar $\mathrm{Ca}^{2+}$ uptake, Cell Calcium 50 (2011) 139-146.
[164] P. Rohloff, K. Miranda, K. Rodrigues, et al., Calcium uptake and proton transport by acidocalcisomes of Toxoplasma gondii, PLoS One 6 (2011) e18390.

[165] X. Yu, S. Carroll, J.L. Rigaud, G. Inesi, $\mathrm{H}^{+}$countertransport and electrogenicity of the sarcoplasmic reticulum $\mathrm{Ca}^{2+}$ pump in reconstituted proteoliposomes Biophys. J. 64 (1993) 1232-1242.

[166] A. Fibich, K. Janko, H.-J. Apell, Kinetics of proton binding to the sarcoplasmic reticulum Ca-ATPase in the E1 state, Biophys. J. 93 (2007) 3092-3104.

[167] M. Kimura, Y. Yamaguchi, S. Takada, K. Tanabe, Cloning of a $\mathrm{Ca}^{2+}-\mathrm{ATPase}$ gene of Plasmodium falciparum and comparison with vertebrate $\mathrm{Ca}^{2+}$-ATPases, J. Cell Sci. 104 (1993) 1129-1136.

[168] F.P. Varotti, F.H. Beraldo, M.L. Gazarini, C.R. Garcia, Plasmodium falciparum malaria parasites display a THG-sensitive $\mathrm{Ca}^{2+}$ pool, Cell Calcium 33 (2003) 137-144.

[169] R. Kissmehl, S. Huber, B. Kottwitz, K. Hauser, H. Plattner, Subplasmalemmal Ca-stores in Paramecium tetraurelia. Identification and characterisation of a sarco(endo)plasmic reticulum-like $\mathrm{Ca}^{2+}$-ATPase by phosphoenzyme intermediate formation and its inhibition by caffeine, Cell Calcium 24 (1998) 193-203.

[170] M.V. Wright, J. Van Houten, $\mathrm{Ca}^{2+}$ transport and chemoreception in Paramecium, J. Comp. Physiol. B 163 (1993) 288-296.

[171] M.V. Wright, N. Elwess, J. Van Houten, $\mathrm{Ca}^{2+}$ transport and chemoreception in Paramecium, J. Comp. Physiol. B 163 (1993) 288-296.

[172] S. Patel, J.S. Marchant, E. Brailoiu, Two-pore channels: regulation by NAADP and customized roles in triggering calcium signals, Cell Calcium 47 (2010) 480-490.

[173] I.B. Ramos, K. Miranda, D.A. Pace, et al., Calcium- and polyphosphatecontaining acidic granules of sea urchin eggs are similar to acidocalcisomes, but are not the targets for NAADP, Biochem. J. 429 (2010) 485-495.

[174] S. Patel, S. Muallem, Acidic $\mathrm{Ca}^{2+}$ stores come to the fore, Cell Calcium 50 (2011) 109-112.

[175] P. Rohloff, R. Docampo, A contractile vacuole complex is involved in osmoregulation in Trypanosoma cruzi, Exp. Parasitol. 118 (2008) 17-24.

[176] R. Docampo, S.N. Moreno, Acidocalcisome: a novel Ca ${ }^{2+}$ storage compartment in trypanosomatids and apicomplexan parasites, Parasitol. Today 15 (1999) 443-448.

[177] C.R. Garcia, Calcium homeostasis and signaling in the blood-stage malaria parasite, Parasitol. Today 15 (1999) 488-491.

[178] K. Miranda, D.A. Pace, R. Cintron, et al., Characterization of a novel organelle in Toxoplasma gondii with similar composition and function to the plant vacuole Mol. Microbiol. 76 (2010) 1358-1375.

[179] P. Rohloff, K. Miranda, J.C. Rodrigues, et al., Calcium uptake and proton transport by acidocalcisomes of Toxoplasma gondii, PLoS One 6 (2011) e18390.

[180] S.N. Moreno, R. Docampo, The role of acidocalcisomes in parasitic protists, J. Eukaryot. Microbiol. 56 (2009) 208-213.

[181] D. Kerboeuf, J. Cohen, $\mathrm{A} \mathrm{Ca}^{2+}$ influx associated with exocytosis is specifically abolished in a Paramecium exocytotic mutant, J. Cell Biol. 111 (1990) 2527-2535.

[182] H. Plattner, J. Hentschel, Sub-second cellular dynamics: time-resolved electron microscopy and functional correlation, Int. Rev. Cytol. 255 (2006) 133-176.

[183] H. Plattner, C. Braun, J. Hentschel, Facilitation of membrane fusion during exocytosis and exocytosis-coupled endocytosis and acceleration of "ghost" detachment in Paramecium by extracellular calcium. A quenchedflow/freeze-fracture analysis, J. Membr. Biol. 158 (1997) 197-208.

[184] M. Hardt, H. Plattner, Quantitative energy-dispersive X-ray microanalysis of calcium dynamics in cell suspensions during stimulation on a subsecond time scale: preparative and analytical aspects as exemplified with Paramecium cells, J. Struct. Biol. 128 (1999) 187-199.

[185] N. Klauke, M.-P. Blanchard, H. Plattner, Polyamine triggering of exocytosis in Paramecium involves an extracellular $\mathrm{Ca}^{2+} /$ (polyvalent cation)-sensing receptor, subplasmalemmal Ca-store mobilization and store-operated $\mathrm{Ca}^{2+}$-influx via unspecific cation channels, J. Membr. Biol. 174 (2000) 141-156

[186] I. Mohamed, N. Klauke, J. Hentschel, J. Cohen, H. Plattner, Functional and fluorochrome analysis of an exocytotic mutant yields evidence of store-operated $\mathrm{Ca}^{2+}$ influx in Paramecium, J. Membr. Biol. 187 (2002) 1-14.

[187] B. Narayanan, M.N. Islam, D. Bartelt, R.S. Ochs, A direct mass-action mechanism explains capacitative calcium entry in Jurkat and skeletal L6 muscle cells, J. Biol. Chem. 278 (2003) 44188-44196.

[188] G. Lavieu, L. Orci, L. Shi, et al., Induction of cortical endoplasmic reticulum by dimerization of a coatomer-binding peptide anchored to endoplasmic reticulum membranes, Proc. Natl. Acad. Sci. U.S.A. 107 (2010) 6876-6881.

[189] C.J. Stefan, A.G. Manford, D. Baird, J. Yamada-Hanff, Y. Mao, S.D. Emr, Osh proteins regulate phosphoinositide metabolism at ER-plasma membrane contact sites, Cell 144 (2011) 389-401.

[190] S. Treves, M. Vukcevic, J. Griesser, C.F. Armstrong, M.X. Zhu, F. Zorzato, Agonist-activated $\mathrm{Ca}^{2+}$ influx occurs at stable plasma membrane and endoplasmic reticulum junctions, J. Cell Sci. 123 (2010) 4170-4181.

[191] T. Wassmer, I.M. Sehring, R. Kissmehl, H. Plattner, The V-ATPase in Paramecium: functional specialization by multiple gene isoforms, Pflugers Arch. Eur. J. Physiol. 457 (2009) 599-607.

[192] A.K. Fok, M.S. Aihara, M. Ishida, K.V. Nolta, T.L. Steck, R.D. Allen, The pegs on the decorated tubules of the contractile vacuole complex of Paramecium are proton pumps, J. Cell Sci. 108 (1995) 3163-3170.

[193] T. Wassmer, M. Froissard, H. Plattner, R. Kissmehl, J. Cohen, The vacuolar proton-ATPase plays a major role in several membrane-bounded organelles in Paramecium, J. Cell Sci. 118 (2005) 2813-2825. 
[194] T. Wassmer, R. Kissmehl, J. Cohen, H. Plattner, Seventeen a-subunit isoforms of Paramecium V-ATPase provide high specialization in localization and function, Mol. Biol. Cell 17 (2006) 917-930.

[195] C.Stock, H.K. Gr $\theta$ nlien, R.D. Allen, The ionic composition of the contractile vacuole fluid of Paramecium mirrors ion transport across the plasma membrane, Eur. J. Cell Biol. 81 (2002) 505-515.

[196] J.L. Browning, D.L. Nelson, Biochemical studies of the excitable membrane of Paramecium aurelia. I. ${ }^{45} \mathrm{Ca}^{2+}$ fluxes across resting and excited membrane, Biochim. Biophys. Acta 448 (1976) 338-351.

[197] A.F. Cowman, B.S. Crabb, Invasion of red blood cells by malaria parasites, Cell 124 (2006) 755-766

[198] V.B. Carruthers, L.D. Sibley, Sequential protein secretion from three distinct organelles of Toxoplasma gondii accompanies invasion of human fibroblasts, Eur. J. Cell Biol. 73 (1997) 114-123.

[199] V.G. Monteiro, E.J. de Melo, M. Attias, W. de Souza, Morphological changes during conoid extrusion in Toxoplasma gondii tachyzoites treated with calcium ionophore, J. Struct. Biol. 136 (2001) 181-189.

[200] E. Lycke, K. Carlberg, R. Norrby, Interactions between Toxoplasma gondii and its host cells: function of the penetration-enhancing factor of toxoplasma, Infect. Immun. 11 (1975) 853-861.

[201] N. Pezzella, A. Bouchot, A. Bonhomme, et al., Involvement of calcium and calmodulin in Toxoplasma gondii tachyzoite invasion, Eur.J.Cell Biol. 74(1997) 92-101.

[202] K.A. Joiner, D.S. Roos, Secretory traffic in the eukaryotic parasite Toxoplasma gondii: less is more, J. Cell Biol. 157 (2002) 557-563.

[203] M. Wasserman, The role of calcium ions in the invasion of Plasmodium falciparum, Blood Cells 16 (1990) 450-451.

[204] N. McCallum-Deighton, A.A. Holder, The role of calcium in the invasion of human erythrocytes by Plasmodium falciparum, Mol. Biochem. Parasitol. 50 (1992) 317-323

[205] F.H. Beraldo, K. Mikoshiba, C.R. Garcia, Human malarial parasite, Plasmodium falciparum, displays capacitative calcium entry: 2-aminoethyl diphenylborinate blocks the signal transduction pathway of melatonin action on the $P$. falciparum cell cycle, J. Pineal Res. 43 (2007) 360-364.

[206] K.L. Carey, N.J. Westwood, T.J. Mitchison, G.E. Ward, A small-molecule approach to studying invasive mechanisms of Toxoplasma gondii, Proc. Natl. Acad. Sci. U.S.A. 101 (2004) 7433-7438.

[207] E.N. Chini, K. Nagamune, D.M. Wetzel, L.D. Sibley, Evidence that the cADPR signalling pathway controls calcium-mediated microneme secretion in Toxoplasma gondii, Biochem. J. 389 (2005) 269-277.

[208] M.L. Jones, C. Cottingham, J.C. Rayner, Effects of calcium signaling on Plasmodium falciparum erythrocyte invasion and post-translational modification of gliding-associated protein 45 (PfGAP45), Mol. Biochem. Parasitol. 168(2009) $55-62$.

[209] S.N. Moreno, L. Zhong, Acidocalcisomes in Toxoplasma gondii tachyzoites Biochem. J. 313 (1996) 655-659.

[210] G.A. Biagini, P.G. Bray, D.G. Spiller, M.R. White, S.A. Ward, The digestive food vacuole of the malaria parasite is a dynamic intracellular $\mathrm{Ca}^{2+}$ store, J. Biol Chem. 278 (2003) 27910-27915.

[211] P. Rohrbach, O. Friedrich, J. Hentschel, H. Plattner, R.H. Fink, M. Lanzer Quantitative calcium measurements in subcellular compartments of Plasmodium falciparum-infected erythrocytes, J. Biol. Chem. 280 (2005) 27960-27969.

[212] K. Nagamune, S.N. Moreno, E.N. Chini, L.D. Sibley, Calcium regulation and signaling in apicomplexan parasites, Subcell. Biochem. 47 (2008) 70-81.

[213] C. Peters, A. Mayer, $\mathrm{Ca}^{2+} /$ calmodulin signals the completion of docking and triggers a late step of vacuole fusion, Nature 396 (1998) 575-580.

[214] M. Momayezi, H. Kersken, U. Gras, J. Vilmart-Seuwen, H. Plattner, Calmodulin in Paramecium tetraurelia: localization from the in vivo to the ultrastructura level, J. Histochem. Cytochem. 34 (1986) 1621-1638.

[215] A.K. Fok, M.S. Aihara, M. Ishida, R.D. Allen, Calmodulin localization and its effects on endocytic and phagocytic membrane trafficking in Paramecium multimicronucleatum, J. Eukaryot. Microbiol. 55 (2008) 481-491.

[216] K. Gonda, M. Komatsu, O. Numata, Calmodulin and $\mathrm{Ca}^{2+} /$ calmodulin-binding proteins are involved in Tetrahymena thermophila phagocytosis, Cell Struct. Funct. 25 (2000) 243-251

217] R.M. Case, D. Eisner, A. Gurney, O. Jones, S. Muallem, A. Verkhratsky, Evolution of calcium homeostasis: from birth of the first cell to an omnipresent signalling system, Cell Calcium 42 (2007) 345-350.

[218] M.R. McAinsh, J.K. Pittman, Shaping the calcium signature, New Phytol. 181 (2009) 275-294

[219] C.P. Ponting, Novel repeats in ryanodine and $\mathrm{IP}_{3}$ receptors and protein Omannosyltransferases, Trends Biochem. Sci. 25 (2000) 48-50.

[220] C.W. Taylor, P.C. da Fonseca, E.P. Morris, $\mathrm{IP}_{3}$ receptors: the search for structure, Trends Biochem. Sci. 29 (2004) 210-219.

[221] J.K. Foskett, C. White, K.H. Cheung, D.O. Mak, Inositol trisphosphate receptor $\mathrm{Ca}^{2+}$ release channels, Physiol. Rev. 87 (2007) 593-658

222] S. Fleischer, Personal recollections on the discovery of the ryanodine receptors of muscle, Biochem. Biophys. Res. Commun. 369 (2008) 195-207.

[223] C.W. Taylor, D. Traynor, Calcium and inositol trisphosphate receptors, J. Membr. Biol. 145 (1995) 109-118.

[224] A.J. Williams, D.J. West, R. Sitsapesan, Light at the end of the $\mathrm{Ca}^{2+}$-release channel tunnel: structures and mechanisms involved in ion translocation in ryanodine receptor channels, Q. Rev. Biophys. 34 (2001) 61-104.

225] C.W. Taylor, D.L. Prole, T. Rahman, $\mathrm{Ca}^{2+}$ channels on the move, Biochemistry 48 (2009) 12062-12080.
[226] S. Kang, H. Kwon, H. Wen, et al., Global dynamic conformational changes in the suppressor domain of $\mathrm{IP}_{3}$ receptor by stepwise binding of the two lobes of calmodulin, FASEB J. 25 (2011) 840-850.

[227] J. Sawynok, T.L. Yaksh, Caffeine as an analgesic adjuvant: a review of pharmacology and mechanisms of action, Pharmacol. Rev. 45 (1993) 43-85.

[228] M. Wehner, H. Rueffert, F. Koenig, C.D. Meinecke, D. Olthoff, The lle2453Thr mutation in the ryanodine receptor gene 1 is associated with facilitated calcium release from sarcoplasmic reticulum by 4 -chloro-m-cresol in human myotubes, Cell Calcium 34 (2003) 163-168.

[229] H.C. Lee, Multiplicity of $\mathrm{Ca}^{2+}$ messengers and $\mathrm{Ca}^{2+}$ stores: a perspective from cyclic ADP-ribose and NAADP, Curr. Mol. Med. 4 (2004) 227-237.

[230] J.D. Fessenden, W. Feng, I.N. Pessah, P.D. Allen, Amino acid residues Gln 4020 and Lys 4021 of the ryanodine receptor type 1 are required for activation by 4-chloro-m-cresol, J. Biol. Chem. 281 (2006) 21022-21031.

[231] F Yoshikawa, M. Morita, T. Monkawa, T. Michikawa, T. Furuichi, K Mikoshiba, Mutational analysis of the ligand binding site of the inositol 1,4,5trisphosphate receptor, J. Biol. Chem. 271 (1996) 18277-18284.

[232] M. Zhao, P. Li, X. Li, L. Zhang, R.J. Winkfein, S.R. Chen, Molecular identification of the ryanodine receptor pore-forming segment, J. Biol. Chem. 274 (1999) 25971-25974.

[233] D.I. Yule, M.J. Betzenhauser, S.K. Joseph, Linking structure to function: recent lessons from inositol 1,4,5-trisphosphate receptor mutagenesis, Cell Calcium 47 (2010) 469-479.

[234] J.M. Aury, O. Jaillon, L. Duret, et al., Global trends of whole-genome duplications revealed by the ciliate Paramecium tetraurelia, Nature 444 (2006) $171-178$.

[235] Y. Van de Peer, S. Maere, A. Meyer, The evolutionary significance of ancient genome duplications, Nat. Rev. Genet. 10 (2009) 725-732.

[236] O. Jaillon, K. Bouhouche, J.F. Gout, et al., Translational control of intron splicing in eukaryotes, Nature 451 (2008) 359-362.

[237] C. Cárdenas, R.A. Miller, I. Smith, et al., Essential regulation of cell bioenergetics by constitutive $\mathrm{InsP}_{3}$ receptor $\mathrm{Ca}^{2+}$ transfer to mitochondria, Cell 142 (2010) 270-283.

[238] G. Leondaritis, T. Sarri, I. Dafnis, A. Efstathiou, D. Galanopoulou, Biochemical and genetic evidence for the presence of multiple phosphatidylinositol- and phosphatidylinositol 4,5-bisphosphate-specific phospholipases C in Tetrahymena, Eukaryot. Cell 10 (2011) 412-422.

[239] I.M. Lindmark, A. Karlsson, L. Serrander, et al., Synaptotagmin II could confer $\mathrm{Ca}^{2+}$ sensitivity to phagocytosis in human neutrophils, Biochim. Biophys. Acta 1590 (2002) 159-166.

[240] A.F. Vinet, M. Fukuda, A. Descoteaux, The exocytosis regulator synaptotagmin $V$ controls phagocytosis in macrophages, J. Immunol 181 (2008) 5289-5295.

[241] C. Czibener, N.M. Sherer, S.M. Becker, et al., $\mathrm{Ca}^{2+}$ and synaptotagmin VIIdependent delivery of lysosomal membrane to nascent phagosomes, J. Cell Biol. 174 (2006) 997-1007.

[242] X.L. Zhou, C.W. Chan, Y. Saimi, C. Kung, Functional reconstitution of ion channels from Paramecium cortex into artificial liposomes, J. Membr. Biol. 144 (1995) 199-208

[243] A.J. Williams, Ion conduction and selectivity in the ryanodine receptor channel, Front. Biosci. 7 (2002) d1223-d1230

[244] D. Gillespie, M. Fill, Intracellular calcium release channels mediate their own countercurrent: the ryanodine receptor case study, Biophys. J. 95 (2008) 3706-3714.

[245] J. Frankel, Cell biology of Tetrahymena thermophila, Methods Cell Biol. 62 (2000) 27-125.

[246] E. Zweifel, J. Smith, D. Romero, et al., Nested genes CDA12 and CDA13 encode proteins associated with membrane trafficking in the ciliate Tetrahymen thermophila, Eukaryot. Cell 8 (2009) 899-912.

[247] A. Spang, On vesicle formation and tethering in the ER-Golgi shuttle, Curr. Opin. Cell Biol. 21 (2009) 531-536.

[248] I.A. Sparkes, T. Ketelaar, N.C. de Ruijter, C. Hawes, Grab a Golgi: laser trapping of Golgi bodies reveals in vivo interactions with the endoplasmic reticulum, Traffic 10 (2009) 567-571.

[249] F.J. Aulestia, P.C. Redondo, A. Rodriguez-Garcia, et al., Two distinct calcium pools in the endoplasmic reticulum of HEK-293T cells, Biochem. J. 435(2011) 227-235.

[250] N. Solovyova, A. Verkhratsky, Neuronal endoplasmic reticulum acts as a single functional $\mathrm{Ca}^{2+}$ store shared by ryanodine and inositol-1,4,5-trisphosphate receptors as revealed by intra-ER $\left[\mathrm{Ca}^{2+}\right]$ recordings in single rat sensory neurones, Pflugers Arch. - Eur. J. Physiol. 446 (2003) 447-454.

[251] J.G. McCarron, M.L. Olson, A single luminally continuous sarcoplasmic retic ulum with apparently separate $\mathrm{Ca}^{2+}$ stores in smooth muscle, J. Biol. Chem. 283 (2008) 7206-7218.

[252] M. Hattori, A.Z. Suzuki, T Higo, et al, Distinct roles of inositol 1,4,5trisphosphate receptor types 1 and 3 in $\mathrm{Ca}^{2+}$ signaling, J. Biol. Chem. 279 (2004) 11967-11975.

[253] A. Muto, S. Kume, T. Inoue, H. Okano, K. Mikoshiba, Calcium waves along the cleavage furrows in cleavage-stage Xenopus embryos and its inhibition by heparin, J. Cell Biol. 135 (1996) 181-190.

[254] O. Dellis, S.G. Dedos, S.C. Tovey, T.-U. Rahman, S.J. Dubel, C.W. Taylor, $\mathrm{Ca}^{2+}$ entry through plasma membrane $I_{3}$ receptors, Science 313 (2006) 229-233.

[255] G. Loirand, P. Pacaud, A. Baron, C. Mironneau, J. Mironneau, Large conduc tance calcium-activated non-selective cation channel in smooth muscle cells isolated from rat portal vein, J. Physiol. 437 (1991) 461-475.

[256] M.D. Bootman, C. Fearnley, I. Smyrnias, F. MacDonald, H.L. Roderick, An update on nuclear calcium signalling, J. Cell Sci. 122 (2009) 2337-2350. 
[257] J. Bak, R.A. Billington, G. Timar, A.C. Dutton, A.A. Genazzani, NAADP receptors are present and functional in the heart, Curr. Biol. 11 (2001) 987-990.

[258] A.P. Passos, C.R. Garcia, Inositol 1,4,5-trisphosphate induced $\mathrm{Ca}^{2+}$ release from chloroquine-sensitive and -insensitive intracellular stores in the intraerythrocytic stage of the malaria parasite $P$. chabaudi, Biochem. Biophys. Res Commun. 245 (1998) 155-160.

259] E. Alves, P.J. Bartlett, C.R. Garcia, A.P. Thomas, Melatonin and $\mathrm{IP}_{3}$-induced $\mathrm{Ca}^{2+}$ release from intracellular stores in the malaria parasite Plasmodium falciparum within infected red blood cells. J. Biol. Chem. 286 (2011) 5905-5912.

[260] D. Traynor, J.L. Milne, R.H. Insall, R.R. Kay, $\mathrm{Ca}^{2+}$ signalling is not required for chemotaxis in Dictyostelium, EMBO J. 19 (2000) 4846-4854.

[261] J.G. Williams, A.A. Noegel, L. Eichinger, Manifestations of multicellularity: Dictyostelium reports in, Trends Genet. 21 (2005) 392-398

[262] F. Verret, G. Wheeler, A.R. Taylor, G. Farnham, C. Brownlee, Calcium channels in photosynthetic eukaryotes: implications for evolution of calcium-based signalling, New Phytol. 187 (2010) 23-43.

[263] T. Imaizumi, S.A. Kay, J.I. Schroeder, Circadian rhythms. Daily watch on metabolism, Science 318 (2007) 1730-1731.

[264] J.M. Ward, P. Maser, J.I. Schroeder, Plant ion channels: gene families, physiology, and functional genomics analyses, Annu. Rev. Physiol. 71 (2009) 59-82.

[265] M.X. Zhu, J. Ma, J. Parrington, P.J. Calcraft, A. Galione, A.M. Evans, Calcium signaling via two-pore channels: local or global, that is the question, Am. J. Physiol. Cell Physiol. 298 (2010) C430-C441.

[266] T. Michikawa, H. Hamanaka, H. Otsu, et al., Transmembrane topology and sites of $\mathrm{N}$-glycosylation of inositol 1,4,5-trisphosphate receptor, J. Biol. Chem. 269 (1994) 9184-9189.

[267] A.A. Genazzani, A. Galione, $\mathrm{A} \mathrm{Ca}^{2+}$ release mechanism gated by the novel pyridine nucleotide, NAADP, Trends Pharmacol. Sci. 18 (1997) 108-110.

[268] O.A. Ogunbayo, Y. Zhu, D. Rossi, et al., Cyclic adenosine diphosphate ribose activates ryanodine receptors, whereas NAADP activates two-pore domain channels, J. Biol. Chem. 286 (2011) 9136-9140

[269] S.J. Pitt, T.M. Funnell, M. Sitsapesan, et al., TPC2 is a novel NAADP-sensitive $\mathrm{Ca}^{2+}$ release channel, operating as a dual sensor of luminal $\mathrm{pH}$ and $\mathrm{Ca}^{2+}, \mathrm{J}$. Biol Chem. 285 (2010) 35039-35046

[270] E. Lloyd-Evans, H. Waller-Evans, K. Peterneva, F.M. Platt, Endolysosomal calcium regulation and disease, Biochem. Soc. Trans. 38 (2010) 1458-1464.

[271] C.C. Scott, J. Gruenberg, lon flux and the function of endosomes and lysosomes: $\mathrm{pH}$ is just the start. The flux of ions across endosomal membranes influences endosome function not only through regulation of the luminal $\mathrm{pH}$, Bioessays 33 (2011) 103-110.

[272] J.P. Luzio, S.R. Gray, N.A. Bright, Endosome-lysosome fusion, Biochem. Soc Trans. 38 (2010) 1413-1416.

[273] M.X. Zhu, J. Ma, J. Parrington, A. Galione, A.M. Evans, TPCs: endolysosomal channels for $\mathrm{Ca}^{2+}$ mobilization from acidic organelles triggered by NAADP, FEBS Lett. 584 (2010) 1966-1974.

[274] M.W. Sherwood, I.A. Prior, S.G. Voronina, et al., Activation of trypsinogen in large endocytic vacuoles of pancreatic acinar cells, Proc. Natl. Acad. Sci. U.S.A. 104 (2007) 5674-5679.

[275] E. Peiter, F.J. Maathuis, L.N. Mills, et al., The vacuolar $\mathrm{Ca}^{2+}$-activated channel TPC1 regulates germination and stomatal movement, Nature 434 (2005) 404-408.

[276] K.A. Christensen, J.T. Myers, J.A. Swanson, pH-dependent regulation of lysosomal calcium in macrophages, J. Cell Sci. 115 (2002) 599-607.

[277] M. Schieder, K. Rotzer, A. Bruggemann, M. Biel, C.A. Wahl-Schott, Characterization of two-pore channel 2 (TPCN2)-mediated $\mathrm{Ca}^{2+}$ currents in isolated lysosomes, J. Biol. Chem. 285 (2010) 21219-21222

[278] M.E. Jaconi, D.P. Lew, J.L. Carpentier, K.E. Magnusson, M. Sjogren, O. Stendahl, Cytosolic free calcium elevation mediates the phagosome-lysosome fusion during phagocytosis in human neutrophils, J. Cell Biol. 110(1990) 1555-1564

[279] C.J. Lumpert, H. Kersken, H. Plattner, Cell surface complexes ('cortices') isolated from Paramecium tetraurelia cells as a model system for analysing exocytosis in vitro in conjunction with microinjection studies, Biochem. J. 269 (1990) 639-645.

[280] G.D. Dickinson, S. Patel, Modulation of NAADP (nicotinic acid-adenine dinucleotide phosphate) receptors by $\mathrm{K}^{+}$ions: evidence for multiple NAADP receptor conformations, Biochem. J. 375 (2003) 805-812.

[281] F.A. Ruiz, S. Luo, S.N. Moreno, R. Docampo, Polyphosphate content and fine structure of acidocalcisomes of Plasmodium falciparum, Microsc. Microanal. 10 (2004) 563-567.

[282] N. Marchesini, F.A. Ruiz, M. Vieira, R. Docampo, Acidocalcisomes are functionally linked to the contractile vacuole of Dictyostelium discoideum, J. Biol Chem. 277 (2002) 8146-8153.

[283] I. Ivanovska, M.D. Rose, Fine structure analysis of the yeast centrin, Cdc31p identifies residues specific for cell morphology and spindle pole body duplication, Genetics 157 (2001) 503-518.

[284] W.Y. Cheung (Ed.), Calcium and Cell Function, vol. 1, Calmodulin, Acad. Press, New York, London, Toronto, Sydney, San Francisco, 1980.

[285] C.B. Klee, T.H. Crouch, P.G. Richman, Calmodulin, Annu. Rev. Biochem. 49 (1980) 489-515.

[286] G.C. Faas, S. Raghavachari, J.E. Lisman, I. Mody, Calmodulin as a direct detector of $\mathrm{Ca}^{2+}$ signals, Nat. Neurosci. 14 (2011) 301-304.

[287] E. Schiebel, M. Bornens, In search of a function for centrins, Trends Cell Biol 5 (1995) 197-201.

[288] D.H. Jung, S.H. Mo, D.H. Kim, Calumenin, a multiple EF-hands $\mathrm{Ca}^{2+}$-binding protein, interacts with ryanodine receptor-1 in rabbit skeletal sarcoplasmic reticulum, Biochem. Biophys. Res. Commun. 343 (2006) 34-42.
[289] D. Chin, A.R. Means, Calmodulin: a prototypical calcium sensor, Trends Cell Biol. 10 (2000) 322-328.

[290] I.M. Sehring, C. Klotz, J. Beisson, H. Plattner, Rapid downregulation of the Ca2+signal after exocytosis stimulation in Paramecium cells: essential role of a centrin-rich filamentous cortical network, the infraciliary lattice, Cell Calcium 45 (2009) 89-97.

[291] D. Guerini, J. Krebs, E. Carafoli, Stimulation of the purified erythrocyte $\mathrm{Ca}^{2+}$-ATPase by tryptic fragments of calmodulin, J. Biol. Chem. 259 (1984) $15172-15177$.

[292] Y. Suzuki, K. Ohnishi, T. Hirabayashi, Y. Watanabe, Tetrahymena calmodulin. Characterization of an anti-Tetrahymena calmodulin and the immunofluorescent localization in Tetrahymena, Exp. Cell Res. 137 (1982) 1-14.

[293] N.J. Maihle, J.R. Dedman, A.R. Means, J.G. Chafouleas, B.H. Satir, Presence and indirect immunofluorescent localization of calmodulin in Paramecium tetraurelia, J. Cell Biol. 89 (1981) 695-699.

[294] D. Kerboeuf, A. Le Berre, J.C. Dedieu, J. Cohen, Calmodulin is essential for assembling links necessary for exocytotic membrane fusion in Paramecium EMBO J. 12 (1993) 3385-3390.

[295] S. Quetglas, C. Iborra, N. Sasakawa, et al., Calmodulin and lipid binding to synaptobrevin regulates calcium-dependent exocytosis, EMBO J. 21 (2002) 3970-3979.

[296] K. Dimova, S. Kalkhof, I. Pottratz, et al, Structural insights into the calmodulinMunc13 interaction obtained by cross-linking and mass spectrometry, Biochemistry 48 (2009) 5908-5921.

[297] Y. Hagalili, N. Bachnoff, D. Atlas, The voltage-gated $\mathrm{Ca}^{2+}$ channel is the $\mathrm{Ca}^{2+}$ sensor protein of secretion, Biochemistry 47 (2008) 13822-13830.

[298] H.J. Junge, J.S. Rhee, O. Jahn, et al., Calmodulin and Munc13 form a $\mathrm{Ca}^{2+}$ sensor/effector complex that controls short-term synaptic plasticity. Cell 118 (2004) 389-401

[299] L. de Haro, G. Ferracci, S. Opi, et al., $\mathrm{Ca}^{2+} /$ calmodulin transfers the membraneproximal lipid-binding domain of the v-SNARE synaptobrevin from cis to trans bilayers, Proc. Natl. Acad. Sci. U.S.A. 101 (2004) 1578-1583

[300] X.S. Wu, B.D. McNeil, J. Xu, et al., $\mathrm{Ca}^{2+}$ and calmodulin initiate all forms of endocytosis during depolarization at a nerve terminal, Nat. Neurosci. 12 (2009) $1003-1010$.

[301] R.A. Nichols, G.R. Suplick, J.M. Brown, Calcineurin-mediated protein dephosphorylation in brain nerve terminals regulates the release of glutamate, J. Biol. Chem. 269 (1994) 23817-23823.

[302] M. Momayezi, R. Kissmehl, H. Plattner, Quantitative immunogold localization of protein phosphatase 2B (calcineurin) in Paramecium cells, J. Histochem. Cytochem. 48 (2000) 1269-1281.

[303] P. Thomas, A. Surprenant, W. Almers, Cytosolic $\mathrm{Ca}^{2+}$, exocytosis, and endocytosis in single melanotrophs of the rat pituitary, Neuron 5(1990) 723-733.

[304] C.R. Artalejo, J.R. Henley, M.A. McNiven, H.C. Palfrey, Rapid endocytosis coupled to exocytosis in adrenal chromaffin cells involves $\mathrm{Ca}^{2+}, G T P$, and dynamin but not clathrin, Proc. Natl. Acad. Sci. U.S.A. 92 (1995) 8328-8332.

[305] V. Haucke, E. Neher, S.J. Sigrist, Protein scaffolds in the coupling of synaptic exocytosis and endocytosis, Nat. Rev. Neurosci. 12 (2011) 127-138.

[306] T.C. Evans, D.L. Nelson, The cilia of Paramecium tetraurelia contain both $\mathrm{Ca}^{2+}$ dependent and $\mathrm{Ca}^{2+}$-inhibitable calmodulin-binding proteins, Biochem. J. 259 (1989) 385-396.

[307] D. Fraga, I.M. Sehring, R. Kissmehl, et al., Protein phosphatase 2B (PP2B, calcineurin) in Paramecium: partial characterization reveals that two members of the unusually large catalytic subunit family have distinct roles in calciumdependent processes, Eukaryot. Cell 9 (2010) 1049-1063.

[308] F. Skouri, J. Cohen, Genetic approach to regulated exocytosis using functiona complementation in Paramecium: identification of the ND7 gene required for membrane fusion, Mol. Biol. Cell 8 (1997) 1063-1071.

[309] C.W. Chan, Y. Saimi, C. Kung, A new multigene family encoding calcium-dependent calmodulin-binding membrane proteins of Paramecium tetraurelia, Gene 231 (1999) 21-32.

[310] M.T. Maicher, A. Tiedtke, Biochemical analysis of membrane proteins from an early maturation stage of phagosomes, Electrophoresis 20 (1999) 1011-1016.

[311] M.L. Schwartz, A.J. Merz, Capture and release of partially zipped trans-SNARE complexes on intact organelles, J. Cell Biol. 185 (2009) 535-549.

[312] K. Gonda, M. Katoh, K. Hanyu, Y. Watanabe, O. Numata, $\mathrm{Ca}^{2+} /$ calmodulin and p85 cooperatively regulate an initiation of cytokinesis in Tetrahymena, J. Cell Sci. 112 (1999) 3619-3626.

[313] J. Rizo, X. Chen, D. Arac, Unraveling the mechanisms of synaptotagmin and SNARE function in neurotransmitter release, Trends Cell Biol. 16 (2006) 339-350.

[314] S. Sugita, O.H. Shin, W. Han, Y. Lao, T.C. Südhof, Synaptotagmins form a hierarchy of exocytotic $\mathrm{Ca}^{2+}$ sensors with distinct $\mathrm{Ca}^{2+}$ affinities, EMBO J. 21 (2002) 270-280.

[315] T. Voets, Dissection of three $\mathrm{Ca}^{2+}$-dependent steps leading to secretion in chromaffin cells from mouse adrenal slices, Neuron 28 (2000) 537-545.

[316] M.S. Perin, P.A. Johnston, T. Ozcelik, R. Jahn, U. Francke, T.C. Südhof, Structural and functional conservation of synaptotagmin (p65) in Drosophila and humans, J. Biol. Chem. 266 (1991) 615-622.

[317] B.E. Paddock, Z. Wang, L.M. Biela, et al., Membrane penetration by synaptotagmin is required for coupling calcium binding to vesicle fusion in vivo, J. Neurosci. 31 (2011) 2248-2257.

[318] J.K. Jaiswal, V.M. Rivera, S.M. Simon, Exocytosis of post-Golgi vesicles is regulated by components of the endocytic machinery, Cell 137 (2009) 1308-1319.

[319] J.L. Tomsig, C.E. Creutz, Copines: a ubiquitous family of $\mathrm{Ca}^{2+}$-dependent phospholipid-binding proteins, Cell. Mol. Life Sci. 59 (2002) 1467-1477. 
[320] M. Knochel, R. Kissmehl, J.D. Wissmann, et al., Annexins in Paramecium cells. Involvement in site-specific positioning of secretory organelles, Histochem. Cell Biol. 105 (1996) 269-281.

[321] C.E. Creutz, J.L. Tomsig, S.L. Snyder, et al., The copines, a novel class of C2 domain-containing, calcium-dependent, phospholipid-binding proteins conserved from Paramecium to humans, J. Biol. Chem. 273 (1998) 1393-1402.

[322] Z.P. Pang, T.C. Südhof, Cell biology of $\mathrm{Ca}^{2+}$-triggered exocytosis, Curr. Opin. Cell Biol. 22 (2010) 496-505.

[323] J.W. Barclay, A. Morgan, R.D. Burgoyne, Calcium-dependent regulation of exocytosis, Cell Calcium 38 (2005) 343-353.

[324] T.C. Südhof, Synaptotagmins: why so many? J. Biol. Chem. 277 (2002) 7629-7632.

[325] B. Adolfsen, S. Saraswati, M. Yoshihara, J.T. Littleton, Synaptotagmins are trafficked to distinct subcellular domains including the postsynaptic compartment, J. Cell Biol. 166 (2004) 249-260.

[326] E. Reisinger, C. Bresee, J. Neef, et al., Probing the functional equivalence of otoferlin and synaptotagmin 1 in exocytosis, J. Neurosci. 31 (2011) 4886-4895.

[327] F. Bemm, R. Schwarz, F. Forster, J. Schultz, A kinome of 2600 in the ciliate Paramecium tetraurelia, FEBS Lett. 583 (2009) 3589-3592

[328] M.R. Sussmann, E.M. Hrabak, J.S. Satterlee, Calmodulin-domain protein kinase, in: M.R. Celio, T.L. Pauls, B. Schwaller(Eds.), Calcium-Binding Proteins, Oxford University Press, Oxford (GB), 1996, pp. 46-48.

[329] K. Kim, L.A. Messinger, D.L. Nelson, $\mathrm{Ca}^{2+}$-dependent protein kinases of Parame cium - cloning provides evidence of a multigene family, Eur. J. Biochem. 25 (1998) 605-612.

[330] V.S. Anil, A.C. Harmon, K.S. Rao, Temporal association of $\mathrm{Ca}^{2+}$-dependent protein kinase with oil bodies during seed development in Santalum album L.: its biochemical characterization and significance, Plant Cell Physiol. 44 (2003) 367-376.

[331] R. Kato, K. Okuyama, M. Kodama, S. Sato, H. Kamada, T. Suzuki, Calciumdependent protein phosphrylation in hairy roots of Daucus carota, Plant Biotechnol. 24 (2007) 487-493.

[332] K. Kim, M. Son, J.B. Peterson, D.L. Nelson, $\mathrm{Ca}^{2+}$-binding proteins of cilia and infraciliary lattice of Paramecium tetraurelia: their phosphorylation by purified endogenous $\mathrm{Ca}^{2+}$-dependent protein kinases, J. Cell Sci. 115 (2002) purified end $1973-1984$.

[333] D. Vetter, R. Kissmehl, T. Treptau, K. Hauser, J. Kellermann, H. Plattner, Molecular identification of a calcium-inhibited catalytic subunit of casein kinas type 2 from Paramecium tetraurelia, Eukaryot. Cell 2 (2003) 1220-1233.

[334] J. Aramburu, J. Heitman, G.R. Crabtree, Calcineurin: a central controller of signalling in eukaryotes, EMBO Rep. 5 (2004) 343-348.

[335] C.B. Klee, H. Ren, X. Wang, Regulation of the calmodulin-stimulated protein phosphatase, calcineurin, J. Biol. Chem. 273 (1998) 13367-13370.

[336] R. Kissmehl, T. Treptau, B. Kottwitz, H. Plattner, Occurrence of a paranitrophenyl phosphate-phosphatase with calcineurin-like characteristics in Paramecium tetraurelia, Arch. Biochem. Biophys. 344 (1997) 260-270.

[337] M. Momayezi, C.J. Lumpert, H. Kersken, et al., Exocytosis induction in Paramecium tetraurelia cells by exogenous phosphoprotein phosphatase in vivo and in vitro: possible involvement of calcineurin in exocytotic membrane fusion, J. Cell Biol. 105 (1987) 181-189.

[338] H. Plattner, Synchronous exocytosis in Paramecium cells, in: A. Sowers (Ed.) Cell Fusion, Plenum Press, New York, 1987, pp. 69-98.

[339] S. Klumpp, P. Cohen, J.E. Schultz, Okadaic acid, an inhibitor of protein phosphatase 1 in Paramecium, causes sustained $\mathrm{Ca}^{2+}$-dependent backward swimming in response to depolarizing stimuli, EMBO J. 9 (1990) 685-689.

[340] G. Nagy, K. Reim, U. Matti, et al., Regulation of releasable vesicle pool sizes by protein kinase A-dependent phosphorylation of SNAP-25, Neuron 41 (2004) $417-429$.

341] J. Castillo Bennett, C.M. Roggero, F.E. Mancifesta, L.S, Mayorga, Calcineurinmediated dephosphorylation of synaptotagmin VI is necessary for acrosomal exocytosis, J. Biol. Chem. 285 (2010) 26269-26278

[342] Y.C. Long, S. Glund, P.M. Garcia-Roves, J.R. Zierath, Calcineurin regulates skeletal muscle metabolism via coordinated changes in gene expression, J. Biol. Chem. 282 (2007) 1607-1614.

[343] G.R. Crabtree, Calcium, calcineurin, and the control of transcription, J. Biol. Chem. 276 (2001) 2313-2316.

[344] M. Bilinski, H. Plattner, H. Matt, Secretory protein decondensation as a distinct, $\mathrm{Ca}^{2+}$-mediated event during the final steps of exocytosis in Paramecium cells, J. Cell Biol. 88 (1981) 179-188.

[345] N.D. Chilcoat, S.M. Melia, A. Haddad, A.P. Turkewitz, Granule lattice protein 1 (Grl1p), an acidic, calcium-binding protein in Tetrahymena thermophila densecore secretory granules, influences granule size, shape, content organization, and release but not protein sorting or condensation, J. Cell Biol. 135 (1996) 1775-1787.

[346] J.W. Verbsky, A.P. Turkewitz, Proteolytic processing and $\mathrm{Ca}^{2+}$-binding activity of dense-core vesicle polypeptides in Tetrahymena, Mol. Biol. Cell 9 (1998) 497-511.

[347] N. Klauke, R. Kissmehl, H. Plattner, N. Haga, T. Watanabe, An exocytotic mutant of Paramecium caudatum: membrane fusion without secretory contents release, Cell Calcium 23 (1998) 349-360.

[348] N. Klauke, H. Plattner, "Frustrated Exocytosis" - a novel phenomenon: membrane fusion without contents release, followed by detachment and reattachment of dense core vesicles in Paramecium cells, J. Membr. Biol. 176 (2000) 237-248
[349] R. Fernández-Chacón, G. Alvarez de Toledo, Cytosolic calcium facilitates release of secretory products after exocytotic vesicle fusion, FEBS Lett. 363 (1995) 221-225.

[350] H. Rosenboom, M. Lindau, Exo-endocytosis and closing of the fission pore during endocytosis in single pituitary nerve terminals internally perfused with high calcium concentrations, Proc. Natl. Acad. Sci.U.S.A. 91 (1994) 5267-5271.

[351] A.W. Henkel, W. Almers, Fast steps in exocytosis and endocytosis studied by capacitance measurements in endocrine cells, Curr. Opin. Neurobiol. 6 (1996) 350-357.

[352] T. Vonderfecht, A.J. Stemm-Wolf, M. Hendershott, T.H. Giddings, J.B. Meehl, $\mathrm{M}$. Winey, The two domains of centrin have distinct basal body functions in Tetrahymena, Mol. Biol. Cell 22 (2011) 2221-2234

[353] D. Gogendeau, C. Klotz, O. Arnaiz, et al., Functional diversification of centrins and cell morphological complexity, J. Cell Sci. 121 (2008) 65-74.

[354] J. Beisson, J.C. Clerot, A. Fleury-Aubusson, N. Garreau de Loubresse, F. Ruiz, C Klotz, Basal body-associated nucleation center for the centrin-based cortical cytoskeletal network in Paramecium, Protist 152 (2001) 339-354

[355] C. Klotz, N. Garreau de Loubresse, F. Ruiz, J. Beisson, Genetic evidence for a role of centrin-associated proteins in the organization and dynamics of the infraciliary lattice in Paramecium, Cell Motil. Cytoskeleton 38 (1997) 172-186.

[356] F. Ruiz, N. Garreau de Loubresse, C. Klotz, J. Beisson, F. Koll, Centrin deficiency in Paramecium affects the geometry of basal-body duplication, Curr. Biol. 15 (2005) 2097-2106

[357] A.J. Stemm-Wolf, G. Morgan, T.H. Giddings, et al., Basal body duplication and maintenance require one member of the Tetrahymena thermophila centrin gene family, Mol. Biol. Cell 16 (2005) 3606-3619.

[358] C. Klöppel, A. Müller, S. Marker, M. Simon, Two isoforms of eukaryotic phospholipase C in Paramecium affecting transport and release of GPI-anchored proteins in vivo, Eur. J. Cell Biol. 88 (2009) 577-592.

[359] G. Leondaritis, D. Galanopoulou, Emerging roles of phosphoinositide-specific phospholipases C in the ciliates Tetrahymena and Paramecium, Commun. Integr. Biol. 4 (2011) 576-578.

[360] R.D. Hinrichsen, P.J. Blackshear, Regulation of peptide-calmodulin complexes by protein kinase C in vivo, Proc. Natl. Acad. Sci. U.S.A. 90 (1993) 1585-1589.

[361] J.S. Rhee, A. Betz, S. Pyott, et al., Beta phorbol ester- and diacylglycerol-induced augmentation of transmitter release is mediated by Munc13s and not by PKCs, Cell 108 (2002) 121-133.

[362] B. Davletov, E. Connell, F. Darios, Regulation of SNARE fusion machinery by fatty acids, Cell. Mol. Life Sci. 64 (2007) 1597-1608.

363] L. Ellgaard, A. Helenius, Quality control in the endoplasmic reticulum, Nat. Rev. Mol. Cell Biol. 4 (2003) 181-191.

[364] S, Dobson, T. May, M. Berriman, et al., Characterization of protein Ser/Thr phosphatases of the malaria parasite, Plasmodium falciparum: inhibition of the parasitic calcineurin by cyclophilin-cyclosporin complex, Mol. Biochem. Parasitol. 99 (1999) 167-181.

[365] K. Hu, J. Johnson, L. Florens, et al., Cytoskeletal components of an invasion machine - the apical complex of Toxoplasma gondii, PLoS Pathog. 2 (2006) e13.

[366] S.R. Pavithra, R. Kumar, U. Tatu, Systems analysis of chaperone networks in the malarial parasite Plasmodium falciparum, PLoS Comput. Biol. 3 (2007) 1701-1715.

[367] F. Seeber, B. Beuerle, H.H. Schmidt, Cloning and functional expression of the calmodulin gene from Toxoplasma gondii, Mol. Biochem. Parasitol. 99 (1999) 295-299.

[368] Y. Matsumoto, G. Perry, L.W. Scheibel, M. Aikawa, Role of calmodulin in Plasmodium falciparum: implications for erythrocyte invasion by the merozoite, Eur. J. Cell Biol. 45 (1987) 36-43.

[369] K. Tanabe, A. Izumo, M. Kato, A. Miki, S. Doi, Stage-dependent inhibition of Plasmodium falciparum by potent $\mathrm{Ca}^{2+}$ and calmodulin modulators, J. Protozool. 36 (1989) 139-143.

[370] Y. Watanabe, Y. Nozawa, Possible roles of calmodulin in a ciliated protozoan Tetrahymena in: W.Y. Cheung (Ed.), Calcium and Cell Function, Il, Academic Press, New York, 1982, pp. 297-323.

[371] J. Hirtzlin, P.M. Farber, R.M. Franklin, A. Bell, Molecular and biochemical characterization of a Plasmodium falciparum cyclophilin containing a cleavable signal sequence, Eur. J. Biochem. 232 (1995) 765-772.

[372] R. Kumar, A. Musiyenko, S. Barik, Plasmodium falciparum calcineurin and its association with heat shock protein 90: mechanisms for the antimalarial activity of cyclosporin A and synergism with geldanamycin, Mol. Biochem. Parasitol. 141 (2005) 29-37.

[373] K. Anamika, N. Srinivasan, A. Krupa, A genomic perspective of protein kinases in Plasmodium falciparum, Proteins 58 (2005) 180-189.

[374] P. Ward, L. Equinet, J. Packer, C. Doerig, Protein kinases of the human malaria parasite Plasmodium falciparum: the kinome of a divergent eukaryote, BMC Genomics 5 (2004) 79.

[375] H. Kieschnick, T. Wakefield, C.A. Narducci, C. Beckers, Toxoplasma gondii attachment to host cells is regulated by a calmodulin-like domain protein kinase, J. Biol. Chem. 276 (2001) 12369-12377.

[376] K.M. Choi, J.Y. Kim, S.U. Moon, et al., Molecular cloning of Plasmodium vivax calcium-dependent protein kinase 4, Korean J. Parasitol. 48 (2010) 319-324.

[377] K. Kato, A. Sudo, K. Kobayashi, T. Sugi, Y. Tohya, H. Akashi, Characterization of Plasmodium falciparum calcium-dependent protein kinase 4, Parasitol. Int. 58 (2009) 394-400.

[378] A.K. Wernimont, J.D. Artz, P. Finerty, et al., Structures of apicomplexan calcium-dependent protein kinases reveal mechanism of activation by calcium, Nat. Struct. Mol. Biol. 17 (2010) 596-601. 
[379] S. Lourido, J. Shuman, C. Zhang, K.M. Shokat, R. Hui, L.D. Sibley, Calciumdependent protein kinase 1 is an essential regulator of exocytosis in Toxoplasma, Nature 465 (2010) 359-362

[380] K.K. Ojo, E.T. Larson, K.R. Keyloun, et al., Toxoplasmagondii calcium-dependent protein kinase 1 is a target for selective kinase inhibitors, Nat. Struct. Mol. Biol. 17 (2010) 602-607.

[381] A. Vaid, D.C. Thomas, P. Sharma, Role of $\mathrm{Ca}^{2+} /$ calmodulin-PfPKB signaling pathway in erythrocyte invasion by Plasmodium falciparum, J. Biol. Chem. 283 (2008) 5589-5597.

[382] A. Vaid, P. Sharma, PfPKB, a protein kinase B-like enzyme from Plasmodium falciparum: II. Identification of calcium/calmodulin as its upstream activator and dissection of a novel signaling pathway, J. Biol. Chem. 281 (2006) 27126-27133.

[383] M. Michalak, J. Groenendyk, E. Szabo, L.l. Gold, M. Opas, Calreticulin, a multiprocess calcium-buffering chaperone of the endoplasmic reticulum, Biochem. J. 417 (2009) 651-666.

[384] N. La Greca, A.R. Hibbs, C. Riffkin, M. Foley, L. Tilley, Identification of an endoplasmic reticulum-resident calcium-binding protein with multiple EF-hand motifs in asexual stages of Plasmodium falciparum, Mol. Biochem. Parasitol. 89 (1997) 283-293.

[385] S. Bonnefoy, G. Attal, G. Langsley, F. Tekaia, O. Mercereau-Puijalon, Molecular characterization of the heat shock protein 90 gene of the human malaria parasite Plasmodium falciparum, Mol. Biochem. Parasitol. 67 (1994) $157-170$.

[386] D. Gogendeau, J. Beisson, N. Garreau de Loubresse, et al., An Sfi1p-like centrin-binding protein mediates centrin-based $\mathrm{Ca}^{2+}$-dependent contractility in Paramecium tetraurelia, Eukaryot. Cell 6 (2007) 1992-2000.

[387] C.G. Di Petrillo, E.F. Smith, Pcdp1 is a central apparatus protein that binds $\mathrm{Ca}^{2+}$ calmodulin and regulates ciliary motility, J. Cell Biol. 189 (2010) 601-612.

[388] L. Quarmby, Ciliary ion channels: location, location, location, Curr. Biol. 19 (2009) R158-R160.

[389] R.R. Preston, Y. Saimi, Calcium ions and the regulation of motility in Paramecium, in: R.A. Bloodgood (Ed.), Ciliary and Flagellar Membranes, Plenum Press, New Yok, London, 1990, pp. 173-200.

[390] W.Q. Yang, C. Braun, H. Plattner, J. Purvee, J.L. Van Houten, Cyclic nucleotides in glutamate chemosensory signal transduction of Paramecium, J. Cell Sci. 110 (1997) 2567-2572.

[391] H. Machemer, Electromotor coupling in cilia, Fortschr. Zool. 33 (1986) 205-250.

[392] M. Salathe, Regulation of mammalian ciliary beating, Annu. Rev. Physiol. 69 (2007) 401-422.

[393] M. Saiki, Y. Hiramato, Control of ciliary activity in Paramecium by intracellular injection of calcium buffers, Cell Struct. Funct. 1 (1975) 33-41.

[394] Y. Naitoh, H. Kaneko, Control of ciliary activities by adenosinetriphosphate and divalent cations in triton-extracted models of Paramecium caudatum, J. Exp. Biol. 58 (1973) 657-676

[395] B. Coste, J. Mathur, M. Schmidt, et al., Piezo1 and Piezo2 are essential components of distinct mechanically activated cation channels, Science 330 (2010) 55-60.

[396] R. Eckert, P. Brehm, Ionic mechanisms of excitation in Paramecium, Annu. Rev. Biophys. Bioeng. 8 (1979) 353-383.

[397] K. Gonda, K. Oami, M. Takahashi, Centrin controls the activity of the ciliary reversal-coupled voltage-gated $\mathrm{Ca}^{2+}$ channels $\mathrm{Ca}^{2+}$-dependently. Biochem. Biophys. Res. Commun. 362 (2007) 170-176.

[398] J.U. Linder, P. Engel, A. Reimer, et al., Guanylyl cyclases with the topology of mammalian adenylyl cyclases and an N-terminal P-type ATPase-like domain in Paramecium, Tetrahymena and Plasmodium, EMBO J. 18 (1999) $4222-4232$

[399] K.S. Ann, D.L. Nelson, Protein substrates for cGMP-dependent protein phosphorylation in cilia of wild type and atalanta mutants of Paramecium, Cell Motil. Cytoskeleton 30 (1995) 252-260.

[400] Y. Nakaoka, H. Machemer, Effects of cyclic nucleotides and intracellular Ca on voltage-activated ciliary beating in Paramecium, J. Comp. Physiol. A 166 (1990) 401-406.

[401] K. Ohnishi, Y. Suzuki, Y. Watanabe, Studies on calmodulin isolated from Tetrahymena cilia and its localization within the cilium, Exp. Cell Res. 137 (1982) 217-227.

[402] H. Machemer, P.F.M. Teunis, Sensory-motor coupling and motor responses, in: K. Hausmann, P.C. Bradbury (Eds.), Ciliates. Cells and Organisms, Gustav Fischer Verlag, Stuttgart, 1996, pp. 379-402.

[403] A.M. Jama, J. Gabriel, A.J. Al-Nagar, et al., Lobe-specific functions of $\mathrm{Ca}^{2+}$.calmodulin in $\alpha \mathrm{Ca}^{2+}$.calmodulin-dependent protein kinase II activation, J. Biol. Chem. 286 (2011) 12308-12316

[404] N.M. Bonini, T.C. Evans, L.A. Miglietta, D.L. Nelson, The regulation of ciliary motility in Paramecium by $\mathrm{Ca}^{2+}$ and cyclic nucleotides, Adv. Sec. Mess. Phosphoprot. Res. 23 (1991) 227-272.

[405] P. Yang, C. Yang, W.S. Sale, Flagellar radial spoke protein 2 is a calmodulin binding protein required for motility in Chlamydomonas reinhardtii, Eukaryot. Cell 3 (2004) 72-81

[406] H. Plattner, S. Diehl, M.R. Husser, J. Hentschel, Sub-second calcium coupling between outside medium and subplasmalemmal stores during overstimulation/depolarisation-induced ciliary beat reversal in Paramecium cells, Cell Calcium 39 (2006) 509-516.

[407] J. Laoukili, E. Perret, S. Middendorp, et al., Differential expression and cellular distribution of centrin isoforms during human ciliated cell differentiation in vitro, J. Cell Sci. 113 (2000) 1355-1364.
[408] J.C. Smith, J.G. Northey, J. Garg, R.E. Pearlman, K.W. Siu, Robust method for proteome analysis by MS/MS using an entire translated genome: demonstration on the ciliome of Tetrahymena thermophila, J. Proteome Res. 4 (2005) 909-919.

[409] K.D. Clark, T.M. Hennessey, D.L. Nelson, External GTP alters the motility and elicits an oscillating membrane depolarization in Paramecium tetraurelia Proc. Natl. Acad. Sci. U.S.A. 90 (1993) 3782-3786.

[410] I.M. Sehring, H. Plattner, $\mathrm{Ca}^{2+}$ oscillations mediated by exogenous GTP in Paramecium cells: assessment of possible $\mathrm{Ca}^{2+}$ sources, Cell Calcium 36(2004) 409-420.

[411] J.J. Wassenberg, K.D. Clark, D.L. Nelson, Effect of SERCA pump inhibitors on chemoresponses in Paramecium, J. Eukaryot. Microbiol. 44 (1997) 574-581

[412] M.L. Tonkin, M. Roques, M.H. Lamarque, et al., Host cell invasion by apicomplexan parasites: insights from the co-structure of AMA1 with a RON2 peptide, Science 333 (2011) 463-467.

[413] V. Polonais, B.J. Foth, K. Chinthalapudi, et al., Unusual anchor of a motor complex (MyoD-MLC2) to the plasma membrane of Toxoplasma gondii, Traffic 12 (2011) 287-300.

[414] D.M. Wetzel, L.A. Chen, F.A. Ruiz, S.N. Moreno, L.D. Sibley, Calcium-mediated protein secretion potentiates motility in Toxoplasma gondii, J. Cell Sci. 117 (2004) 5739-5748.

[415] F. Kawamoto, R. Alejo-Blanco, S.L. Fleck, Y. Kawamoto, R.E. Sinden, Possible roles of $\mathrm{Ca}^{2+}$ and cGMP as mediators of the exflagellation of Plasmodium berghei and Plasmodium falciparum, Mol. Biochem. Parasitol. 42 (1990) 101-108.

[416] D.C. Chang, C. Meng, A localized elevation of cytosolic free calcium is associated with cytokinesis in the zebrafish embryo, J. Cell Biol. 131 (1995) 1539-1545.

[417] R. Wong, I. Hadjiyanni, H.C. Wei, et al., PIP $_{2}$ hydrolysis and calcium release are required for cytokinesis in Drosophila spermatocytes, Curr. Biol. 15 (2005) 1401-1406.

[418] G.M. Wilson, A.B. Fielding, G.C. Simon, et al., The FIP3-Rab11 protein complex regulates recycling endosome targeting to the cleavage furrow during late cytokinesis, Mol. Biol. Cell 16 (2005) 849-860.

[419] F. Baluska, D. Menzel, P.W. Barlow, Cytokinesis in plant and animal cells: endosomes 'shut the door', Dev. Biol. 294 (2006) 1-10.

[420] J.A. Schiel, K. Park, M.K. Morphew, E. Reid, A. Hoenger, R. Prekeris, Endocytic membrane fusion and buckling-induced microtubule severing mediate cell abscission, J. Cell Sci. 124 (2011) 1411-1424.

[421] T.J. Collins, P. Lipp, M.J. Berridge, M.D. Bootman, Mitochondrial $\mathrm{Ca}^{2+}$ uptake depends on the spatial and temporal profile of cytosolic $\mathrm{Ca}^{2+}$ signals, J. Biol Chem. 276 (2001) 26411-26420.

[422] U.C. Hoppe, Mitochondrial calcium channels, FEBS Lett. 584 (2010) $1975-1981$.

[423] R.M. Denton, Regulation of mitochondrial dehydrogenases by calcium ions, Biochim. Biophys. Acta 1787 (2009) 1309-1316.

[424] $\mathrm{H}$. Plattner, R. Kissmehl, Molecular aspects of rapid, reversible, $\mathrm{Ca}^{2+}$ dependent de-phosphorylation of pp63/parafusin during stimulated exoendocytosis in Paramecium cells, Cell Calcium 38 (2005) 319-327.

[425] K. Hauser, R. Kissmehl, J. Linder, J.E. Schultz, F. Lottspeich, H. Plattner, Identification of isoforms of the exocytosis-sensitive phosphoprotein PP63/parafusin in Paramecium tetraurelia and demonstration of phosphoglucomutase activity, Biochem. J. 323 (1997) 289-296.

[426] S.H. Matthiesen, S.M. Shenoy, K. Kim, R.H. Singer, B.H. Satir, A parafusinrelated Toxoplasma protein in $\mathrm{Ca}^{2+}$-regulated secretory organelles, Eur. J. Cel Biol. 80 (2001) 775-783.

[427] S. Müller, K. Diederichs, J. Breed, et al., Crystal structure analysis of the exocytosis-sensitive phosphoprotein, pp63/parafusin (phosphoglucomutase), from Paramecium reveals significant conformational variability, J. Mol. Biol. 315 (2002) 141-153.

[428] R. Kissmehl, K. Hauser, M. Gössringer, M. Momayezi, N. Klauke, H Plattner, Immunolocalization of the exocytosis-sensitive phosphoprotein, PP63/parafusin, in Paramecium cells using antibodies against recombinant protein, Histochem. Cell Biol. 110 (1998) 1-8

[429] N. Өrtenblad, J. Nielsen, B. Saltin, H.C. Holmberg, Role of glycogen availability in sarcoplasmic reticulum $\mathrm{Ca}^{2+}$ kinetics in human skeletal muscle, J. Physiol. 589 (2011) 711-725.

[430] H. Plattner, G. Knoll, R. Pape, Synchronization of different steps of the secretory cycle in Paramecium tetraurelia: trichocyst exocytosis, exocytosiscoupled endocytosis and intracellular transport, in: H. Plattner (Ed.), Membrane Traffic in Protozoa, JAI Press, Greenwich (CT), London, 1993, pp 123-148.

[431] L.S. Jouaville, P. Pinton, C. Bastianutto, G.A. Rutter, R. Rizzuto, Regulation of mitochondrial ATP synthesis by calcium: evidence for a long-term metabolic priming, Proc. Natl. Acad. Sci. U.S.A. 96 (1999) 13807-13812.

[432] E.J. Griffiths, G.A. Rutter, Mitochondrial calcium as a key regulator of mitochondrial ATP production in mammalian cells, Biochim. Biophys. Acta 1787 (2009) 1324-1333.

[433] S.A. Oakes, Mitochondria control calcium entry at the immunological synapse, Proc. Natl. Acad. Sci. U.S.A. 104 (2007) 15171-15172.

[434] S.R. Collins, T. Meyer, Evolutionary origins of STIM1 and STIM2 within ancient $\mathrm{Ca}^{2+}$ signaling systems, Trends Cell Biol. 21 (2011) 202-211.

[435] N.L. Elwess, J.L. Van Houten, Cloning and molecular analysis of the plasma membrane $\mathrm{Ca}^{2+}$-ATPase gene in Paramecium tetraurelia, J. Eukaryot. Microbiol. 44 (1997) 250-257. 
[436] 1. Mohamed, M. Husser, I. Sehring,J. Hentschel, C. Hentschel, H. Plattner, Refilling of cortical calcium stores in Paramecium cells: in situ analysis in correlation with store-operated calcium influx, Cell Calcium 34 (2003) 87-96.

[437] H.S. Choi, D.A. Eisner, The role of sarcolemmal $\mathrm{Ca}^{2+}$-ATPase in the regulation of resting calcium concentration in rat ventricular myocytes, J. Physiol. 515 (1999) $109-118$

[438] B. Burlando, B. March, T. Krüppel, M. Orunesu, A. Viarengo, Occurrence of $\mathrm{Na}^{+} / \mathrm{Ca}^{2+}$ exchange in the ciliate Euplotes crassus and its role in $\mathrm{Ca}^{2+}$ homeostasis, Cell Calcium 25 (1999) 153-160.

[439] M.P. Blaustein, W.J. Lederer, Sodium/calcium exchange: its physiological implications, Physiol. Rev. 79 (1999) 763-854

[440] H.K. Grenlien, C.Stock, M.S. Aihara, R.D. Allen, Y. Naitoh, Relationship between the membrane potential of the contractile vacuole complex and its osmoregulatory activity in Paramecium multimicronucleatum, J. Exp. Biol. 205 (2002) 3261-3270.

[441] A. Verkhratsky, Physiology and pathophysiology of the calcium store in the endoplasmic reticulum of neurons, Physiol. Rev. 85 (2005) 201-279.

[442] S. Hua, G. Inesi, Synthesis of a radioactive azido derivative of thapsigargin and photolabeling of the sarcoplasmic reticulum ATPase, Biochemistry 36 (1997) $11865-11872$

[443] S. Wang, K. Takeyasu, Primary structure and evolution of the ATP-binding domains of the P-type ATPases in Tetrahymena thermophila, Am. J. Physiol. 272 (1997) C715-C728.

[444] B. Arnou, C. Montigny, J.P. Morth, et al., The Plasmodium falciparum $\mathrm{Ca}^{2+}$ ATPase PfATP6: insensitive to artemisinin, but a potential drug target, Biochem. Soc. Trans. 39 (2011) 823-831.

[445] S. Krishna, S. Pulcini, F. Fatih, H. Staines, Artemisinins and the biological basis for the PfATP6/SERCA hypothesis, Trends Parasitol. 26 (2010) $517-523$.
[446] R. Jambou, A. Martinelli, J. Pinto, et al., Geographic structuring of the Plasmodium falciparum sarco(endo)plasmic reticulum $\mathrm{Ca}^{2+}$ ATPase (PfSERCA) gene diversity, PLoS One 5 (2010) e9424.

[447] U. Eckstein-Ludwig, R.J. Webb, I.D. Van Goethem, et al., Artemisinins target the SERCA of Plasmodium falciparum, Nature 424 (2003) 957-961

[448] S.G. Valderramos, D. Scanfeld, A.C. Uhlemann, D.A. Fidock, S. Krishna, Investigations into the role of the Plasmodium falciparum SERCA (PFATP6) L263E mutation in artemisinin action and resistance, Antimicrob. Agents Chemother. 54 (2010) 3842-3852.

[449] M. Prajer, A. Fleury, M. Laurent, Dynamics of calcium regulation in Paramecium and possible morphogenetic implication, J. Cell Sci. 110 (1997) 529-535.

[450] L.F. Jaffe, Fast calcium waves, Cell Calcium 48 (2010) 102-113.

[451] A.B. Parekh, Decoding cytosolic $\mathrm{Ca}^{2+}$ oscillations, Trends Biochem. Sci. 36 (2011) 78-87.

[452] S. Patel, R. Docampo, In with the TRP channels: intracellular functions for TRPM1 and TRPM2, Sci. Signal. 2 (2009) pe69.

[453] S.N.J. Moreno, K. Miranda, J. Fang, P. Rohloff, W. de Souza, Calcium storage and homeostasis in Toxoplasma gondii, in: L.M. Weiss, K. Kim (Eds.), Toxoplasma gondii the Model Apicomplexan: Perspectives and Methods, Academic Press, New York, 2007, pp. 245-263.

[454] R.O. Morgan, S. Martin-Almedina, J.M. Iglesias, M.I. Gonzalez-Florez, M.P. Fernandez, Evolutionary perspective on annexin calcium-binding domains, Biochim. Biophys. Acta 1742 (2004) 133-140.

[455] V. Gerke, C.E. Creutz, S.E. Moss, Annexins: linking $\mathrm{Ca}^{2+}$ signalling to membrane dynamics, Nat. Rev. Mol. Cell Biol. 6 (2005) 449-461

[456] R.J. Williams, The evolution of calcium biochemistry, Biochim. Biophys. Acta 1763 (2006) 1139-1146.

[457] N. King, M.J. Westbrook, S.L. Young, et al., The genome of the choanoflagellate Monosiga brevicollis and the origin of metazoans, Nature 451 (2008) 783-788. 